\title{
Applying stages of change theory to an acute pain situation: Development of the Childbirth Stages of Change Questionnaire (CSOCQ)
}

\author{
Rebecca K. Widoe \\ West Virginia University
}

Follow this and additional works at: https://researchrepository.wvu.edu/etd

\footnotetext{
Recommended Citation

Widoe, Rebecca K., "Applying stages of change theory to an acute pain situation: Development of the Childbirth Stages of Change Questionnaire (CSOCQ)" (2006). Graduate Theses, Dissertations, and Problem Reports. 2485.

https://researchrepository.wvu.edu/etd/2485

This Thesis is protected by copyright and/or related rights. It has been brought to you by the The Research Repository @ WVU with permission from the rights-holder(s). You are free to use this Thesis in any way that is permitted by the copyright and related rights legislation that applies to your use. For other uses you must obtain permission from the rights-holder(s) directly, unless additional rights are indicated by a Creative Commons license in the record and/ or on the work itself. This Thesis has been accepted for inclusion in WVU Graduate Theses, Dissertations, and Problem Reports collection by an authorized administrator of The Research Repository @ WVU. For more information, please contact researchrepository@mail.wvu.edu.
} 
Applying Stages of Change Theory to an Acute Pain Situation:

Development of the Childbirth Stages of Change Questionnaire (CSOCQ)

\author{
Rebecca K. Widoe
}

\author{
Thesis submitted to the \\ Eberly College of Arts and Sciences \\ at West Virginia University \\ in partial fulfillment of the requirements \\ for the degree of \\ Master of Science \\ in \\ Psychology
}

Daniel W. McNeil, Ph.D., Chair

Katherine K. Karraker, Ph.D.

Kevin T. Larkin, Ph.D.

Department of Psychology

Morgantown, WV

2006

Keywords: Childbirth, Acute Pain, Stages of Change, Transtheoretical Model 


\begin{abstract}
Applying Stages of Change Theory to an Acute Pain Situation: Development of the Childbirth Stages of Change Questionnaire (CSOCQ)
\end{abstract}

\title{
Rebecca K. Widoe
}

Various self-management methods and pharmacological agents are available to relieve childbirth pain. Decisions about pain management during labor have medical, psychological, and sociological ramifications, yet research investigating the selection of childbirth pain management strategies is scarce. The purpose of the current study was to develop a self-report instrument, the Childbirth Stages of Change Questionnaire (CSOCQ), to assess a pregnant woman's readiness to self-manage childbirth pain. Items representative of five levels of readiness were generated by experts. Next, 3 pregnant women evaluated items for content validity. A pilot CSOCQ was administered to 536 undergraduate women. Factor analysis and item-reliabilities were conducted to evaluate psychometric properties of the pilot scale. Analyses supported a four-factor measure consistent with the Stages of Change model. A revised CSOCQ was presented to 21 pregnant women, and preliminary item analyses indicated acceptable reliability. Additional research should clarify the validity and clinical utility of the CSOCQ. 


\section{Acknowledgements}

There are many friends and family members I would like to thank for providing support and friendship throughout this project, and during my graduate school experience. First and foremost, I would like to thank my advisor and committee chair, Daniel W. McNeil, Ph.D., who always was more than willing to provide the correct amount of guidance and independence throughout this project. The knowledge I gained from him about design and implementation of research projects, as well as his dedication to helping me improve my writing style, will be carried with me throughout many projects to come.

I would like to extend sincere thanks to the other members of my committee, Katherine K. Karraker, Ph.D., and Kevin T. Larkin, Ph.D., for their valuable input and continued commitment throughout the course of this project. Their advice and feedback was helpful to each phase of the study. I also am grateful to the members of the Anxiety, Psychophysiology, and Pain Research Laboratory for their assistance in item generation and review, and to the West Virginia University Eberly College of Arts and Sciences Alumni Fund for their support.

Several members of the community contributed to this project and helped to make it a reality. Becky Metheny, a doula and childbirth educator, provided support throughout the study, and tremendously helped recruitment efforts. I also would like to thank the organizers of the Morgantown Community Baby Shower for their support.

Finally, I would like to thank my family for their love and encouragement. 


\section{Table of Contents}

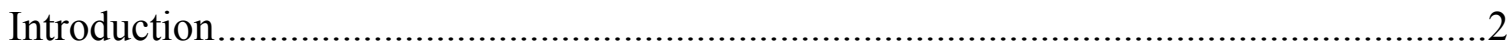

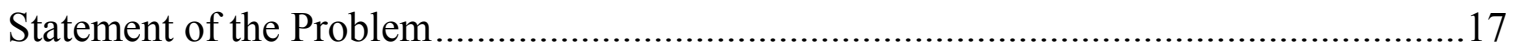

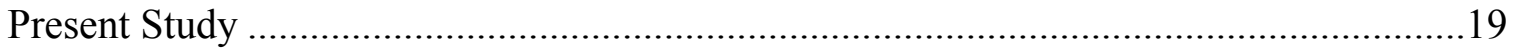

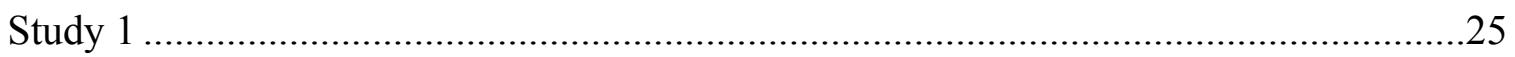

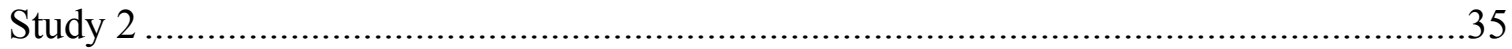

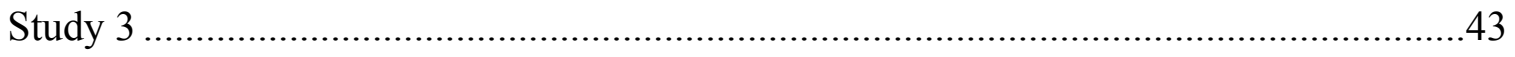

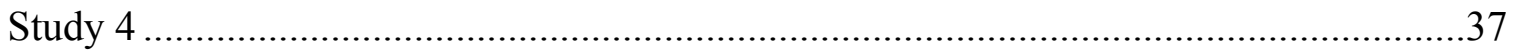

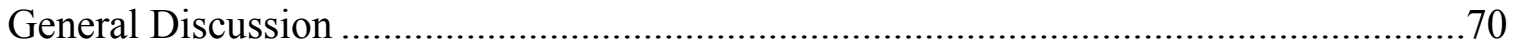

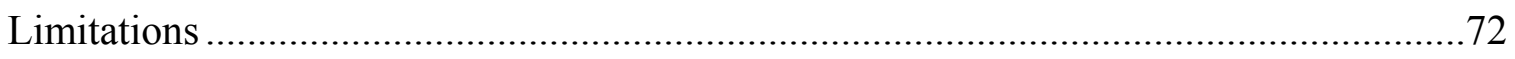

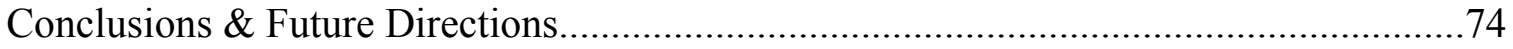

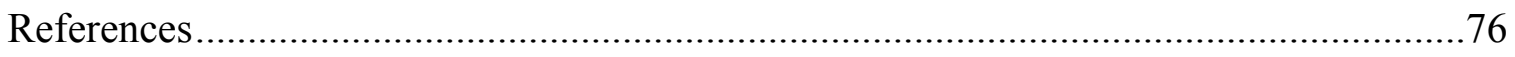

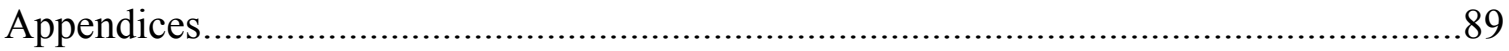




\section{List of Tables}

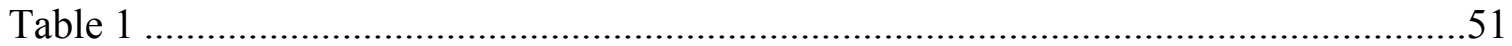

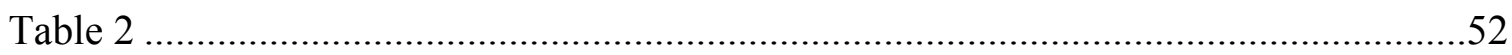

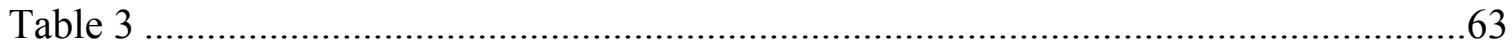

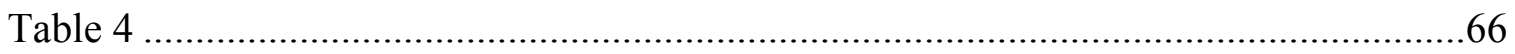

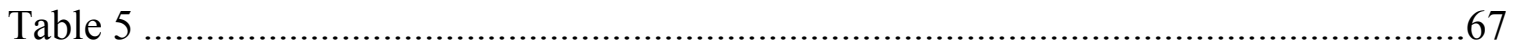


Applying Stages of Change Theory to an Acute Pain Situation:

Development of the Childbirth Stages of Change Questionnaire

Self-management strategies designed to relieve discomfort during labor and delivery are commonly available alternatives or supplements to pharmacological management of childbirth pain in the USA. Self-management methods include any non-pharmacological means of coping with pain, and encompass activities as varied as breathing exercises, relaxation, acupuncture, aromatherapy, distraction (e.g., self-hypnosis, music, conversation), massage, walking or using a birthing ball, taking a bath or shower (hydrotherapy), and cognitive strategies such as imagery, acceptance, and focus upon a mantra or prayer. These approaches may enhance the development of personal control of labor pain (e.g., Browning, 2001; Byrne-Lynch, 1991; Hodnett, 2002; Mehl-Madrona, 2004), and can be used in conjunction with or in place of pharmacological approaches to pain relief. Numerous reports supporting the efficacy of self-management strategies in reducing labor pain and enhancing the childbirth experience have been published (e.g., Cyna, Andrew, \& McAuliffe, 2006; Devine \& Cook, 1986; Koehn, 1993; Leventhal, Leventhal, Shacham, \& Easterling, 1989; Nesheim \& Kinge, 2006; Smith, Collins, Cyna, \& Crowther, 2006). Individuals may differ, however, in their readiness to employ these strategies during childbirth. While self-management methods are an effective means of childbirth pain management, many women in the USA and elsewhere in North America also have the option of pharmacological pain management. As such, readiness to self-manage childbirth pain is an important construct that merits measurement. The present study describes the initial construction and evaluation of a Childbirth Stages of Change Questionnaire (CSOCQ) that measures readiness to employ self-management strategies during childbirth. 
Introduction

According to the National Center for Health Statistics, approximately 4 million births occur in the United States each year, accounting for roughly one-fourth of the medical procedures involving females (DeFrances \& Hall, 2002). The study confirmed that, in the United States, childbirth is the most frequent cause for hospital admission. Worldwide, women have, on average, approximately three children over the course of their lifespan, according to the most recent Global Population Profile (U.S. Census Bureau, 2002). Accordingly, childbirth pain can be considered a frequent manifestation of acute pain across the globe. Moreover, childbirth pain has been ranked as one of the most intense sources of acute pain as compared to other sources (e.g., deep laceration, fracture) on the McGill Pain Questionnaire (Melzack, 1984; Melzack, Wall, \& Ty, 1982). As such, the study of childbirth pain is a highly relevant subset of acute pain investigation.

\section{Childbirth Pain Management}

Childbirth pain management practices have evolved over time, reflecting advances in medicine as well as changes in sociocultural attitudes. In a review of childbirth pain management since the $11^{\text {th }}$ century, Barlow (1994) highlighted the influence of prevailing religious and cultural beliefs upon the management of labor pain. During the Middle Ages, for example, beliefs concerning labor were dictated by religious views that considered childbirth pain to be punishment from God for the sins of Eve (Barlow). As such, any attempt to relieve childbirth pain was viewed negatively. The use of anesthetics, first alcohol and later opium, became acceptable during the $17^{\text {th }}$ and $18^{\text {th }}$ centuries. Common approaches to managing childbirth pain today include pharmacological (e.g., oral medications, nerve blocks, epidural injections) and self-management methods. Current social values influence the popularity of the 
various pain management approaches, however. In the $19^{\text {th }}$ century, for instance, feminists argued for increased use of anesthesia to manage labor pain, whereas feminists in the $20^{\text {th }}$ century often fought against pharmacological interventions and advocated for "natural deliveries" (Caton, 2004). Because social considerations are consistently cited in debates, both historical and current, concerning childbirth pain management, the role of the sociocultural atmosphere on the pain management choices of women has been apparent throughout history.

Pharmacological methods of childbirth pain management. Poole (2003) examined the range of pharmacological pain management options available today for expectant mothers, and how these methods have changed over the past decade. Although the methods of dense-motorblockade regional anesthesia and systemic analgesia are still used, newer neuraxial (e.g., epidural, spinal, intrathecal) and regional methods have become more common. Poole hypothesized that the shift reflects a trend in childbirth analgesia toward more active and collaborative methods, rather than using medications that may render a woman passive during the birthing process.

Epidural anesthesia, currently the most requested form of pharmacological intervention (Howell et al., 2001), has been demonstrated to be an effective pain relief method for discomfort during childbirth (Klein, 2006). Bennett, Lumley, and Bartlett (1987) reviewed the technique, indications, and incidence of epidural anesthesia. Although a highly effective form of pain management, Bennett and colleagues noted that the routine use of epidural anesthesia has not been empirically supported in randomized clinical trials because epidurals have been associated with fetal malposition, longer labors, and additional interventions, such as instrumental delivery. They recommended a "conservative approach" (p. 13) to the use of epidural anesthesia, and even then only for women at low risk for complications during labor and delivery. In a more recent 
review, Klein noted that the use of epidurals is still debated, in large part due to its questionable influence upon the continual rise in cesarean sections, but that epidural analgesia currently remains the most effective form of childbirth pain relief.

Caveats of pharmacological pain management. Managing childbirth pain through pharmacological means is not without risks. In making informed decisions about pain management during labor, it is important for women to be familiar with the potential implications of all pain management options. Kuczkowski (2005) stated that the management of childbirth pain is considered a particularly difficult area within anesthesiology. In an article reviewing guidelines for the safe administration of obstetrical anesthesia, Kuczkowski noted that, in the United States, complications related to anesthesia are a leading cause of pregnancy-related deaths. Some of the risks associated with epidural anesthesia include longer labors, increased forceps deliveries, greater use of oxytocin augmentation, increased incidence of maternal fever, higher rates of perineal trauma, hypotension, and more postpartum bladder catheterizations (Anim-Somuah, Smyth, \& Howell, 2005; Howell, 2000; Leighton \& Halpern, 2002; Lieberman \& O’Donoghue, 2002; Poore \& Foster, 1985; Sharma, 2000). In a randomized control trial of epidural compared with non-epidural analgesia during labor, Howell and colleagues (2001) found a higher incidence of instrumental delivery in the epidural group (30\%) than in the nonepidural group (19\%). Walker and O’Brien (1999) conducted a retrospective comparative chart review of 233 primiparous deliveries to examine method of pain management during labor (assignment into non-narcotic, narcotic, or epidural groups) in relation to birth outcomes. Women receiving anesthesia or epidural analgesia had a significantly longer second stage of labor as compared to women in the non-narcotic group. In addition, anesthesia and epidural analgesia were associated with greater rates of cesarean and instrumental deliveries. Apgar 
scores, evaluations of the infants' physical condition taken immediately following birth and based upon the five factors of activity, pulse, grimace, appearance, and respiration, were lower in situations where the mother received early anesthesia or an epidural as compared to those who received late or no anesthesia or epidural, but were still acceptably high across all groups (Walker \& O’Brien). The authors concluded that, while epidural analgesia is often considered the "gold standard" method of labor pain control (p. 120), there are associations between pharmacological pain management and birth outcomes that, although not causal, imply some degree of risk with anesthesia and epidural analgesia.

In addition to medical risks, pharmacological pain management may have implications for maternal satisfaction. Though epidural anesthesia has proven more effective in reducing pain than non-epidural methods in randomized controlled trials (Howell, 2000), the use of epidural anesthesia had a negative effect upon satisfaction with the birth experience as assessed one year following delivery in a study by Howell and colleagues (2001). In their randomized investigation, epidural versus non-epidural pain relief resulted in comparable maternal satisfaction when assessed immediately after the delivery but, when assessed 1 year following delivery, women in the epidural group reported less satisfaction as compared to the non-epidural group. Kannan, Jamison, and Datta (2001) also assessed maternal satisfaction in relation to natural childbirth versus epidural analgesia. They assessed maternal satisfaction the day following delivery and found that, of the women who had requested epidural analgesia, $88 \%$ of them reported less satisfaction with their childbirth experience as compared to those who did not request an epidural, despite indicating lower pain intensity during labor. Kannan and colleagues concluded that longer labor duration, concerns about the epidural's effect upon the baby's health, higher than expected labor pain, and perceived disappointment at requesting an epidural likely 
accounted for their findings. Taken together, these results indicate that pain relief alone does not necessarily improve maternal satisfaction and, in some ways, epidural analgesia is associated with less maternal satisfaction. These findings are of importance because maternal satisfaction with the childbirth experience has been associated with a woman's willingness to have another baby, as well as with her overall emotional well-being (Goodman, Mackey, \& Tavakoli, 2004; Waldenström, Hildingsson, Rubertsson, \& Rådestad, 2004).

In instances where anesthetic pain management is the woman's preference, selfmanagement methods can supplement the anesthesia, thereby providing additional pain relief. The utilization of complementary self-management strategies is important because pharmacological approaches do not guarantee a pain-free delivery. As illustrated by a study of 278 new mothers in Sweden, despite their wide use of pharmacological means to relieve pain, $91 \%$ of the women still reported high levels of pain during labor at a 2-day follow-up, with $41 \%$ reporting “worst imaginable pain” (Waldenström, Bergman, \& Vasell, 1996). Although pharmacological methods were the most commonly used interventions for pain relief (e.g., 79\% of women utilized nitrous oxide, $34 \%$ epidural anesthesia as compared to $55 \%$ bath or shower, $28 \%$ massage, and $32 \%$ special breathing technique), pharmacological pain relief was actually associated with more negative attitudes to pain and higher ratings of pain severity compared to non-pharmacological methods. Bundsen and colleagues (1982) also examined various pharmacological pain relief methods (e.g., epidural block, nitrous oxide) in relation to overall pain experience, and found that $60 \%$ of their sample reported experiencing "severe to almost unbearable pain" during the first and second stages of labor despite pain medication. These findings demonstrate that pharmacological methods, while empirically-supported pain relievers, may not reduce the experience of labor pain to an acceptable level for many women. In 
summary, existing evidence supports the conclusion that pharmacological methods of pain management are associated with increased risk of medical complications, decreased maternal satisfaction with the childbirth experience, and incomplete resolution of pain symptoms. Thus, the consideration to incorporate additional pain management strategies during labor is advisable.

Self-management methods of childbirth pain management. Self-management includes a diverse and widely taught array of pain management methods, such as distraction (e.g., selfhypnosis, music therapy, conversation, TV/video), cognitive coping strategies (e.g., acceptance, focus upon a mantra or prayer), breathing retraining (e.g., Lamaze), acupuncture, aromatherapy, focal points, walking, using a birthing ball, positioning, and taking a bath or shower (hydrotherapy). Self-management strategies are active and may impart a greater sense of personal control over labor pain than pharmacological interventions (e.g., Browning, 2001; Byrne-Lynch, 1991; Hodnett, 2002; Mehl-Madrona, 2004). Self-management of childbirth pain refers to the use of any of the above strategies during childbirth; any non-pharmacological means of coping with childbirth pain is considered self-management in the current study.

Structured childbirth education classes, sometimes referred to as prepared childbirth training (Brucher, 1984; Schroeder-Zwelling, 1988), offer exposure to a variety of coping strategies that may assist women in self-managing labor pain. The content of these classes typically includes: (a) information about the childbirth experience, to allay concerns such as, "What will happen during childbirth? How will it feel? What can I do?" (b) skills training to reduce complications and discomfort (e.g., positioning, modes of relaxation, physical conditioning exercises); and (c) psychosocial support (Koehn, 1993). Skills training to decrease physical and emotional distress is an important component of childbirth education. Women are exposed to methods such as progressive relaxation, touch relaxation, imagery, massage, focusing 
techniques, comfort measures (e.g., positioning, back rub), and support (Koehn). Breathing techniques also are an essential element of childbirth education (Pierce, 2001).

Childbirth education classes have empirically-established effectiveness and are widely attended, particularly by first-time mothers (Lu, Prentice, Yu, Inkelas, Lange, \& Halfon, 2003). Leventhal, Leventhal, Shacham, and Easterling (1989) examined the effects of both attendance at Lamaze classes and instructions to self-monitor contraction sensations upon distress and pain experienced during labor. Results indicated that participants who had attended Lamaze classes reported less pain and fear during stages one (transition to active labor) and two (active pushing) of labor than did participants who did not attend classes. In addition, women who had attended Lamaze classes indicated having significantly more energy than non-attenders at the beginning of labor. These results support the notion that attending Lamaze classes may reduce negative mood and enhance energy by helping expectant mothers form accurate expectations of childbirth (Leventhal et al., 1989). Additionally, Devine and Cook (1986) determined that psychosocial support, the final aspect of childbirth education training, enhances coping and reduces anxiety related to hospital stays. Finally, in an examination of coping methods typically taught in childbirth education classes, Koehn (1993) reviewed numerous studies that had evaluated the effectiveness of various self-management techniques in reducing the pain and distress of childbirth and improving coping, and found empirical evidence to support the use of relaxation, breathing techniques, imagery, and massage. Although positioning, attention focusing, and music also have been reported to be effective self-management strategies during labor, Koehn noted that empirical support for these techniques still is needed. Taken together, these findings demonstrate the benefits of childbirth education classes and the self-management strategies that these classes teach. 
A wealth of empirical support also is available for the efficacy of specific selfmanagement techniques in reducing pain and negative emotions (e.g., anxiety, fear of pain) during labor, including acupuncture, hypnosis, biofeedback, hydrotherapy, breathing techniques, and massage or skin stimulation methods. Acupuncture, a form of Chinese medicine that dates to approximately 3,000 years ago, is defined as the insertion of slender needles into specific bodily areas to restore balance and thereby reduce pain (Eappen \& Robbins, 2002). In a randomized trial where pregnant women received either acupuncture or no treatment, Ramnero and colleagues (2002) found that women in the acupuncture group requested epidural analgesia at a significantly lower rate (12\%) than women in the control group (22\%). Skilnand, Fossen, and Heilberg (2002) examined the effects of real acupuncture versus false acupuncture in a controlled, randomized single-blind study with 210 healthy pregnant women. These authors found significantly lower use of epidural analgesia, decreased labor pain, and shorter delivery times for those women receiving real as opposed to false acupuncture. Finally, in an observational study examining acupuncture and its relation to requests for epidurals during labor, Nesheim and Kinge (2006) found that women receiving acupuncture requested fewer epidurals compared to women who did not experience acupuncture. Although additional controlled trials are required, current evidence indicates that acupuncture may be beneficial during labor and delivery.

In a recent review of randomized controlled trials examining complementary and alternative therapies for childbirth pain management, Smith and colleagues (2006) did not find empirical support for the use of aromatherapy or audio analgesia. They did find support, however, for acupuncture and hypnosis, as women receiving these treatments showed a decreased need for pharmacological pain relief and greater satisfaction with their pain 
management during labor (Smith et al.). Empirical support documenting the benefits of hypnosis and self-hypnosis during labor includes evidence for decreased use of epidurals, reduced stress, and decreased reports of pain and anxiety for women undergoing hypnosis before or during childbirth as compared to women who do not receive hypnosis (Cyna, Andrew, \& McAuliffe, 2006; Ketterhagen, VandeVusse, \& Berner, 2002; Mehl-Madrona, 2004; Svensson, 2004; Smith et al., 2006).

Limited empirical support is available to document the effects of biofeedback, massage, breathing techniques, and hydrotherapy upon labor pain. Biofeedback has been found to decrease need for epidural analgesia and shorten labor time in one randomized trial (Duchene, 1989). Massage, or skin stimulation, and breathing techniques have been empirically shown to reduce pain perception during labor and thereby enhance satisfaction with the childbirth experience (Yildirim \& Sahin, 2004). Finally, beneficial effects have been found for hydrotherapy, or immersion in warm water, upon pain and anxiety during labor. In a randomized trial conducted by Benfield and colleagues (2001), participants were assigned to either a control group (no hydrotherapy) or experimental group (who bathed in $37^{\circ} \mathrm{C}$ water for one hour). Posthydrotherapy, significant reductions were seen in both reported anxiety and pain for those in the experimental as compared to the control group.

In summary, the benefits of incorporating self-management of labor pain into the birthing process include reduced levels of pain and anxiety (e.g., Benfield, 2001; Yildirim \& Sahin, 2004), a greater sense of personal control (e.g., Browning, 2001; Byrne-Lynch, 1991; Hodnett, 2002; Mehl-Madrona, 2004), and increased satisfaction with the childbirth experience (e.g., Browning, 2000; Devine \& Cook, 1986; Ketterhagen et al., 2002). Although the percentage of pregnant women who select to self-manage childbirth pain has not been established, it appears 
that, despite the benefits of self-management methods, not all pregnant women choose to utilize these techniques during labor. The extent to which an expectant mother considers using selfmanagement strategies to relieve childbirth pain has not been scientifically evaluated. To assess an expectant mother's readiness to use self-management strategies during labor, the current study developed a self-report instrument, the Childbirth Stages of Change Questionnaire (CSOCQ), designed for use at any point during a woman's pregnancy, or perhaps before pregnancy. The theoretical basis for the CSOCQ was the Stages of Change model, a component of the Transtheoretical Model of Change.

\section{The Transtheoretical Model of Change}

With roots in cognitive behavioral theory, Prochaska and DiClemente's (1982) Transtheoretical Model (TTM) of change is a framework for understanding the stages that individuals progress through when making a behavior change. The Transtheoretical Model is composed of three components: Stages of Change, Processes of Change, and Decisional Balance (Prochaska \& DiClemente, 1986). The Stages of Change component refers to a model that describes 5 varying levels of willingness to enact behavior change, the Processes of Change include 10 variables (e.g., consciousness raising, self-reevaluation, self-liberation, stimulus control) that assess how problem behaviors are changed by an individual, and Decisional Balance refers to the weighting of positives and negatives related to a behavior change (Prochaska, Rossi, \& Wilcox, 1991). This model has been utilized to investigate processes of behavior change in several diverse areas, including the management of chronic pain (e.g., Keefe et al., 2000) and behaviors important during pregnancy (e.g., smoking cessation; Slade, LaxtonKane, \& Spiby, 2006; Stotts, DeLaune, Schmitz, \& Grabowski, 2004), but has yet to be applied to acute pain, generally, or to childbirth pain. Although the TTM has been applied most 
frequently to understanding substance abuse (e.g., Migneault, Adams, \& Read, 2005), it also has been utilized in examining change processes related to other behaviors such as exercise (e.g., Lippke \& Plotnikoff, 2006), healthy eating (e.g., Di Noia, Schinke, Prochaska, \& Contento, 2006), HIV prevention (e.g., Prochaska, Redding, Harlow, Rossi, \& Velicer, 1994), and illness management (e.g., Gambling \& Long, 2006).

Stages of change model. The SOC model within the TTM characterizes readiness for change on a 5-part continuum: precontemplation, contemplation, preparation, action, and maintenance. The model also has been frequently applied, however, as a 4-part continuum without the preparation phase (e.g., Kerns, Rosenberg, Jamison, Caudill, \& Haythornwaite, 1997). During precontemplation, the individual does not recognize the need for a behavior change. Contemplation occurs when the individual becomes aware of the possibility for change, but feels ambivalence toward changing. During preparation, the individual has decided to create a change and makes a plan to do so in the near future. In action, the individual has begun to make a change in his or her behavior, but may need help to do so. The final stage is maintenance, in which the individual is successfully changing but has concerns about the durability of change (Prochaska \& DiClemente, 1986).

Evidence for the validity of the SOC model may vary by the domain (i.e., substance abuse, illness management, readiness to self-manage pain) in which it is applied. The bulk of empirical evidence supporting the utility of the SOC model relates to its validity at predicting relapse with addictive behaviors (e.g., Thyrian, Hannover, Roske, Rumpf, John, \& Hapke, 2006; Segan, Borland, Greenwood, 2006). Based on the model's predictive validity, interventions have been designed to facilitate movement through the SOC (e.g., motivational interviewing; Moyers, Miller, \& Hendrickson, 2005). In 2000, Whitelaw, Baldwin, Bunton, and Flynn reviewed the 
application of the SOC model to a variety of behavior changes; these authors found a lack of convincing evidence in support of the model and concluded that improved outcome studies and case studies were needed. A more recent critique of TTM and the associated SOC model was offered by West (2005); he primarily reviewed studies of TTM in regard to smoking and concluded that TTM does not account for a significant amount of variance in smoking behavior, and thus has more descriptive than predictive value. In a response to this critique, Prochaska (2006) provided evidence against the traditional models supported by West, and cited the empirical support of TTM particularly in the area of multiple behavior changes (e.g., stress, unhealthy eating, non-adherence to medications). Prochaska also emphasized the results of population-based studies that empirically demonstrated the value of TTM-based interventions (e.g., tailored TTM interventions for smoking). From the TTM, individual differences across the SOC model continue to be observed for a variety of behaviors and new interventions designed (e.g., to increase fruit and vegetable consumption; Di Noia et al., 2006). Although the usefulness of the SOC model, particularly its predictive validity, still is currently debated, the model has had recent contributions to the study of chronic pain and, as such, was selected as the theoretical basis for the CSOCQ.

Application of the stages of change model to pain. The Transtheoretical Model of Change recently has been applied to the study of pain. This application has been limited, however, to investigations with chronic pain. Specifically, the SOC model has been used to examine readiness of patients to self-manage chronic pain. The research to date includes two assessments of readiness to self-manage chronic pain, the Pain Stages of Change Questionnaire (PSOCQ; Kerns et al., 1997) and the Multidimensional Pain Readiness to Change Questionnaire (MPRCQ; Nielson, Jensen, \& Kerns, 2003), and supports the utility of incorporating the SOC 
model into understanding individual differences in readiness to self-manage chronic pain. Both assessments were developed based on the SOC model. The MPRCQ characterizes readiness to self-manage chronic pain in the five stages of precontemplation (self-management of chronic pain has not been considered), contemplation (patient is considering self-management strategies), preparation (patient is preparing to self-manage chronic pain, e.g., by obtaining information on self-management methods), action (patient has begun to self-manage chronic pain), and maintenance (the patient is actively self-managing chronic pain and has not relapsed to an earlier stage). The PSOCQ characterizes readiness to self-manage chronic pain with the four stages of precontemplation, contemplation, action, and maintenance.

Research evaluating the PSOCQ and MPRCQ has supported the utility of incorporating the SOC model into conceptualizations of chronic pain. Kerns and Habib (2004) concluded that the concept of readiness to self-manage chronic pain, based on the SOC model, has significantly contributed to the current understanding of chronic pain by illuminating motivational issues in completing chronic pain treatment programs and by revealing possible ways to improve selfmanagement treatment approaches to chronic pain. In a study of 300 chronic pain patients, Biller and collaborators (2000) demonstrated that readiness to self-manage chronic pain, as assessed by the PSCOQ, reliably predicted completion of a cognitive-behavioral treatment program within a multidisciplinary pain clinic. Precontemplation was the single best predictor of program completion, correctly identifying $61 \%$ of patients who completed the treatment program and $65 \%$ of patients who dropped out of the program (Biller et al.).

Readiness to self-manage chronic pain also has been implicated in treatment outcome for chronic pain patients. In an investigation of the predictive utility of an individual's stage of readiness to self-manage chronic pain, Hankin and Killian (2004) evaluated readiness stage in 
relation to functional outcome in patients with chronic pain. Stage of readiness to self-manage chronic pain, as assessed by the PSOCQ, combined with work status, accounted for $49 \%$ of the variance in functional outcome 3 months following completion of a multidisciplinary pain management program (Hankin \& Killian). Jenson, Nielson, Turner, Romano, and Hill (2004) also evaluated the validity of the PSOCQ in the context of a multidisciplinary program to treat chronic pain. These authors found that readiness to self-manage pain, as assessed by the PSOCQ, increased from pre-treatment to post-treatment, and that increases in readiness to selfmanage pain were related to improvement in the treatment program and to increased use of pain coping strategies. In addition, progression through the PSOCQ readiness stages has been related to increased goal achievement, decreased pain intensity, decreased disability, and decreased depression (Kerns \& Rosenberg, 2000). The MPRCQ, a newer measure designed to assess readiness to accept adaptive pain coping strategies and reject maladaptive coping strategies, has been developed and validated and currently awaits further investigation (Nielson et al., 2003).

Assessing a patient's readiness to self-manage his or her pain can aid health care providers in devising treatment plans that will target motivational issues, maximizing the possibility of movement toward active stages of change (Hankin \& Killian, 2004). Progress through the stages of readiness to self-manage chronic pain likely increases chances of improved functional outcome, as remaining in the early stages has been related to poor attendance and poor adherence to the treatment program (Hankin \& Killian). Assessing readiness to self-manage pain also has helped identify individual differences in motivation to complete chronic pain programs. As highlighted by Jensen, Nielson, and Kerns (2003), motivational issues influence participation in self-management treatment programs for chronic pain patients. Jensen and colleagues reviewed the motivational model of pain self-management and concluded that measures of 
readiness to self-manage chronic pain can enhance understanding of motivational issues in the context of chronic pain and thereby help guide motivation enhancement interventions. Intervention planning may be similarly guided if an assessment were available to measure individual differences in readiness to self-manage acute pain. In conclusion, because of its successful application to understanding readiness to self-manage chronic pain (e.g., Kerns \& Rosenberg, 2000) the Stages of Change (SOC) model (Prochaska \& DiClemente, 1986), was selected as the theoretical foundation for the CSOCQ.

Application of the stages of change model to labor pain. Although the SOC model previously has not been employed in the understanding of childbirth pain, it has been utilized in pregnancy-related areas of study. The SOC model has been applied to pregnant women for behavior changes such as breast-feeding (Kloeblen, Thompson, \& Miner, 1999) and, more frequently, smoking cessation (e.g., Ruggiero, Tsoh, Everett, Fava, \& Guise, 2000; Slade et al., 2006; Solomon, Secker-Walker, Skelly, \& Flynn, 1996; Stotts, DiClemente, Carbonari, \& Mullen, 2000). Stages of change questionnaires (e.g., Etter \& Perneger, 1999) and decisional balance measures (i.e., assessments of the costs and benefits of making a change/choice and not making a change/choice; e.g., Bane, Ruggiero, Dryfoos, \& Rossi, 1999) have been developed for smoking cessation and validated in samples of pregnant women. In addition, SOC-based motivational interviewing interventions targeted at smoking cessation in pregnant women have been related to increased confidence in one's ability to quit, as well as decreased depression and decreased smoking temptation (Stotts et al., 2004). This prior research applying the SOC model to health behaviors with great impact for pregnancy, such as smoking cessation and breastfeeding, serves as a guide for examining behavior change in the population of expectant or new mothers. SOC questionnaires and decisional balance measures from these fields, particularly 
smoking cessation, helped shape the procedures involved in the development of the CSOCQ (e.g., the incorporation of a decisional balance worksheet in the current study).

\section{Statement of the Problem}

The SOC model is a useful conceptualization to understand an individual's readiness to enact a variety of behavioral changes (Prochaska, 2006). Whether or not a pregnant woman selfmanages her pain, in whole or in part, during labor can potentially impact her experience of childbirth pain, as well as her overall impression of the birthing process. The use of selfmanagement strategies during childbirth has been related to a number of benefits, such as decreased levels of pain severity and anxiety (e.g., Benfield, 2001; Yildirim \& Sahin, 2004) and increased maternal satisfaction following delivery (e.g., Ketterhagen et al., 2002; Koehn, 1993; Mehl-Madrona, 2004; Svensson, 2004). Because self-management strategies also can reduce childbirth pain beyond the relief provided by pharmacological strategies alone (Smith et al., 2006), they comprise an important subset of pain management options for expectant mothers. Understanding a woman's readiness to self-manage childbirth pain may aid health care providers in advising patients in their labor decisions concerning pain management. A questionnaire designed to assess stages of readiness to self-manage childbirth pain also may be valuable in identifying women who are ambivalent about childbirth choices (e.g., self-management versus medication) and alert health care providers that additional education on pain management options may be indicated.

Regardless of a woman's preference of strategies for the management of her childbirth pain, an instrument such as the CSOCQ can inform health care personnel of her intended actions concerning pain management during labor. Incorporating the views of the expectant mother into birth planning is meaningful because there is evidence that the woman's perception of 
involvement in the decision-making concerning pain management is more important than perceived intensity of labor pain in predicting patient satisfaction following delivery (Heitman, Birdwell, \& Bennett, 1995). Finally, completing an assessment related to childbirth pain management may serve an educational or motivational purpose by prompting women to consider the decision regarding self-management during labor.

An individual's readiness to self-manage pain has been assessed in relation to chronic pain, and found to relate to functional outcomes and success in cognitive-behavioral treatment programs for chronic pain (e.g., Kerns \& Rosenberg, 2000). Despite the utility of the SOC model in understanding chronic pain, it has not been utilized to further our understanding of acute pain. Because childbirth is a common and developmentally typical source of acute pain for women, it is an appropriate choice for the development of an initial acute pain SOC questionnaire.

As such, the goal of the present study was to develop a psychometrically-sound selfreport instrument to assess an expectant mother's stage of readiness to self-manage the pain of labor and delivery, thereby enhancing the state of science for both childbirth pain and the applicability of the SOC model to acute pain in general. The development of a questionnaire to assess readiness to self-manage childbirth pain, based on the SOC model, has the potential to contribute to current knowledge of both childbirth pain and acute pain in three primary ways. First, by improving our understanding of the process by which women choose methods to manage childbirth pain, health care providers may be guided in their efforts to help women in the decision-making process. Additionally, as a preliminary investigation into the Transtheoretical Model as applied to acute pain, the study has broader implications for medical and dental procedures in areas other than childbirth. Finally, this research may draw the attention of health 
care providers to the diverse beliefs and attitudes of women toward the management of childbirth pain.

\section{Present Study}

Theoretical Considerations involved in CSOCQ Development

Readiness versus change. The CSOCQ was conceptualized as a stages of readiness, rather than change, questionnaire. Although readiness to self-manage chronic pain has been known as the individual's "stage of change," the concept of change is less applicable to a onetime acute pain situation as compared to the lifestyle changes associated with self-management of chronic pain. Because labor is a temporary situation, self-management of childbirth pain is a future behavior that will be executed for a finite period of time. The CSOCQ was designed to assess an expectant mother's readiness to self-manage childbirth pain, an anticipated event, at any point in her pregnancy. Although a woman's readiness to self-manage childbirth pain may change over the course of her pregnancy, the behavior itself occurs during childbirth and therefore is not the variable assessed with the CSOCQ. Since the CSOCQ assesses readiness to perform a future behavior, it is completed from an anticipatory perspective and thus does not assess readiness to change, but rather, readiness to engage in the behavior (i.e., self-management) at all. As such, "stage of readiness" was the terminology applied to the outcome variable of the CSOCQ in the current study.

Selection of the assessment approach. The current study aimed to assess readiness stages through a more complex algorithm, involving numerous questions, as opposed to the traditional 5-item algorithm SOC measures. This decision follows the established trend in the chronic pain literature and associated chronic pain SOC models of using multiple items to assess each SOC (e.g., Kerns et al., 1997; Maurischat et al., 2006; Nielson et al., 2003). Because the decision to 
self-manage pain is complex and unique, based on individual histories and differences, several facets are involved in the choice to self-manage or to not self-manage. For this reason, it was considered more appropriate to assess each stage of readiness with numerous items, as opposed to a traditional 1-item-per-stage assessment approach.

CSOCQ outcome variable. Of note, the outcome variable for all versions, preliminary through final, of the CSOCQ was categorical, rather than dimensional, as the measure's goal was to identify the one particular stage of readiness that best characterized a woman's readiness to self-manage labor pain at the time of the assessment. The CSOCQ included items to assess each of the five stages of readiness (precontemplation, contemplation, preparation, action, and maintenance) to self-manage childbirth pain. In regard to scoring the measure, the readiness stage with the highest score, relative to the other stages, represented the woman's current readiness to self-manage labor pain. The CSOCQ score could thus be precontemplation, contemplation, preparation, action, or maintenance. Following scoring rules developed for measures of readiness to self-manage chronic pain (Kerns et al., 1997; Maurischat et al., 2006; Nielson et al., 2003), if an individual were to score equally highly on more than one stage, the highest readiness stage would reflect the individual's stage (for example, if scores were equal on action and maintenance, the overall score would be maintenance).

Finally, although it is acknowledged in the SOC model literature that individuals may relapse or drop from a higher stage (e.g., action) to a lower stage of change (e.g., preparation), the conceptualization of the CSOCQ was linear. That is, it was assumed in the current study that a woman's readiness to self-manage childbirth pain would progress, in order, through the stages of readiness from lower to higher stages, without relapse. A linear conceptualization of movement through the readiness stages was hypothesized based on the notion that relapse (i.e., 
return to a lower stage) may be more associated with behaviors that require continual effort (e.g., chronic pain management), whereas acute pain management is short-term and, with the CSOCQ, is assessed prior to the execution of the behavior. It may be likely that relapse to a lower readiness stage occurs as childbirth approaches, or during the labor and delivery process itself (e.g., an individual who intended to self-manage decides during labor to request an epidural, perhaps due to fearful anticipation or pain that exceeded expectation). As scale development was the present objective, however, examining the process of progressing through readiness stages over the course of pregnancy was outside the scope of the current study. The model's assumed linearity and the issue of relapse will merit future investigation upon establishment of a psychometrically sound CSOCQ.

\section{Scale Development and Evaluation: Hypothesis 1}

In the current study, it was hypothesized that a reliable measure of a pregnant woman's readiness to self-manage childbirth pain, the Childbirth Stages of Change Questionnaire (CSOCQ), could be developed. It was expected that with proper expert input and sound theoretical foundation, an internally-consistent scale that discriminates between subgroups (e.g., those in contemplation vs. action) could be developed. Four studies were implemented to test this hypothesis. Study 1 was conducted to generate potential items that would represent various attitudes and beliefs related to the proposed model of readiness to self-manage childbirth pain. Study 2 involved a formal review of the items created in Study 1, and determined items for placement upon a pilot CSOCQ. Study 3 tested the pilot CSOCQ on a sample of undergraduate women with imagined pregnancies. Finally, Study 4, a pilot study, tested a revised CSOCQ on a sample of pregnant women for determination of items for a proposed final CSOCQ. All four 
studies received approval from the West Virginia University Institutional Review Board prior to data collection.

Construct Validity: Hypotheses $2 a-2 d$

It was expected that the CSOCQ would have appropriate divergent or convergent validity from other constructs assessed, such as fear of pain. To evaluate the construct validity of the CSOCQ, Study 4 included four additional measures to assess for relations between CSOCQ outcome (i.e., readiness stage) with other constructs likely to be associated with readiness to selfmanage childbirth pain. Selected based on prior pain research, the constructs examined included fear of pain, anxiety sensitivity, health anxiety, and depressive symptoms.

Hypothesis 2a: Fear of pain will be related to readiness. Fear of pain, particularly chronic pain, is a rapidly growing area within pain research (e.g., Asmundson, Vlaeyen, \& Crombez, 2004). It has been theorized that fear of pain interacts with other factors, such as anxiety and pain catastrophizing, in its effects upon the experience of chronic pain (Asmundson et al.). Recently, fear of pain has been applied to the understanding of acute pain in the context of dental (e.g., McNeil, Au, Zvolensky, McKee, Klineberg, \& Ho, 2001) and medical settings (e.g., Sieben, Vlaeyen, Tuerlinckx, \& Portegijs, 2002). Overall, fear of pain is an evolving area of research that has come to exert a growing influence upon approaches to both chronic and acute pain. Because childbirth pain is a type of acute pain that is particularly common (e.g., U.S. Census Bureau, 2002), an exploration into fear of pain in regard to childbirth pain is a relevant approach to studying this dynamic concept in acute pain. In addition, fear of birthing pain has been associated with reported pain levels during labor (Lowe, 1987) and with an increased likelihood of perceiving the delivery process as a negative experience (Areskog, Uddenberg, \& Kjessler, 1983). Heinze and Sleigh (2003) examined fear of childbirth broadly, and found higher 
childbirth fear in women who selected to have an epidural during labor as compared to women who selected not to have an epidural. In the current study, we hypothesized a relation between higher fear of pain, as assessed by the Fear of Pain Questionnaire-III (FPQ-III; McNeil \& Rainwater, 1998), and stages of readiness (i.e., precontemplation, contemplation) to self-manage childbirth pain. High fear of pain may result in greater utilization of pharmacological means, as suggested by the findings of Heinze and Sleigh, but usage of pharmacological pain management agents may not necessarily preclude the use of self-management in women high in fear of pain. Women with relatively greater fear of pain may be more likely to self-manage in an attempt to maximize pain reduction, or they may be less likely to self-manage due to anxiety or a reliance on pharmacological pain management. Because high fear of pain could result in varying effects upon readiness, a direction was not hypothesized for the relation between fear of pain and readiness stage.

Hypothesis 2b: Anxiety sensitivity will be inversely related to readiness. Anxiety sensitivity has been defined as the fear of bodily sensations related to anxiety, and the accompanying concerns about the negative effects of these sensations (Reiss \& McNally, 1985). It has been theorized that elevated anxiety sensitivity may be a vulnerability factor for the development of clinically significant levels of fear of pain (Asmundson, 1999). Anxiety sensitivity also has demonstrated associations to pain-related fear and anxiety (Zvolensky, Goodie, McNeil, Sperry, \& Sorrell, 2001). To test the hypothesis that individuals with high anxiety sensitivity would be more likely to score in lower readiness stages (i.e., precontemplation, contemplation) than individuals with low anxiety sensitivity, the Anxiety Sensitivity Index (ASI; Reiss, Peterson, Gursky, \& McNally, 1986) was administered.

Hypothesis 2c: Health anxiety will be inversely related to readiness. Health anxiety, 
also known as hypochondriasis, refers to a disproportionate concern about one's health in the absence of medical evidence of disease or despite medical reassurance (Hitchcock \& Mathews, 1992). Because of the theorized relation between health anxiety and pain (Hadjistavropoulos, Asmundson, LaChapelle, \& Quine, 2002), health anxiety was assessed in Study 4. Although measures of health anxiety have not been examined in relation to childbirth pain, measures of anxiety during labor (e.g., $1=$ not at all anxious to $7=$ very anxious) have been associated with women's attitudes about labor pain (Waldenström et al., 1996), with higher levels of anxiety related to more negative attitudes. Additionally, elevated anxiety during pregnancy has been related to increased childbirth pain ratings (Areskog et al., 1983; Nettelbladt, Fagerström, \& Uddenberg, 1976; Reading \& Cox, 1985), as well as to high state anxiety (Charles, Norr, Block, Meyering, \& Meyers, 1978; Leventhal et al., 1989). Based on these findings, we hypothesized that higher health anxiety, as assessed by the Illness Attitudes Scale (IAS; Kellner, 1986), would relate to lower readiness to self-manage childbirth pain (i.e., precontemplation, contemplation).

Hypothesis 2d: Depressive symptoms will be inversely related to readiness. Depressive symptoms were assessed in Study 4 due to the established relations between depressive symptoms, the SOC model, and overall motivation (e.g., Prochaska et al., 2004). Depression also has been related to the SOC model in chronic pain patients, specifically, such that patients with greater depressive symptoms were more likely to indicate lower levels of readiness to selfmanage chronic pain (Kerns \& Rosenberg, 2000). As such, it was expected that higher depressive symptoms, as assessed by the Beck Depression Inventory-II (BDI-II; Beck, Rush, Shaw, \& Emery, 1979) would relate to lower levels of readiness to self-manage childbirth pain (i.e., precontemplation, contemplation). 


\section{STUDY 1}

The purpose of Study 1 was to create and examine potential items for the development of the CSOCQ. It was hypothesized that, using expert input and the SOC model as a theoretical foundation, it would be possible to create an item pool that would represent five stages of readiness to self-manage childbirth pain. Individual semi-structured interviews were conducted with an expert panel, including pregnant women, childbirth educators and doulas, obstetricians, and pain psychologists, to generate a body of items to represent the following stages of readiness: precontemplation, contemplation, preparation, action, and maintenance. The expert panel was composed of four diverse groups of participants, with different experiences with pregnancy, childbirth, and pain management, in order to capture varying perspectives on selfmanagement of childbirth pain. The purpose of incorporating different viewpoints related to the phenomenon of self-management was to maximize the aspects of readiness to self-manage childbirth pain discussed in the interviews, and thereby increase confidence in the content validity of the generated items. As such, the interviews included questions related to the definition of self-management of childbirth pain, the many attitudes and beliefs representative of varying stages of readiness to self-manage childbirth pain, and potential third variables (e.g., number of past pregnancies) that could influence a woman's readiness to self-manage childbirth pain. These questions were designed to elicit qualitative information from each expert group that could be used in interpreting the relevance (i.e., content validity) of the generated items.

\section{Participants}

\section{Method}

There were 16 participants in Study 1, including five pregnant women, three childbirth educators, three obstetricians, and five psychologists with expertise in the study of pain and pain management. 
Pregnant women. Of the five pregnant women, four were multiparous (i.e., had given birth before). Of the multiparae, three women had given birth to one child and one woman had given birth to four children. All of these deliveries were vaginal; none were cesarean. To cope with the pain of labor, three of the four women had employed pharmacological means (e.g., oral analgesics, epidural); all four women indicated that they had used at least one self-management strategy to relieve labor pain. Of the self-management strategies mentioned, breathing and distraction were the most commonly used. All five of the pregnant women interviewed had attended or planned to attend childbirth education classes.

Childbirth educators. Of the three childbirth educators who participated in Study 1, two also worked as doulas, or professional labor assistants. All three childbirth educators were female, and each woman had given birth herself, as well. The childbirth educators had experience in childbirth education ranging from 6 years to 25 years. The average number of women seen per year by these educators was 100, a mean of their estimations.

Obstetricians. Of the obstetricians who participated in Study 1, two were female and one was male. The obstetricians in the current study have been practicing medicine for 12 to 32 years and estimated, on average, seeing between 200 and 600 women per year. Of their deliveries, they reported that approximately $25 \%$ are cesarean. Both female obstetricians noted experiencing childbirth themselves.

Pain psychologists. Five psychologists with expertise in pain and pain management, four male and one female, participated in Study 1. The psychologists ranged in years of experience from 5 to 25 years. Two of the psychologists interviewed were university professors; three were clinicians at a local rehabilitation hospital. The female pain psychologist had personal experience with childbirth, as she had given birth to two children. The four male psychologists 
indicated personal experiences with childbirth, as well, having observed labor and delivery with their spouses.

Materials

Semi-structured interview. All versions of the interview asked participants to consider a pregnant woman at each of the five stages (precontemplation, contemplation, preparation, action, and maintenance) of readiness to self-manage childbirth pain and generate ideas on possible attitudes or beliefs of a woman at each stage. Participants were asked to hypothesize how a woman's beliefs regarding self-management of labor pain could change over the course of her pregnancy and during labor, and whether these beliefs likely would differ based on the number of children a woman has had. The interview also asked participants questions concerning their own beliefs about the most effective methods of childbirth pain management.

Semi-structured interview A-expectant mother version. The expectant mother interview (Appendix A) included questions relating to prior experiences with childbirth and childbirth education classes and views on self-management of labor pain.

Semi-structured interview B - childbirth educator / doula version. The childbirth educator/doula interview (Appendix B) included questions relating to the participant's position as a childbirth educator (e.g., number of women and/or couples educated per year) and his or her experiences with pregnant women, childbirth education, and labor pain management (e.g., common reasons for attending childbirth education).

Semi-structured interview $C$-obstetrician version. The obstetrician interview (Appendix B) included questions relating to the participant's practice (e.g., number of women seen per year) and his or her experiences with pregnant women (e.g., common pain management requests of pregnant women, whether these requests vary based on number of prior pregnancies). 
Semi-structured interview D - pain psychologist version. The psychologist interview (Appendix B) included questions about the Stages of Change (SOC) model and its applicability to acute pain and, more specifically, to childbirth pain. Participants also were asked about their practice and their experiences with pregnant women and childbirth pain management.

Interview education. A portion of the interview was didactic, and covered current selfmanagement approaches to childbirth pain management, as well as an explanation of the SOC model. The first component of education delivered was a definition of self-management strategies (Appendix C). Next, a schematic diagram of the SOC model was presented (Appendix D). Finally, the SOC model was applied to the self-management of childbirth pain through an example item to represent each stage of readiness (Appendix E).

\section{Procedure}

Interviews were conducted individually at various locations, determined by the participants. Typically, the interview location was the place of work of the participant. All participants provided informed consent. After consenting, the first portion of the semi-structured interview was administered, with questions specific to expectant mothers, childbirth educators/doulas, obstetricians, or pain psychologists. Next, educational portion of the interview was delivered to each participant. Following this explanation, participants completed the second portion of the semi-structured interview, which focused on generating potential items for each stage of readiness. Participants also provided descriptive data relating to their experiences and beliefs regarding pregnancy and pain. The length of the interview was 45-60 minutes, on average. At the completion of the interview, participants were thanked with a small gift.

Results

Qualitative Information 
From the interviews, qualitative information related to the management of childbirth pain, reasons for attending childbirth education, and SOC model was obtained. A summary of the most pertinent qualitative information from each group of health care providers follows.

Childbirth educator comments. The childbirth educators cited questions about the extent of childbirth pain and the best way to cope with the pain as the most common concerns of women in their childbirth education classes. Regarding frequent reasons for attending childbirth education classes, the educators noted the following as primary motives: (a) the desire to gain information about childbirth options, and (b) the desire to participate in an activity with their partner/spouse.

Obstetrician comments. All three obstetricians noted a trend toward pharmacological means of pain management as the delivery date approaches, despite intentions earlier in the pregnancy to have a natural delivery. In regard to how childbirth pain management beliefs may vary for primiparae as compared to multiparae, it was noted that multiparae "know what to expect" and typically request the same method of pain management that they used in prior pregnancies (e.g., if a woman had an epidural before, she is more likely to request an epidural, whereas a woman who had a "natural" birth before is more likely to complete a natural childbirth again). For the current study, if a difference in pain management choices, or in the confidence a woman has in her selection of childbirth pain management exists for primiparae as compared to multiparae, the implications for the CSOCQ likely would be that readiness stage would be more consistent for multiparae (who, having been through childbirth before, have prior childbirth experiences to consider when completing the assessment). It would be expected that primiparae have less stable attitudes toward childbirth pain management and, as such, may experience more stages of readiness than multiparae. 
Pain psychologist comments. All five psychologists indicated support for the SOC model, in general. In terms of applying the model to acute pain, however, challenges were noted. The first conceptual issue raised was that of measuring an individual's readiness to manage a future, anticipated pain as opposed to measuring readiness to manage current pain. Specifically, the assessment of readiness to self-manage anticipated pain may be less predictive of actual behavior because it is an expected, rather than current, situation. One of the pain psychologists also speculated that an individual may progress through the stages of readiness more quickly with acute pain self-management, as compared to self-management of chronic pain, because the behavior required to self-manage acute pain is a short-term commitment, whereas self-management of chronic pain is more of a lifestyle change. Because of the longterm commitment required with self-management of chronic pain, the psychologist predicted that an individual with chronic pain would be more likely to progress through the SOC model in a slow and sequential manner. A final conceptual issue raised in the interviews was the issue of maintenance and acute pain. Because childbirth pain is an acute situation, there is not a need to continue the self-management behaviors beyond labor and delivery, unlike chronic pain situations. For this reason, a maintenance stage may not be as applicable in an acute pain setting such as childbirth. On the other hand, one of the psychologists raised the possibility that the SOC model may be more applicable to acute than chronic pain. Specifically, the idea expressed was that readiness to self-manage pain may be more palatable to individuals who will have to self-manage for a shorter period of time, such as childbirth, compared to those who would have to engage in self-management behaviors as part of a lifestyle change to cope with chronic pain. In the current study, maintenance items addressed continued practice of self-management strategies in preparation for labor. An alternative conceptualization of maintenance, however, 
could be the use of the self-management strategies applied during childbirth to other painful situations later in life. Although items were generated in Study 1 that would assess readiness to apply self-management strategies to acute pain in other instances than childbirth (e.g., "I intend to use the coping strategies I learn to ease childbirth pain for other painful situations in my life"), items reflecting this alternate conceptualization of maintenance were not included on the CSOCQ. Although interesting for understanding the SOC model of readiness to self-manage acute pain generally, these items were excluded because the goal of the CSOCQ was to evaluate readiness to self-manage pain specific to labor and delivery.

\section{Item Generation}

The interviews resulted in the generation of 168 items, across all five stages of readiness (Appendix F). Interview questions 1 - 7 (final page of Appendices A and B) elicited items to match particular readiness stages. Specifically, questions 1 and 2 elicited precontemplation items, question 3 elicited contemplation and preparation items, question 4 elicited preparation and action items, and questions $5-7$ elicited action and maintenance items. If the items generated did not match the intended readiness stage, the investigator re-categorized the item to the readiness stage in which it fit best, according to the SOC model and the context of the interview.

Items from the interviews were reviewed, analyzed, and synthesized by a research team of eight individuals with experience studying anxiety, fear, and pain. The research team also generated 153 new items, yielding a grand total of 321 items (Appendix G). Because the structure of the interviews and the research team meeting prompted item generation for each of the five stages of readiness separately and in order, created items were conceptualized into a readiness stage at the time of item generation. The process of item generation differed for the 
research team, comparative to the expert panel, in that they were instructed to create items for each of the 5 readiness stages directly, rather than in response to questions $1-7$ of the interview. As such, re-categorization of some items into readiness stages by the investigator was not necessary. Overall, of the 321 items created, there were 96 precontemplation items, 46 contemplation items, 36 preparation items, 42 action items, and 101 maintenance items. The distribution of items across the five stages was significantly different from an equiprobability model $\left(\mathrm{X}^{2}(4)=62.07, p<.001\right)$. It appears that the greater number of precontemplation and maintenance items, relative to the other three stages, accounts for much of this difference.

Following item generation, qualitative data methods were used to reduce the number of items from 321 to 75 , or 15 items per readiness stage (Appendix H). The 321 items were evaluated in relation to the SOC model, as well as the five guidelines for generating an item pool (e.g., items reflect the purpose of the scale, redundancy) and the characteristics of good and bad scale items (e.g., avoidance of lengthy items, consideration of reading difficulty level, elimination of double barreled items, or items that convey two or more ideas) as outlined by DeVellis (2003). Because DeVellis recommends receiving feedback from experts on the initial item pool as a way to maximize the content validity of the scale, all Study 1 participants were approached to review the final item list. Of the 16 participants, 4 agreed to review the items. The items were reviewed by two childbirth educators, one pain psychologist, and one obstetrician; the obstetrician also obtained feedback on the items from a group of four OB-GYN residents under his supervision. The experts reviewing the items were asked to consider the definition of the phenomenon being assessed, readiness to self-manage childbirth pain, and to suggest elimination of items that they did not consider relevant to the measurement of this phenomenon. Reviewers also were asked to consider the wording of the items (i.e., clarity and 
conciseness) and to suggest new ways of capturing the phenomenon of readiness to self-manage childbirth pain, to ensure that items were tapping into all aspects of self-management of childbirth pain. The expert reviewers eliminated 54 of the 321 items.

Next, the principal investigator eliminated an additional 50 items, based on the qualitative considerations noted above. Of the 217 items that remained, two investigators (the principal investigator and research supervisor) independently selected their choice of the best 10 items per stage (i.e., most appropriate items in relation to the SOC model, considerations of good and bad items, and other qualitative information gathered). The investigators then met to compare independent lists. First, comparisons of the 50 items on the two lists were examined for direct matches with the following results: (a) for precontemplation, investigators agreed on 7 of the 10 items; for contemplation, agreement on 6 of the 10 items; for preparation, agreement on 8 of the 10 items; for action, agreement on 8 of the 10 items; and, for maintenance, agreement on 6 of the 10 items. Those items that were direct matches were examined for readability and clarity, reworded as necessary, and placed on the item list retained for the preliminary CSOCQ. For the 15 items that were not direct matches, the investigators had selected items reflective of the same construct, but differently worded, for 12 of the 15 . In these cases, the investigators discussed the wording differences and agreed upon the item to retain. For 2 of the 12 cases, both similarlyworded items were retained for the preliminary scale. Items included on the list of one investigator but not the other were evaluated individually for retention. All items were critiqued for clarity and re-worded as necessary. At the conclusion of the consensus meeting, the investigators agreed upon the 75 most appropriate items, 15 per readiness stage, to be included on the preliminary CSOCQ. Appendix H summarizes these 75 items by readiness stage. 
One issue discussed in the consensus meeting was that of positively and negatively worded items. As described by DeVellis (2003), positively worded items note the presence of a phenomenon, whereas negatively worded items note lower levels or the absence of a phenomenon. The incorporation of items that are both positively and negatively worded is one way to avoid an agreement bias in responding. Reversals in item polarity, however, can be confusing to respondents (DeVellis). Because the CSOCQ is intended to be a multifaceted scale, with items to assess five different stages of readiness, the concern related to agreement bias was relatively small. The decision reached in the consensus meeting was to use positively worded items within each readiness stage. The choice to utilize positively worded items only was selected for two reasons: (a) to reduce participant confusion when completing the CSOCQ, and (b) to enhance the ease and increase the speed of CSOCQ scoring (i.e., by eliminating the need for reverse scoring). The second reason stemmed from the practical consideration that the CSOCQ likely will be used in health care settings, such as obstetrician offices, where rapid scoring is important.

Finally, because the CSOCQ is intended for women of varying levels of education, it was important to evaluate the reading difficulty of items. Reading level difficulty was considered separately for each of the 75 items selected in Study 1 . All items were below an $8^{\text {th }}$ grade reading level, as reported by the Flesch-Kincaid Grade Level tool of Microsoft Office Word 2003 software.

\section{Discussion}

In Study 1, items for the CSOCQ were generated using the SOC model as a theoretical basis and expert input from four groups of individuals with experience with pregnancy, childbirth, or pain management. The items appeared to differentiate levels of readiness to self- 
manage the pain of labor and delivery. For precontemplation, items reflected the beliefs that self-management training is not likely to be helpful in easing labor pain and that pain relief is the responsibility of medical professionals. Contemplation items indicated ambivalence about how to manage labor pain, reluctance to abandon pursuit of a medical solution to pain, and consideration of the potential value of learning self-management skills in preparation for childbirth. Preparation items reflected an investigation into self-management approaches to childbirth pain, while items generated for the action phase included self-statements noting engagement in self-management skill practice and statements indicating acceptance of a selfmanagement approach to childbirth. Finally, maintenance items reflected a desire to continue to learn self-management skills for coping with pain, including childbirth and other acute pain situations, and an established self-management perspective to handling labor pain.

Results revealed a significant difference in the number of items created for the five readiness stages. The greater number of items generated to represent precontemplation and maintenance suggest greater ease in conceptualizing readiness to self-manage labor pain at the extremes of the SOC model.

\section{STUDY 2}

The purpose of Study 2 was to evaluate the items generated in Study 1 for inclusion in a pilot CSOCQ. Feedback on the 75 items was obtained from three pregnant women, with a particular focus on identifying poorly worded or confusing items. Feedback also was obtained concerning the face validity and perceived relevance of the prospective items. Participants were also asked what aspects of readiness to self-manage childbirth pain were absent from the scale, to improve content validity. The goal of Study 2 was to identify the best (i.e., most appropriate in 
regard to the SOC model and qualitative information gathered about self-management of childbirth pain) 10 items for each of the five readiness stages for placement on the pilot CSOCQ. Method

\section{Participants}

Three pregnant women participated in Study 2. The participant ages were 21, 34, and 37 years. All three participants were Caucasian. Two of the participants were multiparous; one participant was primiparous. Of the multiparae, one had one prior child and the other had two children; these childbirths were all cesarean deliveries. Two of the participants were in their second trimester of pregnancy at the time of the interview; one participant was in the third trimester of pregnancy.

\section{Materials}

Semi-structured interview. The semi-structured individual interview (Appendix I) included questions relating to prior experiences with childbirth and childbirth classes, if any, and views on self-management of labor pain. The interview also included demographic questions and items relating to current pregnancy (e.g., due date). The final portion of the interview included questions regarding the CSOCQ items (e.g., items of particular relevance, items that may belong in another stage of readiness) and the participant's own staging by the preliminary CSOCQ (i.e., Was the readiness stage identified by the preliminary CSOCQ correct in capturing the participant's readiness stage, as verbally reported?).

Interview education. A portion of the interview was didactic, and covered current selfmanagement approaches to childbirth pain management, as well as an explanation of the SOC model. The first component of education delivered was a definition of self-management strategies (Appendix C). Next, a schematic diagram of the SOC model was presented (Appendix 
D). Finally, the SOC model was applied to the self-management of childbirth pain through an example item to represent each stage of readiness (Appendix E).

CSOCQ - preliminary. The 75 items from Study 1 (15 items per stage of readiness) were placed on a 5-point Likert-type scale of completely agree (5), agree (4), neutral (3), disagree (2), and completely disagree (1) to construct a preliminary CSOCQ (Appendix J). Participants were asked to circle the number $(1-5)$ that indicated how much they agreed with each item in relation to their own pregnancy. Items on the preliminary CSOCQ were not randomized, but were administered in order by stage of readiness, beginning with precontemplation. Items were ordered as such to allow participants to easily compare items within readiness stages when providing relevance ratings, and to facilitate quick scoring of the measure, as the investigator discussed the participant's CSOCQ score (i.e., stage of readiness) with her at the end of the interview.

CSOCQ -relevance ratings. The 75 items from Study 1 also were placed on a 5-point Likert-type scale of completely irrelevant ( - ), irrelevant ( - ), neutral (0), relevant (+), and completely relevant $(++)$ to construct a relevance ratings form (Appendix K). Participants were informed of the readiness stage (precontemplation, contemplation, preparation, action, or maintenance) assigned to each item. Participants were asked to read each item and consider its relevance in relation to the stages of readiness to self-manage pain model explained in the interview education. Participants then were asked to circle the symbol that indicated the level of relevance they felt best fit each item, from - - (completely irrelevant) to ++ (completely relevant). Participants also were encouraged to write comments regarding specific items on the relevance ratings form. The purpose of this form was to gather qualitative information on the content validity of the CSOCQ items. 


\section{Procedure}

All participants provided informed consent for Study 2, as well as an authorization for use and disclosure of protected health information. After receiving the interview education, the participants were interviewed briefly to obtain demographic data and information concerning pregnancy, both prior and current. The women then completed the preliminary version of the CSOCQ. Following completion of the CSOCQ, the investigator continued the interview, with questions pertaining to the participant's views on the self-management of childbirth pain.

Next, participants completed the relevance ratings form, providing a relevance rating for each CSOCQ item. While the participant completed the relevance ratings, the investigator scored the participant's preliminary CSOCQ. The CSOCQ score (i.e., stage of readiness to selfmanage childbirth pain) was calculated in two steps. First, values for the 15 items within each stage were summed. Then, summed values for the five stages of readiness were compared and the stage with the highest sum was determined to be the participant's CSOCQ score. If a participant had two equally high sums on more than one stage, the higher stage along the model's continuum was determined to be the score. For example, if a participant had two equally high scores for action and maintenance, the CSOCQ categorization was maintenance.

Following completion of the relevance ratings, participants completed the third and final portion of the semi-structured interview, the goal of which was to elicit additional feedback on the pool of items representing the five stages of readiness and thereby evaluate content validity of the items. Participants were asked which items, if any, they particularly liked or disliked, items they found to be confusing or poorly worded, and items that should be in another readiness stage, conceptually. Participants also were asked if there was any aspect of self-management of childbirth pain (e.g., other possible beliefs about self-management of childbirth pain, additional 
considerations an expectant mother may have when selecting pain management strategies for labor) that was missing from the measure generally, or that was absent from a particular readiness stage. This qualitative information was provided to two independent raters, the primary investigator and the research supervisor, during the item analysis for determining the best (i.e., most appropriate in relation to the SOC model and interview data) items to be used on the CSOCQ-pilot in Study 3.

Finally, to evaluate the accuracy of the preliminary CSOCQ on correctly 'staging' the participants, each participant was asked to report what stage of readiness (e.g., precontemplation, contemplation, preparation, action, or maintenance) in which she currently considered herself regarding her present pregnancy. Next, the investigator shared the participant's CSCOQ score (i.e., readiness stage), as determined by the preliminary CSOCQ, with her, and asked her to report whether she considered her score reflective of her current readiness to self-manage childbirth pain. The length of the interview was 45-60 minutes, on average. At the conclusion of the study, participants were thanked with a small baby gift.

\section{Results}

First, the scores on the preliminary CSOCQ were examined in relation to the participant's interview information concerning her views on self-management of labor pain. None of the women had equally high sums on more than one readiness stage, so scoring was unambiguous. One participant each was scored to be in precontemplation, contemplation, and preparation. To evaluate the accuracy of the preliminary CSOCQ, the investigators reviewed the information from the semi-structured interview regarding how the participant's preliminary CSOCQ score compared to her self-reported perceived stage of readiness to self-manage childbirth pain. For each participant, the individual's verbal report of her current stage matched her stage as 
identified by the preliminary CSOCQ, providing initial support for the validity of the items. All three participants indicated "yes" to the final interview question, "Do you feel that your score is reflective of your current stage of change (readiness)?" The readiness stages endorsed were preparation (participant 1), action (participant 2), and precontemplation (participant 3).

Although the matching of the final question to each score found on the preliminary CSOCQ indicated scale validity, this finding also cast doubt on the necessity of a full scale to assess readiness to self-manage childbirth pain. Expressly, if readiness could be assessed sufficiently with a single question, administering a self-report scale with multiple items would be unwarranted. The ability to assess readiness with one question at the completion of Study 2 was predicated, however, by a full description of the SOC model and its application to childbirth pain. As such, the time required to provide didactic information on the SOC model, allowing staging with one item, may not significantly differ from the time required to complete the full scale. Whether a single item assesses readiness to self-manage childbirth pain as well as the CSOCQ in its entirety is an empirical question for future study.

The final interview question also allowed an initial evaluation of the CSOCQ from the perspective of an expectant mother with a planned cesarean delivery. The applicability of the CSOCQ for women with planned cesareans had been one of the issues raised during Study 1, as these women typically have scheduled deliveries and may not enter into active labor. One of the three participants in Study 2 indicated that the delivery of her current child would be a planned cesarean. She indicated that her score of preparation on the preliminary CSOCQ was reflective of, or matched, her current readiness to self-manage childbirth pain. Qualitative information gathered from this participant demonstrated that the CSOCQ may be applicable for women with planned cesarean deliveries, because of the possibility that labor may begin prior to the 
scheduled delivery time, and that, in such a case, the woman would have a chance to self-manage contraction pains. In regard to her score of preparation on the preliminary CSOCQ, the participant stated, "Yes, I feel that it's exactly right. I will probably seek out more specifics [on self-management strategies] as [the] birth draws closer. Right now, I feel [the stage of preparation] is right because I'm not sure my techniques will help or if I'll have time to use them before the c-section.” This quote highlights the possibility that an individual with an expected cesarean delivery may or may not experience acute pain during childbirth; as such, the CSOCQ appears to be applicable in such cases.

Next, the relevance ratings were qualitatively analyzed. Appendix L summarizes the relevance ratings and comments for the 75 preliminary items across all 3 participants. Based upon the interview feedback and relevance ratings, two investigators (the principal investigator and the research supervisor) independently selected their choice of the best 10 items per stage (i.e., most appropriate items in relation to the SOC model and other qualitative information gathered). The investigators then met to compare independent lists. First, comparisons of the 50 items on the two lists were examined for direct matches with the following results: (a) for precontemplation, investigators agreed on 9 of the 10 items; for contemplation, agreement on 6 of the 10 items; for preparation, agreement on 7 of the 10 items; for action, agreement on 9 of the 10 items; and, for maintenance, agreement on 10 of the 10 items. Those items that were direct matches were examined for readability and clarity, re-worded as necessary, and placed on the item list retained for the pilot CSOCQ. For the 9 items that were not direct matches, the investigators had selected items reflective of the same construct, but differently worded, for 8 of the 9 items. In these cases, the investigators discussed the wording differences and agreed upon the item to retain. The additional item on the list of one investigator was retained for the 
contemplation category. All items were critiqued for clarity and re-worded as necessary. At the conclusion of the consensus meeting, the investigators agreed upon the 50 most appropriate items, 10 per readiness stage, to be included on the CSOCQ-pilot. Decisions to retain items for the pilot scale were influenced to a large extent by the relevance ratings and qualitative comments of the participants. The investigators selected to retain items with lower relevance ratings relative to other items, however, when those items represented a facet of the phenomenon not encompassed by the higher-rated items. The goal was to retain items that were rated as highly relevant, but also representative of different aspects of readiness to self-manage childbirth pain, in order to maximize content validity. Appendix M summarizes these 50 items by readiness stage.

\section{Discussion}

The objective of Study 2 was to evaluate the 75 CSOCQ items in terms of content validity, readability, and face validity. At the conclusion of Study 2, the 50 selected items were randomized and placed on a 5-point Likert-type scale of completely agree (5), agree (4), neutral (3), disagree (2), and completely disagree (1) to construct the CSOCQ-pilot (Appendix N).

Study 2 also provided initial support for the categorization of the various items into readiness stages, as each participant's preliminary CSOCQ score matched her verbal report of her current readiness to self-manage childbirth pain.

In reducing the number of items, both the ratings (completely irrelevant to completely relevant) and the qualitative information gathered in terms of each item's relevance were considered. The relevance ratings and qualitative feedback were used extensively in the consensus meeting that determined the 50 items for the CSOCQ-pilot. Based on comments from the expectant mothers, items were re-worded and re-organized to maximize content validity. 
Finally, the considerations involved in Study 1 (e.g., item length, item reading difficulty) also were factored into the decision of which items to retain for the CSOCQ-pilot. Overall, the findings from Study 2 were critical in evaluating the content and face validity of potential CSOCQ items, and in assuring adherence to current scale development guidelines (e.g., DeVellis, 2003) suggesting item review by a panel of experts. The participants in Study 2 were currently pregnant and had a range of prior experiences with childbirth and labor pain management; as such, it can be concluded that they formed a valid expert panel for item review.

\section{STUDY 3}

The purpose of Study 3 was to evaluate the psychometric properties of the CSOCQ-pilot on a sample of undergraduate women with imagined pregnancies. Although the CSOCQ is intended to assess readiness to self-manage childbirth pain for women who are currently pregnant, undergraduate women were selected to participate in Study 3 in order to provide a sufficient sample size for the intended analyses (i.e., factor analysis). While a sample composed of pregnant women would have been more appropriate, the feasibility of the study required a convenience sample. Factor analysis, an established method for the evaluation of scale items and the analysis selected to evaluate the CSOCQ-pilot, requires a minimum subject-to-item ratio of 5 and a suggested subject-to-item ratio of 10 (Bryant \& Yarnold, 1995). An "essential tool in scale development" (DeVellis, 2003, p. 137), factor analysis was utilized in Study 3 to evaluate the relation of CSOCQ items within each readiness stage to the latent variable, readiness to selfmanage childbirth pain. As the CSOCQ-pilot included 50 items, a sample of 500 participants was required to satisfy the subject-to-item ratio standard of 10 . Because undergraduate women are typically of child-bearing years, female university students instructed to imagine themselves 
as pregnant were the closest approximation to actual pregnant women available for the current study, as it was not feasible to recruit 500 expectant mothers.

Study 3 included three self-report measures, including a demographics questionnaire, the CSOCQ-pilot, and a decisional balance worksheet. When completing the CSOCQ-pilot, participants were instructed to imagine themselves in a particular month of pregnancy: month one, month five, or month nine. The purpose of using three different instructional sets was to vary the month of pregnancy to allow for CSOCQ responding along the continuum of readiness stages. If all participants were instructed to be in month 1 of pregnancy, for example, responses likely would be concentrated at the lower stages of readiness to self-manage childbirth pain. By randomizing the month of pregnancy, the goal was to increase the likelihood that participants would vary in their responding to the CSOCQ-pilot (i.e., a distribution of readiness stages) for better item analyses.

The purpose of the decisional balance worksheet was to obtain qualitative information on the decision-making process related to readiness to self-manage childbirth pain. Information gained from the decisional balance worksheet was analyzed with Interpretative Phenomenological Analysis (IPA; Smith \& Osborn, 2003) and used to create new items for the CSOCQ-revised, in order to improve the scale's content validity. In addition to the qualitative analysis of the decisional balance data, factor analysis and item analyses were performed on the CSOCQ-pilot. Test-retest reliability analysis also was performed, to assess the stability of the CSOCQ-pilot.

\section{Participants}

\section{Method}

There were 536 female university students who participated in Study 3. All participants were asked to complete the re-test portion of the study, which involved taking the CSOCQ-pilot 
again 1-2 weeks following its first administration, for additional extra credit. A subset of 63 of the 536 participants volunteered to complete the re-test portion of the study. Participants who completed the re-test portion of Study 3 did not systematically differ from participants who did not participate in the re-test. Participants had a mean age of 20.3 years (range $18-52, S D=3.5$ ). The majority of participants were Caucasian (92.2\%), single (88.8\%), and from an urban location $(56.3 \%)$. A relatively equal number of participants received each of the 3 instructional sets, with $181(33.8 \%)$ instructed to be in month one, 178 (33.2\%) instructed to be in month five, and 177 $(33.0 \%)$ instructed to be in month nine.

Participants receiving different instructional sets did not systematically differ on any of the demographic variables, including age $(F(2,533)=.35, p=.71)$, race/ethnicity $\left(X^{2}(12)=\right.$ $10.83 p=.55)$, location $\left(X^{2}(2)=.22, p=.90\right)$, marital status $\left(X^{2}(8)=6.17, p=.55\right)$, plans to have children $\left(X^{2}(2)=.73, p=.70\right)$, or experience with the pregnancy of a friend or family member $\left(X^{2}(2)=.22, p=.90\right)$. Re-test participants, however, did differ from non-re-test participants on age, race/ethnicity, and martial status. Specifically, re-test participants were, on average, older $(t(534)=-6.23, \mathrm{p}<.001)$ and more likely to be married $\left(X^{2}(4)=17.63, p<.001\right)$ than non-re-test participants. A greater proportion of re-testers, compared to non-re-testers, were African American $\left(X^{2}(6)=13.29, p=.04\right)$. Re-test participants did not systematically differ from non-re-test participants, however, on location $\left(X^{2}(1)=1.02, p=.31\right)$, plans to have children $\left(X^{2}(1)=1.15, p=.28\right)$, or experience with the pregnancy of a friend or family member $\left(X^{2}(1)=\right.$ $.01, p=.93)$

\section{Materials}

Demographic questionnaire. The demographic questionnaire used in Study 3 (Appendix O) asked the participant to complete basic information such as age, racial or ethnic background, 
marital status, and type of location (i.e., rural or urban) with which the participant most closely identified (e.g., hometown). The demographic questionnaire also included questions about past, current, and future experiences with pregnancy and childbirth. Finally, the questionnaire assessed levels of knowledge about pregnancy, childbirth, and the SOC model developed by Prochaska and DiClemente (1986).

Definition of self-management. Participants were instructed to read a definition of selfmanagement of childbirth pain (Appendix P) prior to completing the CSOCQ-pilot. The purpose of providing a definition of self-management was to enhance participant understanding of the CSOCQ items, and thereby improve the comprehensibility of the measure.

Instructional sets. Prior to completing the CSOCQ-pilot, participants were provided with a set of instructions that directed them to respond to the CSOCQ-pilot as if they were currently pregnant in a specific month of pregnancy. Participants were randomly assigned to 1 of 3 sets of pregnancy instructions, each set approximating the first, second, or third trimester of pregnancy, respectively. Each participant received instructions to imagine herself in either: (a) month 1, (b) month 5, or (c) month 9 of a planned pregnancy (Appendix Q). The purpose of the instructional sets was to provide the participants with a frame of reference for completing the CSOCQ-pilot; because the CSOCQ-pilot asked questions about the self-management of childbirth pain, participants were provided with the reference frame of an imagined pregnancy in order to approximate the situation of responding to the CSOCQ-pilot with a real pregnancy. To control for potential confounds (e.g., number of prior pregnancies, distress about an unplanned pregnancy), all instructional sets directed the participant to imagine herself in a first, planned pregnancy. Of note, though instructional set was random on first administration, re-test 
participants received the same instructional set for the second administration of the CSOCQ-pilot one to two weeks later.

CSOCQ - pilot. The pilot CSOCQ is a 50-item questionnaire designed to assess an expectant mother's readiness to use self-management strategies to cope with labor pain (Appendix N). The order of items on the CSOCQ-pilot was randomized; all participants received the same version of items (alternate forms were not used). Because this pilot version was administered to undergraduate women with imagined pregnancies, the instructions were specific to an imagined pregnancy. Participants were asked to circle the number $(1-5)$ that indicated how much they agreed with each item in relation to their own imagined pregnancy.

Decisional balance worksheet. A decisional balance worksheet, an assessment designed to elicit the benefits and risks to all aspects of making or not making a change/choice, adapted from Miller's Decisional Balance Worksheet for motivational interviewing (Mid Atlantic Addiction Technology Transfer Center, 2005), was administered. Participants were asked to supply as many benefits (pros) and risks (cons) as possible concerning the decision to selfmanage childbirth pain (Appendix R). Participants generated pros and cons regarding the choice to self-manage childbirth pain, and pros and cons regarding the choice not to self-manage childbirth pain. The decisional balance worksheet format was changed from the traditional box format (Mid Atlantic Addiction Technology Transfer Center) to a list format in order to encourage participants to provide as many pros and cons as possible for each of the four sides of the decision. This measure was administered in order to gain qualitative information concerning the factors that women consider when making a decision for or against utilizing selfmanagement strategies to cope with childbirth pain, to be used in the revision and creation of CSOCQ items for the CSOCQ-revised. 


\section{Procedure}

Undergraduate females enrolled in introductory psychology courses were invited to participate in Study 3. Participants were informed that the study involved completing three questionnaires, including the CSOCQ-pilot, demographic questionnaire, and decisional balance worksheet. All participants provided informed consent, as well as an authorization for use and disclosure of protected health information.

Following the completion of the consent form, the participants responded to the demographics questionnaire. Next, participants read an instructional set, directing them to imagine themselves as currently pregnant, and a definition of self-management of childbirth pain. Finally, participants completed the CSOCQ-pilot and the decisional balance worksheet. Participants were informed that they could discontinue participation at any time without penalty and that they need not answer question(s) that they found objectionable. At the conclusion of the study, participants were debriefed and provided with extra credit as compensation. Participants were given the option to return one to two weeks later and complete the CSOCQ-pilot a second time for additional extra credit. All participants were asked to complete the re-test, and re-tests were administered to those who elected to participate a second time. Upon re-test, participants again were instructed to read the definition of self-management of childbirth pain, as well as an instructional set matching the instructions they received on first administration, prior to completing the CSOCQ-pilot.

Results

\section{Initial Analyses}

To evaluate the appropriateness of using undergraduate women in place of pregnant women, several questions on the demographic questionnaire addressed experiences with 
pregnancy, childbirth, and childbirth education. In terms of pregnancy experience, 12 participants (2.2\%) indicated being currently pregnant, $35(6.5 \%)$ had a prior pregnancy, and 22 (4.1\%) had given birth before. Of the 536 women in the sample, $513(95.6 \%)$ indicated that they planned to have children in their lifetime. For those who planned on having children, the mean age of expected first childbirth was 26.6 years (range $17-35, S D=2.5$ ). Of note, $94.6 \%$ of the sample, or 507 participants, indicated a greater than $50 \%$ chance that they would have at least one child in their lifetime, with $73.1 \%$ of participants indicating a $91-100 \%$ likelihood of having at least one child. The majority of participants responded that they had "been through the pregnancy of a friend or family member" $(58.2 \%)$ and that there had been a time when they themselves had thought they were pregnant but did not want to be (58.5\%). Finally, $18.9 \%$ of respondents had witnessed a live birth and $17 \%$ had attended a childbirth education class before. Most participants responded that they knew "some" or "a great deal" about pregnancy (83\%), and nearly half knew "some" or "a great deal" about childbirth (50.9\%). Knowledge about the SOC model was limited, as the bulk of participants (79.5\%) indicated that they did not know about the model at all, with $14.4 \%$ of participants knowing "a little" about the model.

\section{Factor Analysis}

To analyze the CSOCQ-pilot, an exploratory factor analysis was conducted using varimax rotation and specified eigenvalues $>1.0$. A structure weight cut-off of .40 , as recommended by Garbin (2006), was utilized in evaluating the component matrix. A four-factor solution was obtained. Factor 1 (Action/Maintenance) accounted for $30.7 \%$ of the variance and included 8 action items and 6 maintenance items. Factor 2 (Precontemplation), composed of 8 precontemplation items, contributed an additional 9.3\% of the CSOCQ-pilot variance. Factor 3 (Preparation), consisted of 8 preparation items, and accounted for $7.3 \%$ of the variance in 
responding. Finally, Factor 4 (Contemplation) included 6 contemplation items and accounted for $4.2 \%$ of the variance. A fifth factor contributed $2.9 \%$ of the variance but, as it consisted of only one item, this factor was uninterpretable.

Items for the CSOCQ-revised were selected based on this factor analysis. The factor analysis reduced the number of items per readiness stage to 8 precontemplation items, 6 contemplation items, 10 preparation items, 8 action items, and 6 maintenance items for a total of 38 items (summarized in Appendix S). Internal consistencies for each of the hypothesized readiness stages were then calculated based on the remaining items.

\section{Reliability Analyses}

Internal reliability. The internal consistency of each readiness stage was evaluated individually by means of Cronbach's alpha ( $\alpha)$. Reliabilities were computed for the four readiness factors that emerged in the factor analysis, as those were the items retained for the CSOCQ-revised. The reliability coefficients were as follows: (a) precontemplation $\alpha=.91$, (b) contemplation $\alpha=.69,(\mathrm{c})$ preparation $\alpha=.86$, and (d) action/maintenance $\alpha=.91$. The reliability coefficients were acceptably large for all readiness stages except contemplation, which was marginal in this sample. No additional items were eliminated based upon the item-to-total or item-to-scale correlations.

Test-retest reliability. Correlation analyses were conducted to examine the relations between pilot-CSOCQ data at time 1 and time 2, or the measure's temporal stability, for 63 of the undergraduate women (12\% of the Study 3 sample). Results of these analyses are shown in Table 1. Test-retest reliability was sufficiently large for all readiness stages except contemplation, which was marginal. Correlation analyses were repeated for only those items retained from the factor analysis for comparison test-retest reliabilities, and are also shown in 
Table 1. Because action and maintenance loaded together on the factor analysis, these items were evaluated together for the test-retest reliability coefficient. Test-retest reliability was slightly higher for the 38 items retained as compared to all 50 items on the CSOCQ-pilot for contemplation, but were roughly equivalent for the stages of precontemplation, preparation, action, and maintenance.

Table 1

Test-Retest Reliability for the CSOCQ-pilot

$(n=63)$

\begin{tabular}{lcc}
\hline Readiness stage & $\begin{array}{c}\text { Pearson's r (all CSOCQ-pilot } \\
\text { items within each stage) }\end{array}$ & $\begin{array}{c}\text { Pearson's r (only the pilot items } \\
\text { retained for CSOCQ-revised) }\end{array}$ \\
\hline Precontemplation & $.93^{* *}$ & $.93^{* *}$ \\
Contemplation & $.59^{* *}$ & $.66^{* *}$ \\
Preparation & $.74^{* *}$ & $.74^{* *}$ \\
Action & $.83^{* *}$ & \\
Maintenance & $.87^{* *}$ & $.84 * *$ \\
Action/Maintenance & & \\
& & \\
\hline$* * p<.001$ & &
\end{tabular}




\section{Correlation Analyses}

Pearson's correlations were conducted to examine inter-relations between the readiness scores. In concordance with the SOC model, scores on precontemplation, contemplation, preparation, action, and maintenance were significantly related to one another in expected directions. These correlations are shown in Table 2.

Table 2

Correlations between readiness stage scores for Study 3

$(n=536)$

\begin{tabular}{|c|c|c|c|c|c|}
\hline Readiness stage & Precontemplation & Contemplation & Preparation & Action & Maintenance \\
\hline Precontemplation & 1 & $.24 * *$ & $-.55 * *$ & $-.57 * *$ & $-.62 * *$ \\
\hline Contemplation & $.24 * *$ & 1 & $.15 * *$ & -.01 & $-.32 * *$ \\
\hline Preparation & $-.55 * *$ & $.15 * *$ & 1 & $.64 * *$ & $.54 * *$ \\
\hline Action & $-.57 * *$ & -.01 & $.64 * *$ & 1 & $.72 * *$ \\
\hline Maintenance & $-.62 * *$ & $-.32 * *$ & $.54 * *$ & $.72 * *$ & 1 \\
\hline
\end{tabular}




\section{Qualitative Analysis}

Decisional balance worksheets were analyzed qualitatively for the purpose of identifying any relevant themes not already addressed by questions on the CSOCQ-pilot. The decisional balance worksheets were transcribed for the first 275 participants. Interpretative phenomenological analysis (IPA), developed by Jonathan Smith (Smith \& Osborn, 2003), was utilized to extract themes related to the decision of self-managing childbirth pain. Grounded theory, proposed by Glaser and Strauss (Walker \& Myrick, 2006), recommends that qualitative data transcription end once saturation is reached (i.e., no new themes are emerging; themes become highly repetitive). In the current study, saturation was reached at 275 participant transcriptions so the remaining 261 participants' data were not used in the qualitative analysis. Based on the decisional balance transcriptions, two new items emerged. A new item was created for the readiness stages of contemplation ('I'm concerned that self-management strategies alone won't be enough to reduce my labor pain.") and maintenance ("I'm convinced that it would be best for my baby's health if I use self-management strategies instead of medications during labor."). The other themes on the decisional balance worksheets were already reflected in CSOCQ-pilot items.

Post-hoc Analyses: Readiness score and instructional set

To examine the association between CSOCQ-pilot score (i.e., readiness stage ranging from 1, representing precontemplation, to 5, representing maintenance) and instructed month of pregnancy (month one, five, or nine), a one-way analysis of variance (ANOVA) was conducted. Means on the CSOCQ-pilot significantly differed by instructional set, $F(2,533)=7.74, p<$ .001, Mse $=1.02$. Participants instructed to imagine themselves in month one of pregnancy had a mean CSOCQ-pilot score of $2.76(S D=0.86)$, those instructed to be in month five of 
pregnancy had a mean CSOCQ-pilot score of $2.87(S D=1.07)$, and those instructed to be in month nine of pregnancy had a mean CSOCQ-pilot score of $3.16(S D=1.08)$. Post-hoc comparisons using the Tukey HSD test indicated that the mean score for participants receiving month one instructions was significantly different from the mean score of those receiving month nine instructions (Mean difference $=-0.41, p<.001$ ), but not from the mean score of those receiving month five instructions (Mean difference $=-0.11, p=.53$. The mean score for participants receiving month five instructions also was significantly different from those receiving month nine instructions (Mean difference $=-0.29, p=.02$ ).

To examine if mean readiness stage scores differed by instructional set, a multivariate analysis of variance (MANOVA) was conducted. Means did not differ by instructional set for precontemplation $(F(2,495)=.22, p=.81)$, contemplation $(F(2,495)=1.78, p=.17)$, or preparation $(F(2,495)=1.10, p=.33)$. Means were significantly different by instructional set for the stages of action $(F(2,495)=12.50, p<.001)$ and maintenance $(F(2,495)=8.96 p<$ .001). For action, post-hoc comparisons using the Tukey HSD test indicated that the action scores for participants receiving month one instructions $(M=34.37, S D=5.54)$ were significantly different from the action scores of participants with month five $(M=36.43, S D=$ 5.46) or month nine $(M=35.95, S D=5.28)$ instructions. Participants with month five instructions did not significantly differ from those with month nine instructions on action scores. For maintenance, post-hoc comparisons using the Tukey HSD test indicated that the maintenance scores for participants receiving month one instructions $(M=29.69, S D=6.20)$ were significantly different from the maintenance scores of participants with month five ( $M=31.90$, $S D=7.16)$ or month nine $(M=32.67, S D=6.65)$ instructions. Participants with month five 
instructions did not significantly differ from those with month nine instructions on maintenance scores.

\section{Discussion}

The four-factor solution determined by the exploratory factor analysis was largely supportive of the hypothesized stages of readiness. Items on the Precontemplation, Contemplation, and Preparation factors consisted only of items conceptualized in those readiness stages on the CSOCQ-pilot. Items conceptualized as action and maintenance on the CSOCQpilot may not represent distinct conceptual domains, however, as these items grouped together to form the Action/Maintenance factor. Items thought to be assessing maintenance on the CSOCQ may actually represent action, as these items indicate increased practice or confidence with the self-management strategies, rather than actual maintenance of them during or after labor and delivery (as childbirth is an anticipated event). This issue highlights the questionable relevance of a maintenance stage with acute pain. Because the pain of childbirth is temporary, maintenance may not be an applicable concept to self-management of this type of pain. Maintenance items on the CSOCQ thus merit further examination, particularly in relation to action items, in order to determine if these concepts are conceptually separate. A new maintenance item was created for the CSOCQ-revised to help further explore this issue. Future investigations may reveal that action and maintenance represent the same construct in regard to acute pain.

Both the internal and test-retest reliability of the CSCOQ-pilot were acceptable. In terms of consistency, the reliability coefficients for all but the contemplation stage were sufficiently large. As contemplation had the poorest internal consistency reliability, a new contemplation 
item was created from the decisional balance data for placement on the revised CSOCQ. The internal consistency of each of the readiness stages was re-assessed in Study 4.

In terms of temporal stability, the test-retest correlations were adequate for each of the readiness stages. Because two items were added to the CSOCQ-pilot to form the CSOCQrevised, test-retest reliability should be assessed again once a final CSOCQ is proposed. Of note, the temporal stability of the CSOCQ would not be expected to be especially high, considering the measure assesses readiness to perform a behavior, which, according to the SOC model, likely changes throughout the course of pregnancy. It would be reasonable to assume that pregnant women taking the CSOCQ at varying times during pregnancy would be in different stages of readiness to self-manage pain (higher readiness expressed later in the course of pregnancy, for example), as post-hoc analyses conducted in Study 3 did reveal higher mean readiness scores for participants instructed to imagine themselves farther along in their pregnancy (month nine) as compared to earlier in pregnancy (months one or five).

Of note, the relatively low percentage of participants returning for the re-test $(12 \%$ of the sample) was likely influenced by the fact that 126 participants ( $24 \%$ of the sample) participated at time 1 during the final week of the Spring 2006 semester; as such, those participants still had the option of receiving extra credit upon the re-test, but would have had to apply this extra credit to a later semester, rather than the current semester. Due to this timing issue, only 1 of the first 126 participants elected to participate in the re-test. Re-test participation was higher in the summer and fall semesters, as participation at time 1 did not coincide with the end of the semester.

Appendix S summarizes the 40 items selected from the Study 3 analyses for placement on the CSOCQ-revised. The CSOCQ-revised included 38 items retained from the CSOCQ-pilot, 
as determined by the factor analysis, as well as 2 new items, developed from the qualitative decisional balance data. These items were re-randomized for placement on CSOCQ-revised (Appendix T). The CSOCQ-revised included 8 precontemplation items, 7 contemplation items, 10 preparation items, 8 action items, and 7 maintenance items for a total of 40 items.

\section{STUDY 4}

\section{Participants}

\section{Method}

There were 21 pregnant women who participated in Study 4. Participants had a mean age of 26.7 years (range $16-33, S D=4.3)$. The majority of participants, 18 of the $21(85.7 \%)$ were Caucasian; 3 participants (14.3\%) were Black/African American. Most respondents were married (14 or 66.7\%); 3 (14.3\%) were single, 2 (9.5\%) were separated, and $2(9.5 \%)$ had a livein partner. Approximately equal number of participants indicated that they identified most with a rural location (52.4\%) as with an urban location (47.6\%). Education level was distributed across the categories of GED (19.0\%), high school (23.8\%), some college (19.0\%), college degree (28.6\%), and other (9.5\%). In both cases of "other" education, an advanced degree (e.g., doctorate) was indicated. Month of pregnancy ranged from 2 months to 9 months, with 2 (10\%) of the participants in months $1-3$ (first trimester), 7 (33\%) in months $4-6$ (second trimester), and $12(57 \%)$ in months $7-9$ (third trimester).

\section{Materials}

Demographic questionnaire. The demographic questionnaire used in Study 4 (Appendix $\mathrm{U}$ ) asked the participant to complete basic information such as age, racial or ethnic background, martial status, type of location (i.e., rural or urban) with which the participant most closely identified (e.g., hometown), years of education, and income level. The demographic 
questionnaire also included questions about past and current pregnancy, childbirth, and childbirth education.

Definition of self-management. Participants were instructed to read a definition of selfmanagement of childbirth pain (Appendix P) prior to completing the CSOCQ-revised. As in Study 3, the purpose of providing a definition of self-management was to enhance participant understanding of the CSOCQ items, and thereby improve the comprehensibility of the CSOCQrevised.

$C S O C Q$ - revised. The revised CSOCQ is a 40-item questionnaire designed to assess an expectant mother's readiness to use self-management strategies to cope with labor pain (Appendix T). The order of items on the CSOCQ-revised was randomized; all participants received the same version of items (alternate forms were not used). Participants were asked to circle the number $(1-5)$ that indicated how much they agreed with each item in relation to their own current pregnancy. The CSOCQ-revised score is derived by averaging the score within each readiness stage and taking the stage with the highest average as the overall score. If scores were equally high on one or more readiness stage (e.g., precontemplation, contemplation, and action), the highest stage is taken as the score (e.g., action).

Fear of Pain Questionnaire-III. The FPQ-III (McNeil \& Rainwater, 1998) is a 30-item empirically derived self-report instrument designed to measure anxiety or fear specific to pain. Participants indicated, on a 5-point Likert-type scale, the extent to which they fear the pain associated with various painful events. The FPQ-III score is derived by summing all responses, with total scores ranging from 30 to 150 . In addition to a total score, subscores for the dimensions of severe pain, minor pain, and medical-dental pain were calculated. The FPQ-III has acceptable construct validity, internal consistency, test-retest reliability, and predictive 
validity (Hursey \& Jacks, 1992; McNeil \& Rainwater, 1998; Sperry-Clark, McNeil, \& CianoFederoff, 1999).

Anxiety Sensitivity Index. The ASI (Reiss et al., 1986) is a 16-item self-report measure that assesses fear of anxiety-related bodily sensations. Participants indicated, on a 5-point Likert-type scale $(0=$ very little to $4=$ very much $)$, the extent to which they worry about potential harmful consequences of physiological indicators of anxiety. The ASI score is computed by summing all responses, with total scores ranging from 0 to 64 . The ASI has excellent internal consistency and test-retest reliability (McNally, 1996; Peterson \& Reiss, 1992). Illness Attitudes Scale. The IAS (Kellner, 1986) is a measure of attitudes, beliefs, and fears associated with hypochondriasis. Participants indicated, on a 5-point Likert-type scale, the relative frequency that they endorse hypochondriacal statements or behaviors. The IAS provides scores for nine subscales, as well as a total score ranging from 0 to 116 (Stewart \& Watt, 2001). The IAS also includes two questions that address illness and treatment, when applicable, which are not included in the scoring. The IAS has adequate test-retest reliability and good convergent validity with other measures of health anxiety (Speckens, Spinhoven, Sloekers, Bolk, \& van Hemert, 1996).

Beck Depression Inventory-II. The BDI-II (Beck et al., 1979) is a 21-item self-report measure designed to assess depressive symptoms. Participants indicated, on a 4-point Likerttype scale $(0=$ minimal to $3=$ severe $)$, the extent to which they experience common affective, cognitive, and vegetative clinically-relevant symptoms of depression. The BDI-II has established reliability and validity (Beck, Steer, \& Garbin, 1988), as well as good test-retest reliability (Beck, Steer, \& Brown, 1996). 


\section{Procedure}

Expectant mothers in attendance at the Monongalia County Community Baby Shower in Morgantown, West Virginia were invited to participate in Study 4. Participants read a cover letter explaining the study and any potential risks and benefits associated with participation. The cover letter also included a list of mental health referrals, in the event that participation prompted any individual to seek mental health services. Participants were informed that the study consisted of reading a definition of self-management of childbirth pain and completing six questionnaires.

Upon verbally consenting to participate, each participant received a packet with the following questionnaires: a demographics questionnaire, CSOCQ-revised, FPQ-III, ASI, IAS, and BDI-II. In order to control for potential effects of questionnaire order on responding, the order of the questionnaires in each packet was random. Participants were informed that they could discontinue participation at any time without penalty and that they need not answer question(s) that they found objectionable. Participants were instructed to read the definition of self-management of childbirth pain before completing the six questionnaires. At the conclusion of the study, participants were debriefed and thanked with $\$ 10.00$ in cash.

Results

\section{Initial Analyses}

Univariate analyses were conducted to evaluate pregnancy information, current and prior, for the sample. For current pregnancy, participants had a mean of 6.26 months gestation (range $2-9, S D=1.89)$. Specifically, 2 of the women were in the first trimester of pregnancy, 7 were in the second trimester, and 12 were in the third trimester. The majority of the sample was multiparous, as $71.4 \%$ of participants had been pregnant before and $66.7 \%$ of participants had 
given birth before. A greater proportion of the past deliveries reported were vaginal births (60\%), compared to cesarean section (40\%). Of the women who had given birth in the past, $50.0 \%$ had used oral medication, $35.7 \%$ had used IV medication, and $64.3 \%$ had had an epidural for pain relief during labor and delivery. A smaller proportion, 35.7\%, reported using selfmanagement methods during past deliveries. The self-management methods that the women reported using included breathing techniques, focal points, social support, distraction, walking, bath or shower, positioning, and using a birthing ball.

Univariate analysis also was utilized to examine the distribution of readiness stages for the sample. On the CSOCQ-revised, readiness scores ranged from precontemplation to maintenance. Specifically, 6 of the women were in precontemplation, 1 was in contemplation, 8 were in preparation, 2 were in action, and 4 were in maintenance. To examine the association between CSOCQ readiness score and month of pregnancy, a Pearson's correlation was conducted. No association between CSOCQ score and month of pregnancy was found ( $r=-.30$, $p=.18$ ). There also was not a relation between mean CSOCQ score and trimester as tested by a one-way analysis of variance (ANOVA), $F(2,18)=0.90, p=0.43$, Mse $=2.15$. For exploratory purposes, the ANOVA for CSOCQ score and trimester was re-calculated without the 2 participants in Trimester 1; again, no association between mean CSOCQ and trimester was found, $F(1,17)=1.67, p=0.21, M s e=2.28$.

Item Analyses

Item means and variances. Item means and variances were inspected to identify items with extreme means or low variance. Descriptive statistics for the 40 CSCOQ-revised items are presented in Table 3. Item means close to the center of the range of possible scores are most 
desirable, as items too near either extreme of the response range (1 to 5) will have low variances (DeVellis, 2003). Item means and variances for the CSOCQ-revised were acceptable. Internal reliability. The internal consistency of each readiness stage was evaluated individually by means of Cronbach's alpha ( $\alpha)$. Reliabilities were computed for each of the five readiness stages represented on the CSOCQ-revised. The reliability coefficients were as follows: (a) precontemplation $\alpha=.95$, (b) contemplation $\alpha=.85$, (c) preparation $\dot{\alpha}=.89$, (d) action $\alpha=$ .89 , and (e) maintenance $\alpha=.83$. The reliability coefficients were acceptably large for all readiness stages. No additional items were eliminated based upon the item-to-total or item-toscale correlations. 
Table 3

Descriptive Statistics for the CSOCQ-Revised Items

$(n=21)$

\begin{tabular}{|c|c|c|c|c|c|}
\hline Item \# & Range & $\begin{array}{l}\text { Minimum } \\
\text { Value }\end{array}$ & $\begin{array}{l}\text { Maximum } \\
\text { Value }\end{array}$ & Mean & $\begin{array}{c}\text { Standard } \\
\text { Deviation }\end{array}$ \\
\hline 1 & 3 & 2 & 5 & 3.67 & 0.86 \\
\hline 2 & 3 & 2 & 5 & 3.19 & 0.98 \\
\hline 3 & 4 & 1 & 4 & 2.76 & 1.22 \\
\hline 4 & 4 & 1 & 5 & 2.52 & 1.63 \\
\hline 5 & 4 & 1 & 5 & 3.24 & 1.04 \\
\hline 6 & 3 & 1 & 4 & 2.10 & 0.96 \\
\hline 7 & 3 & 2 & 5 & 3.81 & 0.81 \\
\hline 8 & 3 & 2 & 5 & 3.38 & 1.02 \\
\hline 9 & 3 & 2 & 5 & 3.67 & 0.73 \\
\hline 10 & 4 & 1 & 5 & 3.28 & 1.38 \\
\hline 11 & 3 & 1 & 4 & 2.86 & 0.91 \\
\hline 12 & 4 & 1 & 5 & 3.10 & 1.41 \\
\hline 13 & 4 & 1 & 5 & 3.24 & 1.04 \\
\hline 14 & 3 & 2 & 5 & 3.48 & 0.87 \\
\hline 15 & 3 & 2 & 5 & 3.05 & 0.86 \\
\hline 16 & 3 & 2 & 5 & 3.33 & 0.86 \\
\hline 17 & 4 & 1 & 5 & 2.90 & 1.34 \\
\hline 18 & 4 & 1 & 5 & 3.00 & 1.22 \\
\hline 19 & 3 & 2 & 5 & 3.43 & 0.75 \\
\hline
\end{tabular}




\begin{tabular}{|c|c|c|c|c|c|}
\hline Item \# & Range & $\begin{array}{l}\text { Minimum } \\
\text { Value }\end{array}$ & $\begin{array}{l}\text { Maximum } \\
\text { Value }\end{array}$ & Mean & $\begin{array}{c}\text { Standard } \\
\text { Deviation }\end{array}$ \\
\hline 20 & 4 & 1 & 5 & 3.19 & 0.87 \\
\hline 21 & 3 & 2 & 5 & 3.43 & 0.75 \\
\hline 22 & 3 & 2 & 5 & 3.10 & 0.89 \\
\hline 23 & 3 & 2 & 5 & 3.15 & 0.91 \\
\hline 24 & 4 & 1 & 5 & 2.67 & 1.39 \\
\hline 25 & 3 & 1 & 4 & 2.90 & 0.77 \\
\hline 26 & 3 & 2 & 5 & 3.14 & 0.85 \\
\hline 27 & 3 & 2 & 5 & 3.62 & 0.80 \\
\hline 28 & 4 & 1 & 5 & 2.86 & 1.39 \\
\hline 29 & 3 & 2 & 5 & 3.43 & 0.81 \\
\hline 30 & 3 & 2 & 5 & 3.76 & 0.70 \\
\hline 31 & 4 & 1 & 5 & 3.05 & 1.20 \\
\hline 32 & 3 & 1 & 4 & 3.05 & 0.97 \\
\hline 33 & 3 & 2 & 5 & 3.00 & 0.84 \\
\hline 34 & 4 & 1 & 5 & 2.81 & 1.44 \\
\hline 35 & 3 & 2 & 5 & 3.57 & 0.75 \\
\hline 36 & 3 & 2 & 5 & 3.14 & 0.91 \\
\hline 37 & 3 & 2 & 5 & 3.43 & 0.87 \\
\hline 38 & 3 & 2 & 5 & 3.38 & 0.92 \\
\hline 39 & 3 & 1 & 4 & 2.71 & 0.96 \\
\hline 40 & 4 & 1 & 5 & 3.14 & 1.15 \\
\hline
\end{tabular}




\section{Correlation Analyses}

Hypothesis 2a: Fear of pain will be related to readiness. In the current study, we hypothesized a relation between higher fear of pain, as assessed by the FPQ-III (McNeil \& Rainwater, 1998), and stages of readiness (i.e., precontemplation, contemplation) to self-manage childbirth pain, as assessed by the CSOCQ-revised. Participants had a mean FPQ-III total score of $74.6(S D=20.4)$. Results did not support Hypothesis 2a, as there was not a significant relation between CSOCQ score (i.e., readiness stage) and total FPQ score $(r=-.14, p=.56)$.

Hypothesis 2b: Anxiety sensitivity will be inversely related to readiness. To test the hypothesis that individuals with high anxiety sensitivity would be more likely to score in lower readiness stages (i.e., precontemplation, contemplation) than individuals with low anxiety sensitivity, the ASI (Reiss et al., 1986) was administered. Participants had a mean ASI total score of $31.0(S D=8.4)$. Because there was not a relation between CSOCQ score and ASI $(r=$ $.26, p=.28)$, Hypothesis $2 \mathrm{~b}$ was not supported.

Hypothesis 2c: Health anxiety will be inversely related to readiness. Based on prior literature, we hypothesized that higher health anxiety would relate to lower readiness to selfmanage childbirth pain (i.e., precontemplation, contemplation stages). Participants had a mean IAS total score of $60.4(S D=12.6)$. Results did not support Hypothesis $2 \mathrm{c}(r=.11, p=.64)$.

Hypothesis 2d: Depressive symptoms will be inversely related to readiness. It was expected that depressive symptoms would relate to lower levels of readiness to self-manage childbirth pain (i.e., precontemplation, contemplation stages). Participants had a mean BDI-II total score of $8.6(S D=6.3)$. Results did not support Hypothesis $2 \mathrm{~d}$, as readiness stage did not relate to depressive symptoms $(r=.03, p=.89)$. 
Correlations between readiness stages: Pearson's correlations were conducted to examine inter-relations between the readiness scores. In concordance with the SOC model, scores on precontemplation, contemplation, preparation, action, and maintenance were significantly related to one another in expected directions. These correlations are shown in Table 4. For exploratory purposes, the inter-correlations were re-examined without the 2 participants in Trimester 1 . These correlations, shown in Table 5, were slightly higher numerically than those represented in Table 4, but no new correlations emerged and none changed direction.

Table 4

Correlations between readiness stage scores for Study 4 $(n=21)$

\begin{tabular}{lccccc}
\hline Readiness stage & Precontemplation & Contemplation & Preparation & Action & Maintenance \\
\hline Precontemplation & 1 & $.71^{* *}$ & $-.57 * *$ & $-.72^{* *}$ & $-.66^{* *}$ \\
Contemplation & $.71^{* *}$ & 1 & -.21 & $-.45^{* *}$ & $-.59^{* *}$ \\
Preparation & $-.57^{* *}$ & -.21 & 1 & $.81^{* *}$ & $.60^{* *}$ \\
Action & $-.72^{* *}$ & $-.45^{*}$ & $.81^{* *}$ & 1 & $.87^{* *}$ \\
Maintenance & $-.66^{* *}$ & $-.59 * *$ & $.60 * *$ & $.87 * *$ & 1 \\
& & & & & \\
$* \mathrm{p}<.05$ & & & &
\end{tabular}


Table 5

Correlations between readiness stage scores for Study 4 without Trimester 1 participants $(n=19)$

\begin{tabular}{lccccc}
\hline Readiness stage & Precontemplation & Contemplation & Preparation & Action & Maintenance \\
\hline Precontemplation & 1 & $.72^{* *}$ & $-.60^{* *}$ & $-.76^{* *}$ & $-.67^{* *}$ \\
Contemplation & $.72^{* *}$ & 1 & -.25 & $-.51^{*}$ & $-.63^{* *}$ \\
Preparation & $-.60^{* *}$ & -.25 & 1 & $.81^{* *}$ & $.59^{* *}$ \\
Action & $-.76^{* *}$ & $-.51^{*}$ & $.81^{* *}$ & 1 & $.86^{* *}$ \\
Maintenance & $-.67^{* *}$ & $-.63^{* *}$ & $.59 * *$ & $.86^{* *}$ & 1 \\
& & & & & \\
\hline$* \mathrm{p}<.05$ & & & &
\end{tabular}

Correlations between readiness stage scores and additional questionnaires: For exploratory purposes, the readiness stage scores were correlated to the total scores of the FPQIII, BDI-II, IAS, and ASI. None of the individual readiness scores (precontemplation, contemplation, preparation, action, or maintenance) were significantly correlated to scores on the FPQ-III, BDI-II, IAS, or ASI.

Post-hoc Analyses: Readiness score and trimester

To examine if mean readiness stage scores differed by trimester, a multivariate analysis of variance (MANOVA) was conducted. Means did not differ by trimester for contemplation $(F$ $(2,18)=0.55, p=0.59)$, preparation $(F(2,18)=0.50, p=0.95)$, action $(F(2,18)=0.13, p=$ $0.88)$, or maintenance $(F(2,18)=0.22, p=0.80)$. There was not significant power to test the 
relation between precontemplation and trimester. For exploratory purposes, the MANOVA was conducted again for only those participants in trimesters 2 and 3 of pregnancy, and means still did not significantly differ between trimesters 2 and 3 for any of the five readiness scores.

\section{Comparisons of proportion of sample in each readiness stage for Study 3 and Study 4}

The proportion of individuals in each of the five readiness stages was compared for Study 3 and Study 4. In Study 3, 44 participants (8.2\%) were in precontemplation, 122 (22.8\%) were in contemplation, $243(45.3 \%)$ were in preparation, $82(15.3 \%)$ were in action, and $45(8.4 \%)$

were in maintenance. In Study 4, 6 participants (28.6\%) were in precontemplation, 1 (4.8\%) was in contemplation, $8(38.1 \%)$ were in preparation, $2(9.5 \%)$ were in action, and $4(19.0 \%)$ were in maintenance. These proportions were compared using the $z$ test for significance of a difference between two proportions (Bruning \& Kintz, 1997). The difference in the proportions of the samples in the five readiness stages was significantly different at the .05 level $(z \geq \pm 1.96)$ for the readiness stages of precontemplation $(z=-3.21)$, contemplation $(z=-2.09)$, and maintenance $(z=$ -2.35). The proportion of the sample in Study 3 and Study 4 did not differ, however, for the readiness stages of preparation $(z=-1.88)$ or action $(z=1.79)$.

\section{Discussion}

Item means and variances for the CSOCQ-revised met guidelines established by DeVellis (2003). In addition, the internal consistency of each readiness stage was acceptable. Taken together, these results indicate preliminary support for Hypothesis 1. Item analyses alone, however, did not provide enough evidence to select items from the CSOCQ-revised for a proposed final CSOCQ. Selection of items for a final CSOCQ is deferred until the CSOCQrevised can be tested on a larger sample of pregnant women. Considering the small sample size in Study 4, a factor analysis was not appropriate. Confirmatory factor analysis on the CSOCQ- 
pilot is intended upon collection of an appropriate sample of pregnant women. A sample of 200 women will be collected, as a subject-to-item ratio of 5 is the minimum standard suggested for factor analysis by Bryant and Yarnold (1995). A sample of 200 also would satisfy the factor analysis "Rule of 200" sample size recommendation of Gorsuch (1983). Once an appropriate sample size is obtained, it will be conceptually interesting to compare the factor solution of the CSOCQ-revised to that found with the CSOCQ-pilot. If a four-factor solution again results, with action and maintenance loading on one factor, it would further confirm the notion that the maintenance items on the CSOCQ currently represent action to a more practiced degree or comfortable level. The traditional notion of maintenance as continued behavior beyond the event may thus not be relevant to an acute pain situation, such as childbirth, as the event is finite.

In sum, despite initial support for Hypothesis 1, findings did not support Hypotheses $2 \mathrm{a}-$ 2d. None of the additional measures used to evaluate construct validity (i.e., FPQ-III, ASI, IAS, or BDI-II) correlated with readiness stage as measured by the CSOCQ-revised. These associations merit re-examination upon collection of a larger sample, however, as the current sample size did not provide adequate power to test these hypotheses. The only significant correlations were among the readiness stages themselves (e.g., precontemplation was positively correlated with contemplation, but negatively correlated with preparation, action, and maintenance), associations examined during post-hoc data exploration. The fact that the readiness stages correlated with each other, in the expected directions, supports the initial validity of the SOC conceptualization of readiness to self-manage labor pain.

The lack of association between readiness stages, as assessed by the CSOCQ-revised, and the additional measures may reflect measurement error, as opposed to a lack of construct validity. A significant limitation of using the BDI-II and IAS in the current study was that 
responding may have been influenced by pregnancy and, as such, the scores on the IAS and BDIII may be inflated. For example, several of the IAS questions relate to number of doctor visits during the past month and over a year, a variable highly related to pregnancy (e.g., prenatal visits would inflate responses). Future research should establish norms for these measures on samples of pregnant women.

Finally, inadequate power may have contributed to the null association found between CSOCQ score and point in pregnancy, as tested both by month of pregnancy and by trimester. Testing this relation in a larger sample may reveal that point in pregnancy moderates responding on the CSOCQ. If future analyses demonstrate a relation between time in pregnancy and CSOCQ score, time in pregnancy should be considered as a covariate in re-analyses of Hypotheses $2 \mathrm{a}-2 \mathrm{~d}$.

\section{General Discussion}

The purpose of the current study was to develop a psychometrically-sound instrument to measure a pregnant woman's readiness to self-manage childbirth pain. Findings indicate that the CSOCQ is a promising measure meriting future validation. Through individual interviews with an expert panel, items were developed for a preliminary CSOCQ. Next, these items were reviewed and evaluated for content validity by a panel of pregnant women. A sub-set of 50 items, with established readability at an $8^{\text {th }}$ grade level, was administered to a sample of 536 undergraduate females with imagined pregnancies. Results from this CSOCQ-pilot supported a four-factor measure, with distinct Precontemplation, Contemplation, Preparation, and Action/Maintenance factors. Item reliabilities, including internal consistency, as measured by Cronbach's alpha, and test-retest reliability, were adequate for the CSOCQ-pilot. Items were revised based on the factor analysis. In addition, qualitative analysis of decisional balance data 
suggested the inclusion of two new items, one each for the contemplation and maintenance readiness stages, on the revised CSOCQ. A CSOCQ-revised, consisting of 40 items, was then presented to a sample of pregnant women for further evaluation. Initial item analyses (means, ranges) and internal consistency provide support for Hypothesis 1, the hypothesis that a reliable instrument of readiness to self-manage childbirth pain could be developed. Although the CSOCQ-revised requires further testing on a larger sample of pregnant women to establish its psychometric properties, results of Study 4 are encouraging.

The CSOCQ is designed for use with expectant mothers and therefore does not include a staging mechanism for women who are not currently pregnant, paralleling current chronic pain SOC measures (e.g., Kerns et al., 1997; Maurischat et al., 2006; Nielson et al., 2003) that, due to intended use only with chronic pain patients, do not include a stage for individuals without chronic pain. The lack of a stage for non-pregnant women follows the assumption that women who are not currently pregnant do not have reason to self-manage childbirth pain and, therefore, assessing their readiness to self-manage childbirth pain is not relevant.

The applicability of the CSOCQ may be lessened for those pregnant women for whom a cesarean delivery is planned. Because these women have scheduled cesarean births and, as such, may not go into active labor, assessing their readiness to self-manage labor pain may be of decreased relevance. To evaluate this issue, the CSOCQ should be utilized with pregnant women with both vaginal and cesarean deliveries in future studies and its clinical utility further analyzed.

The CSOCQ is intended to assess planned self-management of labor pain at any point in a woman's pregnancy. The validity of the CSOCQ as a predictive measure of a woman's pain management choices during labor and delivery, however, may increase as the time of delivery 
more closely approximates the time of assessment. It is possible that women in the later months of pregnancy may indicate a readiness to self-manage labor pain that is more stable than the readiness indicated by women earlier in pregnancy, as plans about labor pain management may become more firmly established as the pregnancy progresses. The predictive validity and temporal stability of the CSOCQ also may vary as a function of number of prior childbirths. In particular, it was proposed by participants in Study 1 that multiparae "know what to expect" during childbirth and are likely to utilize the same pain management strategies that they have used in the past. As such, the predictive validity of the CSOCQ may be higher for multiparae who intend to employ similar pain management strategies, either pharmacological or selfmanagement, to those used in their prior deliveries. If multiparous women plan to incorporate strategies used in prior deliveries for pain management in their current pregnancy (i.e., upcoming labor and delivery), one extension may be increased temporal stability of the CSOCQ for multiparae, as their readiness to self-manage childbirth pain may be more established as a result of their prior childbirth experience(s).

\section{Limitations}

\section{Internal Validity}

One significant limitation of the current study was the sample of Study 3. Specifically, this sample consisted of undergraduate women with imagined pregnancies, as opposed to actual pregnant women. Although demographic variables collected in Study 3 suggest that undergraduate women were a reasonable sample due to their vicarious experiences with pregnancy (e.g., the high percentage of undergraduate women who intended to give birth at some point in their lifetime, high percentage who had considered themselves possibly pregnant before), given the feasibility limitations, the reliability and validity of the CSOCQ-pilot would 
have been better evaluated with a sample of pregnant women. Also, the utility of the pregnancy instructions in helping the undergraduate women to imagine themselves as pregnant was not evaluated. As such, the extent to which these instructions were useful in setting the appropriate stage for responding to the CSOCQ-pilot is uncertain; it is possible that undergraduate females differed in their ability to imagine themselves as pregnant. In regard to Study 4, inadequate power, a result of the small sample size, was a significant weakness. Furthermore, the sample in Study 4 was biased toward the end of pregnancy, as the majority of participants, 12 women, were in the third trimester of their pregnancy; only 2 of the women were in the first trimester. These limitations highlight the need to test the CSOCQ-revised further with additional pregnant women across varying months of pregnancy.

\section{External Validity}

The samples for each of the four studies presented were highly restricted in regard to racial and ethnic background. Specifically, participants were predominantly Caucasian, limiting the generalizability of the findings. Several factors may contribute to women's choices concerning management of labor pain, including personal beliefs about pregnancy, learning history (e.g., witnessing others experience childbirth), and judgments about the relative risks of pain management options. Cultural background, a factor not accounted for in the current study, is known to influence attitudes toward labor pain and its management, and thus may also factor into a woman's readiness to self-manage childbirth pain. As discussed by Callister, Khalaf, Semenic, Kartchner, and Vehvilainen-Julkunen (2003), cultural influences shape a woman's beliefs about childbirth pain, as well as her viewpoint on its management (e.g., the acceptability of various coping strategies differs across cultures). Relying on spiritual beliefs during labor and viewing the pain as a challenge to be mastered were coping mechanisms identified by these 
researchers as common to several cultures. Callister and colleagues emphasized that sociocultural attitudes toward childbirth may impact a woman's decision of whether or not to use medications as a strategy to manage the pain, given that accepting and enduring childbirth pain is viewed as an important means of growing spiritually in some societies. As an example, the authors note, "A proverb often used by Chinese women is, 'If you wish to be the best person, you must suffer the bitterest of the bitter.' "(Callister et al., 2003, p. 150). Because cultural and religious background impacts attitudes about childbirth and childbirth pain, future research on the CSOCQ should evaluate its efficacy at staging pregnant women of diverse backgrounds. Establishing CSOCQ norms by cultural background may be an appropriate research area once a final scale is established.

\section{Conclusions \& Future Directions}

The current study contributed to the existing literature on self-management of childbirth pain and the SOC model by proposing a measure to assess readiness to self-manage childbirth pain, the CSOCQ. Prior research had focused upon measuring readiness to self-manage chronic pain. Readiness to self-manage labor pain, an important subset of acute pain, was evaluated by means of the CSOCQ-revised and initial support was found for the reliability of the instrument. The CSOCQ appears to be a promising instrument with the potential to enhance current understanding of readiness to manage acute pain. As such, the CSOCQ-revised merits additional study in a larger sample of pregnant women. Although results provide preliminary support for the reliability and validity of the measure, a factor analysis of the CSOCQ-revised is indicated once a sufficient sample size of pregnant women is obtained. Further research is needed to clarify the construct validity and psychometric properties of a final CSOCQ, based upon additional analyses of the CSOCQ-revised. Future studies to investigate the use of the CSOCQ 
as a predictor of the pain management choices made during labor and delivery are needed to evaluate the measure's predictive validity, and help clarify the utility of the SOC model in understanding readiness to self-manage acute pain. A comparison between the CSOCQ and a standard staging algorithm, with fewer questions, also is merited. A final avenue of recommended research should investigate whether CSOCQ scores differentiate between subgroups of pregnant women (e.g., primiparae vs. multiparae, assessment at first trimester vs. third trimester) and the variables (e.g., self-efficacy, maternal confidence during labor) that influence this differentiation. 


\section{References}

Anim-Somuah, M., Smyth, R., \& Howell, C. (2005). Epidural versus non-epidural or no analgesia in labour. The Cochrane Database of Systematic Reviews, 4, AN: CD000331. The Cochrane Collaboration. Chichester, England: John Wiley \& Sons, Ltd.

Areskog, B., Uddenberg, N., \& Kjessler, B. (1983). Experience of delivery in women with and without antenatal fear of childbirth. Gynecologic and obstetric investigation, 16, 1-12.

Asmundson, G. J. G. (1999). Anxiety sensitivity and chronic pain: Empirical findings, clinical implications, and future directions. In S. Taylor (Ed.), Anxiety sensitivity: Theory, research, and treatment of the fear of anxiety (pp. 269-285). Mahwah, NJ: Erlbaum.

Asmundson, G. J. G., Vlaeyen, J. W. S., \& Crombez, G. (Eds.). (2004). Understanding and treating fear of pain. New York: Oxford University Press.

Bane, C. M., Ruggiero, L., Dryfoos, J. M., \& Rossi, J. S. (1999). Development of a pregnancytailored decisional balance measure for smoking cessation. Addictive Behaviors, 24, 795799.

Barlow, Y. (1994). Childbirth: Management of labour through the ages. Nursing Times, 90(35), 41-43.

Beck, A. T., Rush, A. J., Shaw, B. F., \& Emery, G. (1979). Cognitive therapy of depression. New York: Guilford Press.

Beck, A. T., Steer, R. A., \& Brown, G. K. (1996). Manual for the Beck Depression InventoryII. San Antonio, TX: The Psychological Corporation.

Beck, A. T., Steer, R. A., \& Garbin, M. (1988). Psychometric properties of the Beck Depression Inventory: Twenty-five years of evaluation. Clinical Psychology Review, 8, 77-100.

Benfield, R., Herman, J., Katz, V., Wilson, S., \& Davis, J. (2001). Hydrotherapy in labor. 
Research in Nursing \& Health, 24, 57-67.

Bennett, A., Lumley, J., \& Bartlett, D. (1987). The use of epidural Bupivacaine for the relief of childbirth pain. Australian Paediatric Journal, 23, 13-19.

Biller, N., Arnstein, P., Caudill, M., Federman, C. W., \& Guberman, C. (2000). Predicting completion of a cognitive-behavioral pain management program by initial measure of a chronic pain patient's readiness for change. The Clinical Journal of Pain, 16, 352-359.

Browning, C. A. (2001). Music therapy in childbirth: research in practice. Music Therapy Perspectives, 19, 74-81.

Browning, C. A. (2000). Using music during childbirth. Birth, 27, 272-276.

Brucher, M. C. (1984). Nonpharmaceutical methods for relieving pain and discomfort during pregnancy. Maternal Child Nursing, 9, 390-394.

Bruning, J. L., \& Kintz, B. L. (1997). Computational handbook of statistics, $4^{\text {th }}$ ed. New York: Addison-Wesley Educational Publishers, Inc.

Bryant, F. B., \& Yarnold, P. R. (1995). Principal-components analysis and exploratory and confirmatory factor analysis. In L. G. Grimm \& P. R. Yarnold (Eds.), Reading and understanding multivariate analysis (pp. 99-136). American Psychological Association Books.

Bundsen, P., Peterson, L. E., Selstam U. (1982). Pain relief during delivery: An evaluation of conventional methods. Acta obstetricia et gynecologica Scandinavica, 61, 289-297.

Byrne-Lynch, A. (1991). Coping strategies, personal control and childbirth. Irish Journal of Psychology, 12, 145-152.

Callister, L.C., Khalaf, I., Semenic, S., Kartchner, R., \& Vehvilainen-Julkunen, K. (2003). The pain of childbirth: Perceptions of culturally diverse women. Pain Management Nursing, 
4, 145-154.

Caton, D. (2004). Medical science and social values. International Journal of Obstetric Anesthesia, 13, 167-173.

Charles, A., Norr, K., Block, C., Meyering, S., \& Meyers, E. (1978). Obstetric and psychological effects of psychoprophylactic preparation for childbirth. American Journal of Obstetrics and Gynecology, 131, 44-52.

Cyna, A. M., Andrew, M. I., \& McAuliffe, G. L. (2006). Antenatal self-hypnosis for labor and childbirth: a pilot study. Anaesthesia and Intensive Care, 34, 464-469.

DeFrances, C.J., \& Hall, M.J. (2002). National Hospital Discharge Survey. Advance Data from Vital and Health Statistics, No. 342. Hyattsville, MD: National Center for Health Statistics.

DeVellis, R. F. (2003). Scale development: Theory and applications, $2^{\text {nd }}$ ed. Thousand Oaks, CA: Sage Publications, Inc.

Devine, E. C., \& Cook, T. D. (1986). A meta-analytic analysis of effects of psychoeducational interventions on length of postsurgical hospital stay. Nursing Research, 32, 267-274.

Di Noia, J., Schinke, S. P., Prochaska, J. O., \& Contento, I. R. (2006). Application of the Transtheoretical model to fruit and vegetable consumption among economically disadvantaged African-American adolescents: preliminary findings. American Journal of Health Promotion, 20, 342-348.

Duchene, P. (1989). Effects of biofeedback on childbirth pain. Journal of Pain and Symptom Management, 4, 117-123.

Eappen, S., \& Robbins, D. (2002). Nonpharmacological means of pain relief for labor and delivery. International Anesthesiology Clinics, 40, 103-114. 
Etter, J., \& Perneger, T. V. (1999). A comparison of two measures of stage of change for smoking cessation. Addiction, 1999, 1881-1889.

Gambling, T., \& Long, A. F. (2006). Exploring patient perceptions of movement through the Stages of Change model with a diabetes tele-care intervention. Journal of Health Psychology, 11, 117-128.

Garbin, C. P. (2006). Factor rotation / interpretation. Retrieved October 20, 2006 from http://www-class.unl.edu/psycrs/statpage/factoring.html

Goodman, P., Mackey, M. C., \& Tavakoli, A. S. (2004). Factors related to childbirth satisfaction. Journal of Advanced Nursing, 46, 212-219.

Gorsuch, R. L. (1983). Factor analysis. Hillsdale, NJ: Lawrence Erlbaum. Orig. ed. 1974.

Hadjistavropoulos, H. D., Asmundson, G. J. G., LaChapelle, D. L., \& Quine, A. (2002). The role of health anxiety among patients with chronic pain in determining response to therapy. Pain Research \& Management: The Journal of the Canadian Pain Society, 7(3), 127-133.

Hankin, H.A., \& Killian, C.B. (2004). Prediction of functional outcomes in patients with chronic pain. Work, 22, 125-130.

Heinze, S. D., \& Sleigh, M. J. (2003). Epidural or no epidural anaesthesia: Relationships between beliefs about childbirth and pain control choices. Journal of Reproductive and Infant Psychology, 21, 323-333.

Heitman, D.E., Birdwell, S.W., \& Bennett, D.L. (1995). Patient satisfaction as an outcome predictor of pain management during labor and delivery. Hospital Pharmacy, 30, 589595.

Hitchcock, P. B., \& Mathews, A. (1992). Interpretation of bodily symptoms in hypochondriasis. 
Behaviour Research and Therapy, 30, 223-234.

Hodnett, E. D. (2002). Caregiver support for women during childbirth. The Cochrane Database of Systematic Reviews, 1, AN: CD000199. The Cochrane Collaboration. Chichester, England: John Wiley \& Sons, Ltd.

Howell, C. J. (2000). Epidural versus non-epidural analgesia for pain relief in labour. The Cochrane Database of Systematic Reviews, 2, AN: CD000331. The Cochrane Collaboration. Chichester, England: John Wiley \& Sons, Ltd.

Howell, C. J., Kidd, C., Roberts, W., Upton, P., Lucking, L., Jones, P. W., et al. (2001). A randomised controlled trial of epidural compared with nonepidural analgesia in labour. BJOG : An International Journal of Obstetrics and Gynaecology, 108, 27-33.

Hursey, K.G., \& Jacks, S.D. (1992). Fear of pain in recurrent headache sufferers. Headache, $32,283-286$.

Jensen, M. P., Nielson, W. R., \& Kerns, R. D. (2003). Toward the development of a motivational model of pain self-management. The Journal of Pain, 4, 477-492.

Jenson, M. P, Nielson, W. R., Turner, J. A., Romano, J. A., \& Hill, M. L. (2004). Changes in readiness to self-manage pain are associated with improvement in multidisciplinary pain treatment and pain coping. Pain, 111, 84-95.

Kannan, S., Jamison, R. N., Datta, S. (2001). Maternal satisfaction and pain control in women electing natural childbirth. Regional Anesthesia and Pain Medicine, 26, 468-472.

Keefe, F. J., Lefebvre, J. C., Kerns, R. D., Rosenberg, R., Beaupre, P., Prochaska, J., et al. (2000). Understanding the adoption of arthritis self-management: Stages of change profiles among arthritis patients. Pain, 87, 303-313.

Kellner, R. (1986). Somatization and hypochondriasis. New York: Praeger-Greenword. 
Kerns, R. D., \& Habib, S. (2004). A critical review of the pain readiness to change model. The Journal of Pain, 5, 357-367.

Kerns, R. D., \& Rosenberg, R. (2000). Predicting responses for self-management treatments for chronic pain: Application of the pain stages of change model. Pain, 84, 49-55.

Kerns, R. D., Rosenberg, R., Jamison, R. N., Caudill, M. A., \& Haythornwaite, J. (1997). Readiness to adopt a self-management approach to chronic pain: The Pain Stages of Change Questionnaire (PSOCQ). Pain, 72, 227-234.

Ketterhagen, D., VandeVusse, L., \& Berner, M.A. (2002). Self-hypnosis: alternative anesthesia for childbirth. MCN: The American Journal of Maternal/Child Nursing, 27, 335-341.

Klein, M. C. (2006). Epidural analgesia: does it or doesn't it? Birth, 33, 74-76.

Kloeben, A.S., Thompson, N.J., \& Miner, K.R. (1999). Predicting breast-feeding intention among low-income pregnant women: A comparison of two theoretical models. Health Education \& Behavior, 26, 675-688.

Koehn, M. L. (1993). The psychoeducational model of prepared childbirth education. AWHONN's clinical issues in perinatal and women's health nursing, 4(1), 66-71.

Kuczkowski, K.M. (2005). Anesthetic management of labor pain: What does an obstetrician need to know? Archives of Gynecology and Obstetrics, 271, 97-103.

Leighton, B. L., \& Halpern, S. H. (2002). The effects of epidural analgesia on labor, maternal, and neonatal outcomes: A systematic review. American Journal of Obstetrics \& Gynecology, 186, S69-S77.

Leventhal, E. A., Leventhal, H., Shacham, S., \& Easterling, D. V. (1989). Active coping reduces reports of pain from childbirth. Journal of Consulting and Clinical Psychology, 57, 365-371. 
Lieberman, E., \& O’Donoghue, C. (2002). Unintended side effects of epidural analgesia during labor: A systematic review. American Journal of Obstetrics \& Gynecology, 186, S31S68.

Lippke, S., \& Plotnikoff, R. C. (2006). Stages of change in physical exercise: a test of stage discrimination and nonlinearity. American Journal of Health Behavior, 30, 290-301.

Lowe, N. K. (1987). Individual variation in childbirth pain. Journal of Psychosomatic Obstetrics and Gynecology, 7, 183-192.

Lu, M. C., Prentice, J., Yu, S. M., Inkelas, M., Lange, L. O., \& Halfon, N. (2003). Childbirth education classes: sociodemographic disparities in attendance and the association of attendance with breastfeeding initiation. Maternal and Child Health Journal, 7, 87-93.

Maurischat, C., Härter, M., Kerns, R. D., \& Bengel, J. (2006). Further support for the pain stages of change model: suggestions for improved measurement. European Journal of Pain, 10, 41-49.

McNally, R. J. (1996). Anxiety sensitivity is distinguishable from trait anxiety. In R. M. Rapee (Ed.), Current controversies in anxiety disorders (pp. 214-227). New York: Guilford Press.

McNeil, D. W., Au, A. R., Zvolensky, M. J., McKee, D. R., Klineberg, I. J., \& Ho, C. C. K. (2001). Fear of pain in orofacial pain patients. Pain, 89, 245-252.

McNeil, D.W., \& Rainwater, A.J. (1998). Development of the Fear of Pain Questionnaire-III. Journal of Behavioral Medicine, 21, 389-410.

Mehl-Madrona, L. E. (2004). Hypnosis to facilitate uncomplicated birth. American Journal of Clinical Hypnosis, 46, 299-312.

Melzack, R. (1984). The myth of painless childbirth. Pain, 19, 321-337. 
Melzack, R., Wall, P. D., \& Ty, C. D. (1982). Acute pain in an emergency clinic: latency of onset and descriptor patterns related to different injuries. Pain, 14, 33-43.

Mid Atlantic Addiction Technology Transfer Center. (2005). Decisional balance worksheet. Retrieved April 28, 2005 from http://www.motivationalinterview.org/clinical/decisionalbalance.pdf

Migneault, J. P., Adams, T. B., \& Read, J. P. (2005). Application of the Transtheoretical Model to substance abuse: historical development and future directions. Drug and Alcohol Review, 24, 437-438.

Moyers, T. B., Miller, W. R., \& Hendrickson, S. M. (2005). How does motivational interviewing work? Therapist interpersonal skill predicts client involvement within motivational interviewing sessions. Journal of Consulting and Clinical Psychology, 73, $590-598$.

Nesheim, B. I., \& Kinge, R. (2006). Performance of acupuncture as labor analgesia in the clinical setting. Acta obstetricia et gynecologica Scandinavica, 85, 441-443.

Nettelbladt, P., Fagerström, C. F., \& Uddenberg, N. (1976). The significance of reported childbirth pain. Journal of Psychosomatic Research, 20, 215-221.

Nielson, W. R., Jensen, M. P., \& Kerns, R. D. (2003). Initial development and validation of a Multidimensional Pain Readiness to Change Questionnaire. The Journal of Pain, 4, 148158.

Peterson, R. A., \& Reiss, S. (1992). Anxiety Sensitivity Index manual (2 ${ }^{\text {nd }}$ ed.). Worthington, OH: International Diagnostic Systems.

Pierce, B. (2001). Toning in pregnancy and labor. Journal of Prenatal and Perinatal Psychology \& Health, 15, 217-223. 
Poole, J. H. (2003). Neuraxial analgesia for labor and birth: Implications for mother and fetus. The Journal of Perinatal \& Neonatal Nursing, 17, 252-267.

Poore, M., \& Foster, J. C. (1985). Epidural and no epidural anesthesia: Differences between mothers and their experience of birth. Birth, 12, 205-212.

Prochaska, J. O. (2006). Moving beyond the Transtheoretical model. Addiction, 101, 768-774.

Prochaska, J. J., Rossi, J. S., Redding, C. A., Tsoh, J. Y., Humfleet, G. L., Eisendrath, S. J., et al. (2004). Depressed smokers and stages of change: Implications for treatment interventions. Drug \& Alcohol Dependence, 76, 143-151.

Prochaska, J. O., \& DiClemente, C. C. (1986). Toward a comprehensive model of change. In W.R. Miller (Ed.), Treating addictive behaviors: Processes of Change (pp. 3-27). New York: Plenum.

Prochaska, J. O., \& DiClemente, C. C. (1982). Transtheoretical therapy: Toward a more integrative model of change. Psychotherapy: Theory, Research and Practice, 19, 276288.

Prochaska, J. O., Redding, C. A., Harlow, L. L., Rossi, J. S., \& Velicer, W. F. (1994). The transtheoretical model of change and HIV prevention: A review. Health Education Quarterly, 21, 471-476.

Prochaska, J. O., Rossi, J. S., \& Wilcox, N. S. (1991). Change processes and psychotherapy outcome in integrative case research. Journal of Psychotherapy Integration, 1, 103-120.

Ramnero, A., Hanson, V., \& Kihlgren, M. (2002). Acupuncture treatment during labour - a randomized controlled trial. British Journal of Obstetrics \& Gynecology, 109, 637-644.

Reading, A., \& Cox, D. (1985). Psychosocial predictors of labor pain. Pain, 22, 309-315.

Reiss, S., \& McNally, R. J. (1985). Expectancy model of fear. In S. Reiss \& R. R. Bootzin 
(Eds.), Theoretical issues in behavior therapy (pp. 107-121). San Diego: Academic Press.

Reiss, S., Peterson, R. A., Gursky, D. M., \& McNally, R. J. (1986). Anxiety sensitivity, anxiety frequency, and the prediction of fearfulness. Behaviour Research \& Therapy, 24, 1-8.

Ruggiero, L., Tsoh, L., Everett, J. Y., Fava, J. L., \& Guise, B. J. (2000). The transtheoretical model of smoking: Comparison of pregnant and nonpregnant smokers. Addictive Behaviors, 25, 239-251.

Schroeder-Zwelling, E. (1988). The pregnancy experience. In F. H. Nichols \& S. Humenick (Eds.), Childbirth education: Practice, research, and theory (pp. 37-51). Philadelphia: WB Saunders.

Segan, C. J., Borland, R., \& Greenwood, K. M. (2006). Can Transtheoretical model measures predict relapse from the action stage of change among ex-smokers who quit after calling a quitline? Addictive Behaviors, 31, 414-428.

Sharma, S. K. (2000). Epidural analgesia during labor and maternal fever. Current Opinion in Anaesthesiology, 13, 257-260.

Sieben, J. M., Vlaeyen, J. W. S., Tuerlinckx, \& Portegijs, P. J. M. (2002). Pain-related fear in acute low back pain: The first two weeks of a new episode. European Journal of Pain, 6, 229-237.

Skilnand, E., Fossen, D., \& Heilberg, G. (2002). Acupuncture in the management of pain in labor. Acta obstetricia et gynecologica Scandinavica, 81, 943-948.

Slade, P., Laxton-Kane, M., \& Spiby, H. (2006). Smoking in pregnancy: the role of the Transtheoretical model and the mother's attachment to the fetus. Addictive Behaviors, $31,743-757$. 
Smith, C. A., Collins, C. T., Cyna, A. M., \& Crowther, C. A. (2006). Complementary and alternative therapies for pain management in labour. The Cochrane Database of Systematic Reviews, 2, AN: CD003521. The Cochrane Collaboration. Chichester, England: John Wiley \& Sons, Ltd.

Smith, J. A., \& Osborn, M. (2003). Interpretative phenomenological analysis. In J. A. Smith (Ed.), Qualitative psychology: A practical guide to research methods (pp. 51-80). Thousand Oaks, CA: Sage Publications, Inc.

Solomon, L. J., Secker-Walker, R. H., Skelly, J. M., Flynn, B. S. (1996). Stages of change in smoking during pregnancy in low-income women. Journal of Behavioral Medicine, 19, $333-344$.

Speckens, A. E. M., Spinhoven, P., Sloekers, P. P. A., Bolk, J. H., \& van Hemert, A. M. (1996). A validation study of the Whiteley Index, the Illness Attitude Scales, and the Somatosensory Amplification Scale in general medical and general practice patients. Journal of Psychosomatic Research, 40, 95-104.

Sperry-Clark, J. A., McNeil, D. W., \& Ciano-Federoff, L. (1999). Assessing chronic pain patients: The Fear of Pain Questionnaire - III. In L. Vandercreek \& T. L. Jackson (Eds.), Innovations in clinical practice: A source book (pp. 293-305). Sarasota, FL: Professional Resource Press.

Stewart, S. H., \& Watt, M. C. (2001). Assessment of health anxiety. In. G. J. G. Asmundson, S. Taylor, \& B. J. Cox (Eds.), Health Anxiety (pp. 95-131). New York: John Wiley \& Sons. Stotts, A.L., DeLaune, K.A., Schmitz, J.M., \& Grabowski, J. (2004). Impact of a motivational intervention on mechanisms of change in low-income pregnant smokers. Addictive Behaviors, 29, 1649-1657. 
Stotts, A. L., DiClemente, C. C., Carbonari, J. P., \& Mullen, P. D. (2000). Postpartum return to smoking: Staging a "suspended” behavior. Health Psychology, 19, 324-332.

Svensson, P. W. (2004). Hypnosis in the management of acute and persistent pain: support from the recent literature. Australian Journal of Clinical and Experimental Hypnosis, 32, $103-$ 110.

Thyrian, J. R., Hannover, W., Roske, K., Rumpf, H - J., John, U., \& Hapke, U. (2006). Postpartum return to smoking: Identifying different groups to tailor interventions. Addictive Beahviors, 31, 1785-1796.

U.S. Census Bureau. (2002). Global population profile: 2002, Highlights. Retrieved April 28, 2005 from http://www.census.gov/ipc/www/wp02.html

Waldenström, U., Bergman, V., \& Vasell, G. (1996). The complexity of labor pain: experiences of 278 women. Journal of Psychosomatic Obstetrics and Gynecology, 17, 215-228.

Waldenström, U., Hildingsson, I., Rubertsson, C., \& Rådestad, I. (2004). A negative birth experience: prevalence and risk factors in a national sample. Birth, 31, 17-27.

Walker, D., \& Myrick, F. (2006). Grounded theory: an exploration of process and procedure. Qualitative Health Research, 16, 547-559.

Walker, N.C., \& O’Brien, B. (1999). The relationship between method of pain management during labor and birth outcomes. Clinical Nursing Research, 8, 119-134.

West, R. (2005). Time for a change: putting the Transtheoretical (Stages of Change) model to rest. Addiction, 100, 1036-1039.

Whitelaw, S., Baldwin, S., Bunton, R., \& Flynn, D. (2000). The status of evidence and outcome in Stages of Change research. Health Education Research, 15, 707-718. 
Yildirim, G., \& Sahin, N. H. (2004). The effect of breathing and skin stimulation techniques on labour pain perception of Turkish women. Pain Research \& Management, 9, 183-187.

Zvolensky, M. J., Goodie, J. L., McNeil, D. W., Sperry, J. A., \& Sorrell, J. T. (2001). Anxiety sensitivity in the prediction of pain-related fear and anxiety in a heterogeneous chronic pain population. Behaviour Research \& Therapy, 39, 683-696. 
Appendix A

Expectant Mother Interview (Study 1)

\section{Explain cover letter to the participant explaining the purpose of the study and the} procedure. Answer all participant questions.

1. Have you ever given birth to a child before? If so:
A. How many?
B. Number vaginally?
C. Number c-section?
D. Please tell me about your labor experience(s).
E. Now, please tell me what you did, and what the nurses and doctors did, to help you cope with any discomfort during labor.

2. When is your due date?

3. How do you feel about self-management of labor pain at this point in time?

How have these feelings changed during your pregnancy?

If not a first-time mom:

How are these feelings different from those you had in earlier pregnancies?

If any differences: What has changed your beliefs / feelings?

4. Have you ever attended childbirth education classes? If so:

A. What was your experience like?

B. Did any part of childbirth education alter your views or beliefs about managing childbirth pain?

5. What about dealing with labor pain have you learned

- from your experiences?

- from your doctor?

- from your childbirth educator?

- from family / friends? 


\section{Deliver Stages of Change Education to participant. \\ - Describe self-management of pain. \\ - Describe stages of change model.}

1. Consider a woman who has never considered self-management of childbirth pain. What do you think some of her beliefs are?

2. Consider a woman who has only considered medication to manage childbirth pain. What do you think some of her beliefs are?

3. Consider a woman who is just beginning to consider self-managing her childbirth pain. What do you think some of her beliefs are?

4. Consider a woman who is beginning to practice self-management strategies. What do you think some of her beliefs are?

5. Consider a woman who is actively practicing self-management strategies in preparation for labor pain. What do you think some of her beliefs are?

6. Consider a woman who has only considered self-management of childbirth pain. What do you think some of her beliefs are?

7. Consider a woman who is not considering medication to self-manage childbirth pain. What do you think some of her beliefs are?

8. In your opinion, how may these beliefs change over the course of pregnancy? Over the course of labor?

9. In your experience, do these beliefs typically change? If so, based upon what (if any discernable) factors?

Thank participant and provide gift of appreciation. 
Appendix B

Health Care Provider Interview (Study 1)

Explain cover letter to the participant explaining the purpose of the study and the procedure. Answer all participant questions.

1. How long have you been in practice / childbirth education / psychology?

2. How would you describe your practice / position / research?

\section{A. (For obstetricians)}

Number of women seen / year?

Of your deliveries per year, approximately how many are vaginal?

Of your deliveries per year, approximately how many are c-section?

How may a woman's opinions about the management of childbirth pain change over the course of her pregnancy?

How may a woman's feelings and beliefs about pain management be different for women who are giving birth for the first time as opposed to those who already have delivered children?

Do you commonly see differences (in pain management beliefs) based on number of children a woman has had?

In your opinion, what is the best strategy, or the best combination of strategies, to help women cope with labor pain? Here, I'm asking about both medical procedures and self-management.

\section{(For childbirth educators / doulas)}

Number of women seen / year?

What are the most common requests made of women in childbirth education?

In your opinion, what are the most common reasons for attending childbirth education classes? 
How may a woman's opinions about the management of childbirth pain change over the course of childbirth education?

How may a woman's feelings and beliefs about pain management be different for women who are giving birth for the first time as opposed to those who already have delivered children?

Do you commonly see differences (in pain management beliefs) based on number of children a woman has had?

In your opinion, what is the best strategy, or the best combination of strategies, to help women cope with labor pain? Here, I'm asking about both medical procedures and self-management.

What are the goals of the childbirth educator in relation to pain management?

\section{(For pain psychologists)}

What are your thoughts concerning the Stages of Change model?

What are your thoughts concerning the usefulness or applicability of the Stages of Change model to acute pain versus chronic pain?

What is your experience with pregnancy?

What are your thoughts concerning childbirth pain management?

How may a woman's opinions about the management of childbirth pain change over the course of her pregnancy?

How may a woman's feelings and beliefs about pain management be different for women who are giving birth for the first time as opposed to those who already have delivered children?

Do you commonly see differences (in pain management beliefs) based on number of children a woman has had?

In your opinion, what is the best strategy, or the best combination of strategies, to help women cope with labor pain? Here, I'm asking about both medical procedures and self-management.

\section{Questions for all, continued:}

B. In your experience, what are some of the most common sentiments expectant mothers express concerning childbirth pain? 
C. What do you hear from expectant mothers about their expectations and concerns about childbirth pain?

\section{Deliver Stages of Change Education to participant. \\ - Describe self-management of pain. \\ - Describe stages of change model.}

1. Consider a woman who has never considered self-management of childbirth pain. What do you think some of her beliefs are?

2. Consider a woman who has only considered medication to manage childbirth pain. What do you think some of her beliefs are?

3. Consider a woman who is just beginning to consider self-managing her childbirth pain. What do you think some of her beliefs are?

4. Consider a woman who is beginning to practice self-management strategies. What do you think some of her beliefs are?

5. Consider a woman who is actively practicing self-management strategies in preparation for labor pain. What do you think some of her beliefs are?

6. Consider a woman who has only considered self-management of childbirth pain. What do you think some of her beliefs are?

7. Consider a woman who is not considering medication to self-manage childbirth pain. What do you think some of her beliefs are?

8. In your opinion, how may these beliefs change over the course of pregnancy? Over the course of labor?

9. In your experience, do these beliefs typically change? If so, based upon what (if any discernable) factors?

\section{Thank participant and provide gift of appreciation.}


Appendix C

Definition of Self-Management

\section{COPING WITH CHILDBIRTH PAIN}

What are self-management strategies?

\section{Any non-pharmacological (non-medical) means used to cope with childbirth pain is considered a self-management strategy.}

Pharmacological strategies: drugs, epidural, etc.

\section{Self-management strategies:}

- Lamaze techniques

1. Relaxation (progressive or touch)

2. Positioning

- Breathing

- Distraction

1. Self-hypnosis

2. Music therapy or aromatherapy

3. Conversation, information-seeking

- Cognitive coping strategies

1. Acceptance

2. Focus upon a mantra or prayer, imagery

- Massage or back rub, touch, acupuncture

- Bath or shower

- Any other non-pharmacological (non-medical) intervention 


\section{Appendix D}

Diagram of the Stages of Change Model

\section{The Five Stages of Change}

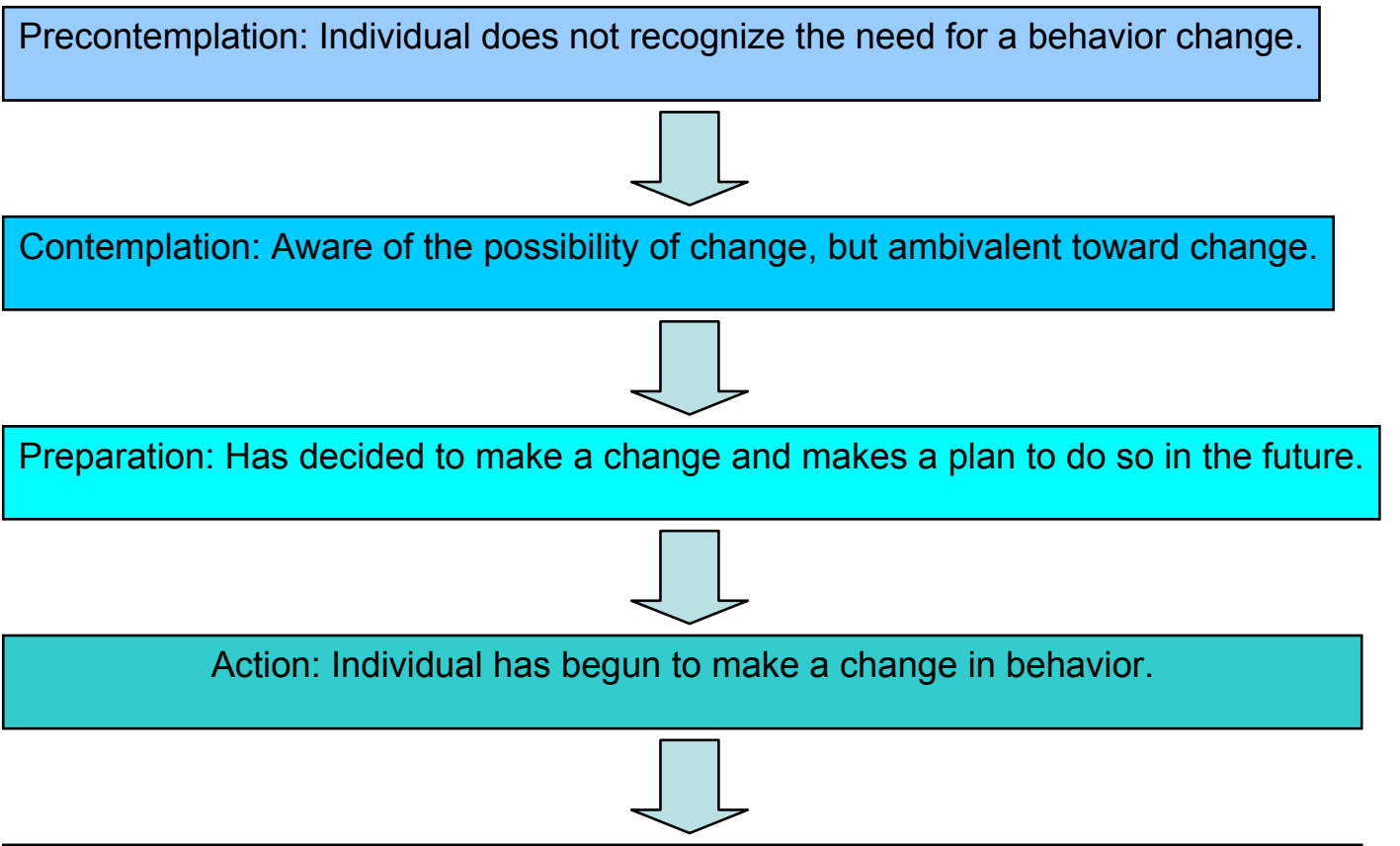

Maintenance: Successful change and takes action to ensure durability of change. 


\section{Appendix E}

Application of the SOC Model to Readiness to Self-Manage Childbirth Pain

\section{Example Stages of Change Items for readiness to self-manage childbirth pain:}

Precontemplation:

Contemplation:

Preparation:

Action:

Maintenance:
"I have not thought much about learning self-management strategies to help cope with childbirth pain."

"I think I might be ready to learn some self-management strategies to help cope with childbirth pain."

"I've decided to learn some selfmanagement strategies to help cope with childbirth pain."

"I have attempted a strategy that could help me cope with childbirth pain."

"I am practicing a strategy that could help me cope with childbirth pain." 


\author{
Appendix F \\ Items Generated from Study 1 Semi-Structured Interviews \\ (168 items) \\ ITEMS FROM INTERVIEWS
}

\title{
$\underline{\text { Childbirth Educators }}$
}

Stage

1. I've heard that the only way to get through childbirth is with an epidural.

2. I'm really scared of labor pain.

3. Labor pain is going to be too intense for me to handle.

4. Women have given birth before, so I don't need childbirth education.

5. Childbirth is going to happen no matter what I do.

6. I don't need to find out ways to handle labor pain.

7. Childbirth is going to be unbearably painful.

8. I can only do childbirth if I have medication.

9. I'm not strong.

10. I have no ability to give birth naturally.

11. I want an epidural during labor.

12. I don't know anyone who has done natural childbirth.

13. Whatever my doctor decides for labor pain is fine with me.

14. Most women forget their coping strategies when labor pain hits.

15. I don't see why someone would want to go through the pain of natural childbirth.

16. Medication works better than self-management to ease labor pain.

17. Using medication/epidural is a more accepted way to give birth.

18. Medications/epidural will really reduce my labor pain.

19. I am very anxious about labor pain.

20. I'm going to call about childbirth classes, but l'm not sure they're going to help.

21. I'm not sure how to remember what I learn in childbirth classes.

22. I'm not sure how well l'll cope during labor.

23. I'm not sure what the tools are to help me deal with labor pain.

24. I'm afraid that self-management techniques won't help enough during labor.

25. I'm unsure what strategies are best to deal with my labor pain.

26. I want to find out more about ways to deal with labor pain.

27. I feel silly practicing self-management strategies, like breathing.

28. Self-management techniques feel unnatural.

29. I'm embarrassed practicing self-management methods.

30. I don't see how self-management will help during labor.

31. Childbirth educators are too optimistic about labor pain.

32. I hope no one sees me doing my self-management strategies.

33. I'm embarrassed to admit that I want medications/epidural during labor.

34. I'm worried about how l'll deal with labor pain.

35. I hope self-management will help during labor but I'm not entirely sure they will.

36. I am looking into options for childbirth pain management.

37. I'm thinking about what normally helps me when I'm in pain.

38. I am going to at least try to go natural during my labor.

39. My own coping strategies might reduce my labor pain.

40. I've found the right self-management technique for me to use during labor.

41. I'll try to do natural childbirth.

42. I've researched all of my options for childbirth pain management.

43. There is no way l'm going to have medications/epidural during labor.

44. Women were meant to give birth naturally.

45. I'll be OK without medication. 
46. Medication is not an option for my labor.

M

47. I'm tough enough to handle labor on my own.

$M$

48. I'm afraid of needles, so an epidural is out of the question.

$M$

49. I'll feel more connected to my baby if I deliver naturally.

$\mathrm{M}$

50. My own coping strategies will really reduce my labor pain.

1. I wonder if I am tough enough to handle labor pain.

$\mathrm{PC}$

2. I don't see why I need special training to deal with labor pain.

3. Other women handle labor pain without self-management.

4. Doctors know how to control labor pain, so I don't need to worry.

5. My doctor knows how to keep me comfortable during labor.

6. Most of the people I know have had epidurals.

7. I'd like to wake up when labor is over.

8. It would be nice to be knocked out during labor.

9. Medicine is fine for other women, so it will be fine for me.

10. I've had friends who had medications during labor and their babies were fine.

11. Modern medicine is wonderful.

12. I don't need to learn self-management skills because medicine works fine.

13. Childbirth pain is not natural.

14. Childbirth pain should be controlled with an outside agent.

15. Childbirth is too intense or powerful for me to manage.

16. It is the job of the doctor to relieve childbirth pain.

17. Childbirth pain is can be eliminated with medications/epidural.

18. I don't have to do much to deal with labor because the pain won't be that bad.

19. Someone will take care of my labor pain for me.

20. I have no control over my labor pain.

21. I'll deal with labor pain when I have to.

22. Doctors are authority figures.

23. Doctors know best.

24. I think I should learn about my options for handling labor pain.

25. I believe it's wise to consider all of my resources before labor.

26. Medication/epidural might not eliminate my pain entirely.

27. Lots of people take childbirth classes so they must work for some women.

28. I've heard that self-management skills have helped some women.

29. I think it might help to learn some ways to cope with labor on my own.

30. I have some hope that there are things I can do during labor to help relieve the pain.

31. I'm fearful about my ability to use self-management techniques.

32. I'm worried I won't be able to give birth naturally.

33. I believe it is valuable to prepare for labor pain.

34. I have practiced some skills and seen that they've calmed me.

35. I am using skill development as a coping strategy for labor pain.

36. I'm taking action to take care of my child and myself.

37. I'm trying to prepare for labor ahead of time.

38. I would really like to have a natural childbirth, if I can.

39. Self-management strategies can improve my chances of delivering without medications.

40. Other women use self-management techniques to cope and do childbirth naturally.

41. I want to use medication in my labor only if it is necessary.

42. I am practicing a strategy to help during labor.

43. I have faith in self-management strategies for labor pain.

44. I'm anticipating a favorable outcome from trying naturally.

45. I'm refining my coping skills in preparation for labor.

46. I feel ready to give birth.

47. I have high tolerance for distress.

$\mathrm{PC}$

PC

PC

PC

PC

PC

PC

PC

PC

PC

PC

PC

PC

PC

PC

PC

PC

PC

PC

PC

PC

PC

C

C

C

C

C

C

$\mathrm{P}$

$P$

$P$

P

A

A

A

A

A

A

A

A

A

M

$M$

$\mathrm{M}$ 
48. It is important to me to be active during my labor.

M

49. I am good at handling pain on my own.

50. I think it is important for childbirth to be natural.

51. I'm getting good at self-management skills.

52. My own preparation for labor is paying off.

53. It's nice to have my partner give me a back rub.

54 . I want to do childbirth by myself.

55. I don't want to have to rely on medications during labor.

56. I want to have a natural childbirth for my baby (and his/her health?)

57. I don't trust medications or the doctors that push them.

58. Self-management techniques are really going to help me during labor.

59. I feel more in control of labor if I use self-management.

60 . I don't want my baby to be drugged up.

61. Maybe medications will hurt my baby.

62. Medicines will keep me from enjoying the childbirth experience.

63. I am very tolerant of pain.

1. I don't think l'll receive good support to encourage me during labor.

2. Medication is the only option for my labor experience.

3. I don't want to experience any pain during labor.

4. Childbirth will hurt too much.

5. Childbirth is just a medical procedure.

6. Childbirth is an unpleasant experience.

7. I don't have the patience to use my own coping strategies during labor.

8. I want all the medicine I can get during labor.

9. I need medication during labor.

10. No matter what I try on my own to handle the pain, childbirth will still hurt.

11. I don't see the need to bother with self-management of labor pain.

12. I want medication to be an option during labor, just in case.

13. I don't know what to think about medication to deal with labor pain.

14. I'm trying to get good at self-management in preparation for labor.

15. I hope my strategies work during labor.

16. I am receiving encouragement to use my own strategies during labor.

17. I'll feel good about myself if I don't need an epidural.

18. Pain can be overcome.

19. I will use the self-management strategies for labor pain later in my life.

20. I'm confident that I will get through childbirth.

21. I want to teach other women how to deal with childbirth other ways than with medicines.

22. I feel I will cherish my childbirth more if I go naturally, because I worked harder for it.

23. Giving birth naturally is the "right" way to go.

24. Medications are necessary for a healthy delivery.

25. Other women have gone natural, so I can, too.

26. Medical interventions for pain are more for the comfort of the practitioner than for the mother.

27. Recovery is easier if you do not use medications during labor.

28. Natural childbirth is better for the health of the baby.

29. I am anti-medication.

30. God planned for women to give birth naturally.

31. Childbirth is an emotional experience.

32. I want the total experience of childbirth.

33. Self-management is the only way to go during labor.

34. Every mother since the dawn of time has done childbirth.

35. I feel that God won't give me anything to do that I am not capable of doing.

36. As long as my baby is not in distress, I can handle the pain during childbirth. 
37. I've been warned that medications/epidural my affect my baby.

1. Everyone in my family has had an epidural during labor.

$\mathrm{PC}$

2. I've never considered a natural childbirth.

$P C$

3. Someone should take care of my labor pain.

$P C$

4. I'm not responsible for dealing with my labor pain.

$P C$

5. I'm deciding what my focal point will be during labor.

A

6. I'm learning about how labor will progress.

7. I am learning different ways to handle labor pain.

A

8. I have a positive attitude about using self-management strategies.

A

9. I have considered having a doula at my childbirth.

10. I have a self-management plan ready for my labor.

11. I've heard about or seen a woman deliver a baby without any drugs.

12. I believe in holistic healing.

13. I want to be in control during my birth.

14. I feel that I can conquer labor pain.

15. I'm concerned that an epidural will cause me back pain.

A

16. I'll feel more like a real woman if I give birth naturally.

17. I know what to expect during labor. 


\section{Appendix G}

\section{All Items Generated in Study 1}

(321 items)

\section{PRECONTEMPLATION ITEMS - PAGE 1 OF 2}

1. I have not thought much about learning self-management strategies to help cope with childbirth pain.

2. Learning self-management strategies, like breathing and relaxation, to manage my labor pain is a waste of my time.

3. I trust my doctor or nurse to help me cope with my labor pain.

4. I won't be able to remember coping strategies during my labor.

5. The reason doctors have drugs for labor pain is because they work.

6. I don't need to bother learning self-management strategies because there are medical ways to handle labor pain.

7. I have heard from my friends or family that medications or an epidural are the best way to handle labor pain.

8. I expect childbirth to be extremely painful, no matter what.

9. Compared to other people, I think I have a relatively low pain tolerance.

10. I am afraid of the idea of childbirth pain.

11. I believe that medications are a safe way to cope with labor pain.

12. I believe that an epidural is a safe way to cope with labor pain.

13. I believe that medications are the most effective way to cope with childbirth pain.

14. I believe that an epidural is the most effective way to cope with childbirth pain.

15. If medications / epidurals were not safe, doctors would not give them to women.

16. I am not interested in learning more self-management skills to cope with labor pain.

17. The nurses or doctors will tell me what to do to manage my labor pain when I get to the hospital to deliver.

18. I don't need to learn self-management skills because handling labor will come naturally to me.

19. Childbirth will happen no matter what I do to try to ease the pain on my own.

20. I can only handle labor pain with medication.

21. I don't think I have the ability to handle labor pain on my own.

22. I have never thought that I needed to cope with pain.

23. Medicine is the only means to coping with pain.

24. I plan on getting an epidural when I give birth.

25. I know all of the tools I will need in order to cope with pain during labor.

26. I will die during labor if I do not take pain medications.

27. It's not so important to plan to deal with labor pain because they will take care of you in the hospital.

28. A caesarean is the only way to go.

29. I want to be knocked out during labor.

30. Childbirth is natural and therefore does not require additional preparation.

31. Labor pain cannot be controlled by any other means than medication.

32. It would be silly not to use medications during labor to help with the pain.

33. The hospital staff knows best when it comes to my pain management.

34. I don't think it's worth the time to learn ways to cope with labor pain.

35. I don't think I have time to learn coping strategies for labor.

36. Self-management methods don't really help with labor.

37. I am too busy to learn new coping strategies for labor.

38. I don't believe in self-management strategies.

39. I don't believe that trying to control pain during labor truly could work.

40. Breathing exercises won't help during labor.

41. I've heard that the only way to get through childbirth is with an epidural.

42. I'm really scared of labor pain.

43. Labor pain is going to be too intense for me to handle.

44. Women have given birth before, so I don't need childbirth education. 


\section{PRECONTEMPLATION ITEMS - PAGE 2 OF 2}

45. Childbirth is going to happen no matter what I do.

46. I don't need to find out ways to handle labor pain.

47. Childbirth is going to be unbearably painful.

48. I can only do childbirth if I have medication.

49. I'm not strong.

50. I have no ability to give birth naturally.

51. I want an epidural during labor.

52. I don't know anyone who has done natural childbirth.

53. Whatever my doctor decides for labor pain is fine with me.

54. Most women forget their coping strategies when labor pain hits.

55. I don't see why someone would want to go through the pain of natural childbirth.

56. Medication works better than self-management to ease labor pain.

57. Using medication/epidural is a more accepted way to give birth.

58. Medications/epidural will really reduce my labor pain.

59. I am very anxious about labor pain.

60 . I wonder if I am tough enough to handle labor pain.

61. I don't see why I need special training to deal with labor pain.

62. Other women handle labor pain without self-management.

63. Doctors know how to control labor pain, so I don't need to worry.

64. My doctor knows how to keep me comfortable during labor.

65 . Most of the people I know have had epidurals.

66. I'd like to wake up when labor is over.

67 . It would be nice to be knocked out during labor.

68. Medicine is fine for other women, so it will be fine for me.

69. I've had friends who had medications during labor and their babies were fine.

70. Modern medicine is wonderful.

71. I don't need to learn self-management skills because medicine works fine.

72. Childbirth pain is not natural.

73. Childbirth pain should be controlled with an outside agent.

74. Childbirth is too intense or powerful for me to manage.

75. It is the job of the doctor to relieve childbirth pain.

76. Childbirth pain can be eliminated with medications/epidural.

77. I don't have to do much to deal with labor because the pain won't be that bad.

78. Someone will take care of my labor pain for me.

79. I have no control over my labor pain.

80. I'll deal with labor pain when I have to.

81. Doctors know best.

82. I don't think l'll receive good support to encourage me during labor.

83. Medication is the only option for my labor experience.

84. I don't want to experience any pain during labor.

85. Childbirth will hurt too much.

86. Childbirth is just a medical procedure.

87. Childbirth is an unpleasant experience.

88. I don't have the patience to use my own coping strategies during labor.

89. I want all the medicine I can get during labor.

90. I need medication during labor.

91. No matter what I try on my own to handle the pain, childbirth will still hurt.

92. I don't see the need to bother with self-management of labor pain.

93. Everyone in my family has had an epidural during labor.

94. I've never considered a natural childbirth.

95. Someone should take care of my labor pain.

96. I'm not responsible for dealing with my labor pain. 


\section{CONTEMPLATION ITEMS - PAGE 1 OF 1}

1. I think I might be ready to learn some self-management strategies to help cope with childbirth pain.

2. I have been thinking about using some of the self-management strategies that l've heard of during my labor.

3. I want to learn some ways to cope with labor pain on my own.

4. There is a chance that self-management strategies may help ease labor pain.

5. I'm not sure I want to go without medications during my labor.

6. I'm not sure of the best way for me to manage my labor pain.

7. I may be interested in learning ways to manage labor pain on my own.

8. I believe than medication may be an effective way to cope with childbirth pain.

9. I'm not sure self-management skills will help ease my labor pain.

10. I question my ability to handle labor pain on my own.

11. I'm going to look into learning some coping skills for labor, but l'm not sure they are going to help.

12. If I learn self-management strategies, I may forget them during labor.

13. I should learn ways to cope with pain.

14. Maybe medications aren't the only way to deal with childbirth pain.

15. Maybe self-management could help me during labor.

16. I have heard that breathing exercises could help me during labor.

17. I have wondered if drugs don't eliminate pain during childbirth.

18. I have wondered what I can do to help myself during childbirth.

19. I have wondered if taking medications could hurt my baby.

20. I want to use as little pain medication as possible during labor.

21. It's not so important to learn to cope with labor pain, as childbirth only happens rarely in a woman's life.

22. Sometimes I think that it might be time to learn about getting myself ready for labor.

23. I've heard about ways that you can cope with labor, but I don't know a lot about them.

24. I've heard medication isn't always required to get you through labor.

25. I've wondered if medications will help me enough during labor.

26. It may be wise to learn some techniques to cope with labor.

27. Drugs don't always work, so it's best to have a backup strategy to cope with labor.

28. I wish I knew more about ways to cope with pain during labor, other than having to receive drugs.

29. I wish my doctor had more information about non-drug ways to cope with labor.

30. I don't know much about how to survive labor pain, but l'd like to learn.

31. I'm not sure if my strategies would work when the labor pain gets really intense.

32. I'm not sure if l'd remember my strategies to cope with labor pain.

33. I'm going to call about childbirth classes, but l'm not sure they're going to help.

34. I'm not sure how to remember what I learn in childbirth classes.

35. I'm not sure how well l'll cope during labor.

36. I'm not sure what the tools are to help me deal with labor pain.

37. I'm afraid that self-management techniques won't help enough during labor.

38. I'm unsure what strategies are best to deal with my labor pain.

39. I think I should learn about my options for handling labor pain.

40. I believe it's wise to consider all of my resources before labor.

41. Medication/epidural might not eliminate my pain entirely.

42. Lots of people take childbirth classes so they must work for some women.

43. I've heard that self-management skills have helped some women with labor pain.

44. I think it might help to learn some ways to cope with labor on my own.

45. I want medication to be an option during labor, just in case.

46. I don't know what to think about medication to deal with labor pain. 


\section{PREPARATION ITEMS - PAGE 1 OF 1}

1. I've decided to learn some self-management strategies to help cope with childbirth pain.

2. I think self-management strategies might ease labor pain.

3. Self-management strategies are worth looking in to as a way to cope with labor pain.

4. I might be ready to try some coping skills to use during labor.

5. I think trying self-management skills might feel silly.

6. I'm not sure if the self-management strategies I know about will help during labor.

7. I have signed up for Lamaze/childbirth classes.

8. I believe that Lamaze is an underrated strategy for pregnancy.

9. I plan to get more information about childbirth coping skills.

10. Maybe I will look on the Internet for more information about coping skills.

11. I plan on using techniques besides or in addition to medication to help with pain during labor.

12. I will talk to my doctor about my pain management plan for labor.

13. I have read pamphlets and brochures about ways to get ready for labor.

14. I think it might be helpful to learn more about yoga or breathing strategies to cope with pain.

15. It's important to learn ways to cope with labor pain.

16. I've considered learning how to cope with labor pain on my own.

17. I want to learn to cope with labor pain.

18. I will explore options for dealing with labor pain.

19. I will read books about childbirth pain.

20. I've heard about prenatal yoga.

21. I have signed up for childbirth classes.

22. I have surfed the Internet for childbirth information.

23. I want to find out more about ways to deal with labor pain.

24. I feel silly practicing self-management strategies, like breathing.

25. Self-management techniques feel unnatural.

26. I'm embarrassed practicing self-management methods.

27. I don't see how self-management will help during labor.

28. Childbirth educators are too optimistic about labor pain.

29. I hope no one sees me doing my self-management strategies.

30. I'm embarrassed to admit that I want medications/epidural during labor.

31. I'm worried about how l'll deal with labor pain.

32. I hope self-management will help during labor but I'm not entirely sure they will.

33. I have some hope that there are things I can do during labor to help relieve the pain.

34. I'm fearful about my ability to use self-management techniques.

35. I'm worried I won't be able to give birth naturally.

36. I believe it is valuable to prepare for labor pain. 


\section{ACTION ITEMS - PAGE 1 OF 1}

1. I have tried a strategy that could help me deal with childbirth pain.

2. I value self-management strategies to cope with labor pain.

3. I have begun to learn some strategies to help myself cope with labor pain.

4. I'm getting help learning strategies for coping with labor pain.

5. I am testing out some coping skills to use during labor.

6. I am learning ways to control my labor pain other than with medications or an epidural.

7. I believe that self-management strategies will me help cope with labor pain.

8. I have tried some coping skills to use during labor.

9. I have tried a breathing or relaxation exercise in preparation for labor.

10. I feel silly when I try coping strategies such as breathing or relaxation.

11. I have completed a Lamaze class.

12. I don't know if I can be hypnotized.

13. I'm not confident that my self-management strategy will work to ease my labor pain.

14. I think that what I have learned in Lamaze classes just might help me during labor.

15. I know how to breathe during childbirth, but I am not sure if I will be able to do it during labor itself.

16. I am afraid that what I have learned in childbirth classes will not be enough to ease my labor pain.

17. I have tried meditation in preparation for labor.

18. I have explored my options for labor pain management.

19. I have learned pain coping strategies in order to avoid using medications and/or epidurals.

20. I might use a coping strategy I have practiced different from medications or epidurals.

21. I am looking into options for childbirth pain management.

22. I'm thinking about what normally helps me when I'm in pain.

23. I am going to at least try to go natural during my labor.

24. My own coping strategies might reduce my labor pain.

25. I've found the right self-management technique for me to use during labor.

26. I have practiced some skills for reducing labor pain and seen that they've calmed me.

27. I am using skill development as a coping strategy for labor pain.

28. I'm taking action to take care of my child and myself.

29. I'm trying to prepare for labor ahead of time.

30. I would really like to have a natural childbirth, if I can.

31. Self-management strategies can improve my chances of delivering without medications.

32. Other women use self-management techniques to cope and do childbirth naturally.

33. I want to use medication in my labor only if it is necessary.

34. I am practicing a strategy to help during labor.

35. I'm trying to get good at self-management in preparation for labor.

36. I hope my strategies work during labor.

37. I am receiving encouragement to use my own strategies during labor.

38. I'll feel good about myself if I don't need an epidural or medications for labor pain.

39. I'm deciding what my focal point will be during labor.

40. I'm learning about how labor will progress.

41. I am learning different ways to handle labor pain.

42. I have a positive attitude about using self-management strategies to help reduce labor pain. 


\section{MAINTENANCE ITEMS - PAGE 1 OF 2}

1. I have been repeatedly practicing some coping skills that will help me cope with childbirth pain.

2. I feel comfortable handling labor pain without medication.

3. I expect labor pain to be manageable.

4. I have practiced a breathing or relaxation exercise to prepare for labor.

5. I believe that self-management skills are the best way to handle labor pain.

6. I believe that medications I take during labor may hurt my baby.

7. I believe that I can cope with labor pain completely with self-management strategies.

8. I have made a lot of progress in learning ways to cope with labor pain on my own.

9. I have confidence in my ability to take care of my pain on my own.

10. Compared to other people, I think I have a relatively high pain tolerance.

11. I am not very afraid of the idea of labor pain.

12. Labor pain is not very different from other pain I have already experienced.

13. I would like to be in control of my labor.

14. I have learned some good ways to manage labor pain on my own.

15. It is important to me that I have a natural childbirth.

16. Because women have been giving birth for years, childbirth will not be a big deal.

17. I intend to use the coping strategies I learn to ease childbirth pain for other painful situations in my life.

18. When I'm in pain, I find myself automatically using coping strategies that have worked in the past, such as a relaxation exercise or mental distraction technique.

19. I am interested in learning more self-management skills to cope with labor pain.

20. I'll be OK without medication during my labor.

21. Medication is not an option for my childbirth.

22. Childbirth pain won't be that bad.

23. Women were meant to have children, so childbirth can be done without medication.

24. I know that I am going to use breathing exercises in my labor.

25. I know that I am ready for labor pain.

26. I know that my pain strategies will be enough during labor.

27. I feel prepared for labor pain.

28. I will be successful in my practice getting ready for pregnancy.

29. I will be successful in my practice getting ready for labor.

30. Other women I know have had easy labors.

31. Labor won't be bad.

32. Pain is all in your head.

33. I can control my pain mentally.

34. I have confidence that I can control my pain during labor.

35. Most women find childbirth to be easy.

36. Using medication during my labor would be a weakness.

37. Needing medication during labor means I have failed.

38. Medication should be a last resort during my labor.

39. Medication hasn't always been around for women, so it's not necessary for labor.

40. I have been looking forward to labor.

41. I'll try to do natural childbirth.

42. I've researched all of my options for childbirth pain management.

43. There is no way l'm going to have medications/epidural during labor.

44. Women were meant to give birth to deliver naturally.

45. I'll be OK without medication during my labor.

46. Medication is not an option for my labor.

47. I'm tough enough to handle labor on my own.

48. I'm afraid of needles, so an epidural is out of the question.

49. I'll feel more connected to my baby if I deliver naturally.

50 . My own coping strategies will really reduce my labor pain.

51. I have faith in self-management strategies for labor pain.

52. I'm anticipating a favorable outcome from trying naturally. 


\section{MAINTENANCE ITEMS - PAGE 2 OF 2}

53. I'm refining my coping skills in preparation for labor.

54. I feel ready to give birth.

55. I have high tolerance for distress.

56. It is important to me to be active during my labor.

57. I am good at handling pain on my own.

58. I think it is important for childbirth to be natural.

59. I'm getting good at self-management skills.

60 . My own preparation for labor is paying off.

61. It's nice to have my partner give me a back rub.

62. I want to do childbirth by myself.

63. I don't want to have to rely on medications during labor.

64. I want to have a natural childbirth for my baby and his/her health.

65. I don't trust medications or the doctors that push them.

66. Self-management techniques are really going to help me during labor.

67 . I feel more in control of labor if I use self-management.

68. I don't want my baby to be drugged up.

69. Maybe medications will hurt my baby.

70. Medicines will keep me from enjoying the childbirth experience.

71. I am very tolerant of pain.

72. Pain can be overcome.

73. I will use the self-management strategies for labor pain later in my life.

74. I'm confident that I will get through childbirth without any medications / epidural.

75. I want to teach other women how to deal with childbirth other ways than with medicines.

76. I feel I will cherish my childbirth more if I go naturally, because I worked harder for it.

77. Giving birth naturally is the "right" way to go.

78. Medications are necessary for a healthy delivery.

79. Other women have gone natural, so I can, too.

80. Medical interventions for pain are more for the comfort of the practitioner than for the mother.

81. Recovery is easier if you do not use medications during labor.

82. Natural childbirth is better for the health of the baby.

83. I am anti-medication.

84. God planned for women to give birth naturally.

85. Childbirth is an emotional experience.

86. I want the total experience of childbirth.

87. Self-management is the only way to go during labor.

88. Every mother since the dawn of time has done childbirth.

89. I feel that God won't give me anything to do that I am not capable of doing.

90. As long as my baby is not in distress, I can handle the pain during childbirth.

91. I've been warned that medications/epidural may affect my baby.

92. My own coping strategies work to help ease my pain.

93. I have considered having a doula at my childbirth.

94. I have a self-management plan ready for my labor.

95. I've heard about or seen a woman deliver a baby without any drugs.

96. I believe in holistic healing.

97. I want to be in control during my birth.

98. I feel that I can conquer labor pain.

99. I'm concerned that an epidural will cause me back pain.

100. I'll feel more like a real woman if I give birth naturally.

101. I know what to expect during labor. 


\section{Appendix H}

Items for Study 2:

Item Evaluation by Expectant Mothers

(75 items)

\section{PRECONTEMPLATION ITEMS}

1. I haven't really thought about learning self-management strategies to help cope with pain during childbirth.

2. Learning self-management skills, like breathing and relaxation, to manage my labor pain, is a waste of my time.

3. I don't need to bother learning self-management strategies because there are medical ways to handle labor pain.

4. I believe that medications or an epidural are the best ways to handle labor pain.

5. Knowing my own pain tolerance, I think l'll need an epidural or medications during labor.

6. I believe that medications are the only effective way to cope with childbirth pain.

7. It would be foolish not to use medications during labor to help with pain.

8. I can only handle labor pain with medication.

9. I don't think I have the ability to handle labor pain on my own.

10. I plan on receiving medicine or an epidural during labor.

11. It's not so important to learn to cope with labor pain because you'll be taken care of in the hospital.

12. I don't think it's worth the time to learn ways to cope with labor pain.

13. I've heard that the only way to get through childbirth is with an epidural.

14. I don't see why someone would want to go through the pain of natural childbirth.

15. I've never considered natural childbirth.

\section{CONTEMPLATION ITEMS}

1. I think I might be ready to learn some self-management strategies to help cope with childbirth pain.

2. I may be able to learn some ways to cope with labor pain on my own.

3. It is possible that self-management strategies may help ease my pain during labor.

4. I'm still considering whether to use medications or natural childbirth. 
5. I may be interested in learning ways to manage labor pain on my own.

6. I'm not sure that self-management skills could help ease my labor pain.

7. I'm going to look into learning some coping skills for labor, but I'm not sure they are going to help.

8. I still wonder if self-management strategies, like breathing exercises, could help me during labor.

9. I wonder whether I can help myself cope during childbirth.

10. I've heard about ways that you can cope with labor on your own, but I don't know a lot about them.

11. I'm not sure if strategies I could learn would work when the labor pain gets really intense.

12. I'm worried that self-management techniques won't help enough during labor.

13. I'm unsure whether my own coping skills are the best way to deal with labor pain.

14. I'm not sure I want to go without medications during my labor.

15. I've heard that some women use only natural childbirth techniques, but I'm not sure I could do that.

\section{PREPARATION ITEMS}

1. I've decided to learn some self-management skills to help cope with childbirth pain.

2. I think there are techniques that I could use to ease labor pain.

3. Self-management strategies are worth looking in to as a way to cope with labor pain.

4. I have signed up for, or already taken, a class that teaches ways of coping with labor.

5. I plan on getting more information about childbirth coping skills.

6. I plan on using techniques in addition to medication, or instead of medication, to help with pain during labor.

7. I plan to look for ways to cope with labor pain other than medications or an epidural.

8. I will be exploring options for dealing with labor pain other than medicine or an epidural.

9. I believe self-management methods will help me during labor, but I haven't learned any yet.

10. I know there are things I can do on my own during labor to help relieve pain, but I haven't practiced yet.

11. I have information, for example, from brochures, the internet, or the advice of others, that will prepare me for coping during labor without medications.

12. I know that I can learn ways to cope with labor pain on my own.

13. I believe I can learn even more about getting ready for childbirth. 
14. I'm ready to learn ways to cope with labor on my own.

15. I plan to find out more about ways to deal with labor pain on my own.

\section{ACTION ITEMS}

1. I have begun to practice a strategy that could help me deal with childbirth pain.

2. I have learned some skills to help myself cope with labor pain.

3. I am testing out some coping skills to use during labor.

4. I am learning ways to control my labor pain, other than with medications or an epidural.

5. I believe that I have some self-management skills to help me cope with labor pain.

6. I know how to breathe properly during childbirth to reduce discomfort.

7. I know some coping skills, like breathing, to do during labor, but I'm not sure l'll remember them.

8. I've learned some skills about coping with labor, but l'm not entirely comfortable with them yet.

9. I am going to try to have a natural childbirth.

10. I would really like to have a natural childbirth, if I can.

11. I am practicing new ways to reduce discomfort during labor.

12. I'm trying to get good at self-management skills in preparation for labor.

13. I feel encouraged about using my own coping skills during labor.

14. I am learning different ways to handle labor pain.

15. I'm not quite sure that l've practiced my coping skills enough yet to get through labor.

\section{MAINTENANCE ITEMS}

1. I feel comfortable handling labor pain with little or no medication.

2. I believe that self-management skills are the best way to handle labor pain.

3. I believe that I can cope with labor pain using only self-management strategies.

4. No matter what pain I experience during labor, I'll be able to use my self-management skills.

5. I feel totally prepared to use self-management in labor.

6. I've learned a lot about coping during labor, and I know I'll remember the skills.

7. Given the skills l've learned, l'll be just fine during labor.

8. During labor, I know that I am going to use breathing exercises or other skills l've learned. 
9. With the skills l've learned, I know I can handle labor.

10. I have confidence that I can control my pain during labor.

11. There is no way l'll go through labor without using my own coping skills.

12. My own coping strategies will really reduce my labor pain.

13. I'm perfecting my coping skills in preparation for labor.

14. I have skills all ready for my labor.

15. I know I'm ready to use my own coping skills during labor. 


$$
\begin{gathered}
\text { Appendix I } \\
\text { Expectant Mother Interview (Study 2) }
\end{gathered}
$$

Explain the purpose of the study and the procedure. Answer all participant questions. Provide education about SOC and self-management.

1. Age:

2. Ethnicity:

3. Have you ever given birth to a child before? If so:
A. How many?
B. Number vaginally?
C. Number c-section?
D. Please tell me about your labor experience(s).

E. Now, please tell me what you did, and what the nurses and doctors did, to help you cope with any discomfort during labor.

4. When is your due date? Current trimester

Give participant the preliminary CSOCQ to fill out. Explain the measure.

5. How do you feel about self-management of labor pain at this point in time? 
How have these feelings changed during your pregnancy?

If not a first-time mom:

How are these feelings different from those you had in earlier pregnancies?

If any differences: What has changed your beliefs / feelings?

Explain the purpose of the relevance ratings. Ask participant to complete ratings. Briefly discuss / debrief the ratings with them.

1. Which items did you like? Dislike?

2. What was missing generally?

3. What was missing from each category?

4. Items that stood out as particularly relevant?

5. Any items that should be in a different stage?

6. What items did you find to be poorly worded?

7. Other comments? 
Discuss their CSOCQ outcome with them (highest in which stage).

1. What stage of change do you believe you are currently in regarding selfmanagement of labor pain?

2. Do you feel that your score is reflective of your current SOC?

Thank participant and provide gift of appreciation. 
Appendix J

\section{Preliminary CSOCQ}

INSTRUCTIONS: The items listed below describe different ideas or beliefs expectant mothers may hold concerning childbirth pain and labor. Please look at each statement and think about how much each item applies to you. Please read each statement carefully and then a circle a number in the space to the right of each statement that indicates how much you agree with each item in relation to your own pregnancy, with 1 $=$ completely disagree and $5=$ completely agree.

\begin{tabular}{|c|c|c|c|c|c|}
\hline & $\begin{array}{c}\text { Completely } \\
\text { disagree }\end{array}$ & Disagree & Neutral & Agree & $\begin{array}{c}\text { Completely } \\
\text { agree }\end{array}$ \\
\hline $\begin{array}{l}\text { 1. I haven't really thought about learning self- } \\
\text { management strategies to help cope with pain } \\
\text { during childbirth. }\end{array}$ & 1 & 2 & 3 & 4 & 5 \\
\hline $\begin{array}{l}\text { 2. Learning self-management skills, like breathing } \\
\text { and relaxation, to manage my labor pain, is a } \\
\text { waste of my time. }\end{array}$ & 1 & 2 & 3 & 4 & 5 \\
\hline $\begin{array}{l}\text { 3. I don't need to bother learning self-management } \\
\text { strategies because there are medical ways to } \\
\text { handle labor pain. }\end{array}$ & 1 & 2 & 3 & 4 & 5 \\
\hline $\begin{array}{l}\text { 4. I believe that medications or an epidural are the } \\
\text { best ways to handle labor pain. }\end{array}$ & 1 & 2 & 3 & 4 & 5 \\
\hline $\begin{array}{l}\text { 5. Knowing my own pain tolerance, I think I'll need an } \\
\text { epidural or medications during labor. }\end{array}$ & 1 & 2 & 3 & 4 & 5 \\
\hline $\begin{array}{l}\text { 6. I believe that medications are the only effective } \\
\text { way to cope with childbirth pain. }\end{array}$ & 1 & 2 & 3 & 4 & 5 \\
\hline $\begin{array}{l}\text { 7. It would be foolish not to use medications during } \\
\text { labor to help with pain. }\end{array}$ & 1 & 2 & 3 & 4 & 5 \\
\hline 8. I can only handle labor pain with medication. & 1 & 2 & 3 & 4 & 5 \\
\hline $\begin{array}{l}\text { 9. I don't think I have the ability to handle labor pain } \\
\text { on my own. }\end{array}$ & 1 & 2 & 3 & 4 & 5 \\
\hline $\begin{array}{l}\text { 10. I plan on receiving medicine or an epidural during } \\
\text { labor. }\end{array}$ & 1 & 2 & 3 & 4 & 5 \\
\hline $\begin{array}{l}\text { 11. It's not so important to learn to cope with labor pain } \\
\text { because you'll be taken care of in the hospital. }\end{array}$ & 1 & 2 & 3 & 4 & 5 \\
\hline $\begin{array}{l}\text { 12. I don't think it's worth the time to learn ways to } \\
\text { cope with labor pain. }\end{array}$ & 1 & 2 & 3 & 4 & 5 \\
\hline $\begin{array}{l}\text { 13. I've heard that the only way to get through } \\
\text { childbirth is with an epidural. }\end{array}$ & 1 & 2 & 3 & 4 & 5 \\
\hline $\begin{array}{l}\text { 14. I don't see why someone would want to go through } \\
\text { the pain of natural childbirth. }\end{array}$ & 1 & 2 & 3 & 4 & 5 \\
\hline 15. I've never considered natural childbirth. & 1 & 2 & 3 & 4 & 5 \\
\hline
\end{tabular}




\begin{tabular}{|c|c|c|c|c|c|}
\hline & $\begin{array}{c}\text { Completely } \\
\text { disagree }\end{array}$ & $\overline{\text { Disagree }}$ & Neutral & Agree & $\begin{array}{c}\text { Completely } \\
\text { agree }\end{array}$ \\
\hline $\begin{array}{l}\text { 16. I think I might be ready to learn some self- } \\
\text { management strategies to help cope with childbirth } \\
\text { pain. }\end{array}$ & 1 & 2 & 3 & 4 & 5 \\
\hline $\begin{array}{l}\text { 17. I may be able to learn some ways to cope with } \\
\text { labor pain on my own. }\end{array}$ & 1 & 2 & 3 & 4 & 5 \\
\hline $\begin{array}{l}\text { 18. It is possible that self-management strategies may } \\
\text { help ease my pain during labor. }\end{array}$ & 1 & 2 & 3 & 4 & 5 \\
\hline $\begin{array}{l}\text { 19. I'm still considering whether to use medications or } \\
\text { natural childbirth. }\end{array}$ & 1 & 2 & 3 & 4 & 5 \\
\hline $\begin{array}{l}\text { 20. I may be interested in learning ways to manage } \\
\text { labor pain on my own. }\end{array}$ & 1 & 2 & 3 & 4 & 5 \\
\hline $\begin{array}{l}\text { 21. I'm not sure that self-management skills could help } \\
\text { ease my labor pain. }\end{array}$ & 1 & 2 & 3 & 4 & 5 \\
\hline $\begin{array}{l}\text { 22. I'm going to look into learning some coping skills } \\
\text { for labor, but l'm not sure they are going to help. }\end{array}$ & 1 & 2 & 3 & 4 & 5 \\
\hline $\begin{array}{l}\text { 23. I still wonder if self-management strategies, like } \\
\text { breathing exercises, could help me during labor. }\end{array}$ & 1 & 2 & 3 & 4 & 5 \\
\hline $\begin{array}{l}\text { 24. I wonder whether I can help myself cope during } \\
\text { childbirth. }\end{array}$ & 1 & 2 & 3 & 4 & 5 \\
\hline $\begin{array}{l}\text { 25. I've heard about ways that you can cope with labor } \\
\text { on your own, but I don't know a lot about them. }\end{array}$ & 1 & 2 & 3 & 4 & 5 \\
\hline $\begin{array}{l}\text { 26. I'm not sure if strategies I could learn would work } \\
\text { when the labor pain gets really intense. }\end{array}$ & 1 & 2 & 3 & 4 & 5 \\
\hline $\begin{array}{l}\text { 27. I'm worried that self-management techniques won't } \\
\text { help enough during labor. }\end{array}$ & 1 & 2 & 3 & 4 & 5 \\
\hline $\begin{array}{l}\text { 28. I'm unsure whether my own coping skills are the } \\
\text { best way to deal with labor pain. }\end{array}$ & 1 & 2 & 3 & 4 & 5 \\
\hline $\begin{array}{l}\text { 29. I'm not sure I want to go without medications } \\
\text { during my labor. }\end{array}$ & 1 & 2 & 3 & 4 & 5 \\
\hline $\begin{array}{l}\text { 30. I've heard that some women use only natural } \\
\text { childbirth techniques, but I'm not sure I could do } \\
\text { that. }\end{array}$ & 1 & 2 & 3 & 4 & 5 \\
\hline $\begin{array}{l}\text { 31. I've decided to learn some self-management skills } \\
\text { to help cope with childbirth pain. }\end{array}$ & 1 & 2 & 3 & 4 & 5 \\
\hline $\begin{array}{l}\text { 32. I think there are techniques that I could use to ease } \\
\text { labor pain. }\end{array}$ & 1 & 2 & 3 & 4 & 5 \\
\hline
\end{tabular}




\begin{tabular}{|c|c|c|c|c|c|}
\hline & $\begin{array}{c}\text { Completely } \\
\text { disagree }\end{array}$ & Disagree & Neutral & Agree & $\begin{array}{c}\text { Completely } \\
\text { agree }\end{array}$ \\
\hline $\begin{array}{l}\text { 33. Self-management strategies are worth looking in to } \\
\text { as a way to cope with labor pain. }\end{array}$ & 1 & 2 & 3 & 4 & 5 \\
\hline $\begin{array}{l}\text { 34. I have signed up for, or already taken, a class that } \\
\text { teaches ways of coping with labor. }\end{array}$ & 1 & 2 & 3 & 4 & 5 \\
\hline $\begin{array}{l}\text { 35. I plan on getting more information about childbirth } \\
\text { coping skills. }\end{array}$ & 1 & 2 & 3 & 4 & 5 \\
\hline $\begin{array}{l}\text { 36. I plan on using techniques in addition to } \\
\text { medication, or instead of medication, to help with } \\
\text { pain during labor. }\end{array}$ & 1 & 2 & 3 & 4 & 5 \\
\hline $\begin{array}{l}\text { 37. I plan to look for ways to cope with labor pain other } \\
\text { than medications or an epidural. }\end{array}$ & 1 & 2 & 3 & 4 & 5 \\
\hline $\begin{array}{l}\text { 38. I will be exploring options for dealing with labor } \\
\text { pain other than medicine or an epidural. }\end{array}$ & 1 & 2 & 3 & 4 & 5 \\
\hline $\begin{array}{l}\text { 39. I believe self-management methods will help me } \\
\text { during labor, but I haven't learned any yet. }\end{array}$ & 1 & 2 & 3 & 4 & 5 \\
\hline $\begin{array}{l}\text { 40. I know there are things I can do on my own during } \\
\text { labor to help relieve pain, but I haven't practiced } \\
\text { yet. }\end{array}$ & 1 & 2 & 3 & 4 & 5 \\
\hline $\begin{array}{l}\text { 41. I have information, for example, from brochures, } \\
\text { the internet, or the advice of others, that will } \\
\text { prepare me for coping during labor without } \\
\text { medications. }\end{array}$ & 1 & 2 & 3 & 4 & 5 \\
\hline $\begin{array}{l}\text { 42. I know that I can learn ways to cope with labor pain } \\
\text { on my own. }\end{array}$ & 1 & 2 & 3 & 4 & 5 \\
\hline $\begin{array}{l}\text { 43. I believe I can learn even more about getting ready } \\
\text { for childbirth. }\end{array}$ & 1 & 2 & 3 & 4 & 5 \\
\hline $\begin{array}{l}\text { 44. I'm ready to learn ways to cope with labor on my } \\
\text { own. }\end{array}$ & 1 & 2 & 3 & 4 & 5 \\
\hline $\begin{array}{l}\text { 45. I plan to find out more about ways to deal with } \\
\text { labor pain on my own. }\end{array}$ & 1 & 2 & 3 & 4 & 5 \\
\hline $\begin{array}{l}\text { 46. I have begun to practice a strategy that could help } \\
\text { me deal with childbirth pain. }\end{array}$ & 1 & 2 & 3 & 4 & 5 \\
\hline $\begin{array}{l}\text { 47. I have learned some skills to help myself cope with } \\
\text { labor pain. }\end{array}$ & 1 & 2 & 3 & 4 & 5 \\
\hline $\begin{array}{l}\text { 48. I am testing out some coping skills to use during } \\
\text { labor. }\end{array}$ & 1 & 2 & 3 & 4 & 5 \\
\hline $\begin{array}{l}\text { 49. I am learning ways to control my labor pain, other } \\
\text { than with medications or an epidural. }\end{array}$ & 1 & 2 & 3 & 4 & 5 \\
\hline
\end{tabular}




\begin{tabular}{|c|c|c|c|c|c|}
\hline & $\begin{array}{c}\text { Completely } \\
\text { disagree }\end{array}$ & Disagree & Neutral & Agree & $\begin{array}{c}\text { Completely } \\
\text { agree }\end{array}$ \\
\hline $\begin{array}{l}\text { 50. I believe that I have some self-management skills } \\
\text { to help me cope with labor pain. }\end{array}$ & 1 & 2 & 3 & 4 & 5 \\
\hline $\begin{array}{l}\text { 51. I know how to breathe properly during childbirth to } \\
\text { reduce discomfort. }\end{array}$ & 1 & 2 & 3 & 4 & 5 \\
\hline $\begin{array}{l}\text { 52. I know some coping skills, like breathing, to do } \\
\text { during labor, but I'm not sure l'll remember them. }\end{array}$ & 1 & 2 & 3 & 4 & 5 \\
\hline $\begin{array}{l}\text { 53. I've learned some skills about coping with labor, } \\
\text { but I'm not entirely comfortable with them yet. }\end{array}$ & 1 & 2 & 3 & 4 & 5 \\
\hline 54. I am going to try to have a natural childbirth. & 1 & 2 & 3 & 4 & 5 \\
\hline $\begin{array}{l}\text { 55. I would really like to have a natural childbirth, if I } \\
\text { can. }\end{array}$ & 1 & 2 & 3 & 4 & 5 \\
\hline $\begin{array}{l}\text { 56. I am practicing new ways to reduce discomfort } \\
\text { during labor. }\end{array}$ & 1 & 2 & 3 & 4 & 5 \\
\hline $\begin{array}{l}\text { 57. I'm trying to get good at self-management skills in } \\
\text { preparation for labor. }\end{array}$ & 1 & 2 & 3 & 4 & 5 \\
\hline $\begin{array}{l}\text { 58. I feel encouraged about using my own coping skills } \\
\text { during labor. }\end{array}$ & 1 & 2 & 3 & 4 & 5 \\
\hline 59. I am learning different ways to handle labor pain. & 1 & 2 & 3 & 4 & 5 \\
\hline $\begin{array}{l}\text { 60. I'm not quite sure that I've practiced my coping } \\
\text { skills enough yet to get through labor. }\end{array}$ & 1 & 2 & 3 & 4 & 5 \\
\hline $\begin{array}{l}\text { 61. I feel comfortable handling labor pain with little or } \\
\text { no medication. }\end{array}$ & 1 & 2 & 3 & 4 & 5 \\
\hline $\begin{array}{l}\text { 62. I believe that self-management skills are the best } \\
\text { way to handle labor pain. }\end{array}$ & 1 & 2 & 3 & 4 & 5 \\
\hline $\begin{array}{l}\text { 63. I believe that I can cope with labor pain using only } \\
\text { self-management strategies. }\end{array}$ & 1 & 2 & 3 & 4 & 5 \\
\hline $\begin{array}{l}\text { 64. No matter what pain I experience during labor, l'll } \\
\text { be able to use my self-management skills. }\end{array}$ & 1 & 2 & 3 & 4 & 5 \\
\hline $\begin{array}{l}\text { 65. I feel totally prepared to use self-management in } \\
\text { labor. }\end{array}$ & 1 & 2 & 3 & 4 & 5 \\
\hline $\begin{array}{l}\text { 66. I've learned a lot about coping during labor, and I } \\
\text { know l'll remember the skills. }\end{array}$ & 1 & 2 & 3 & 4 & 5 \\
\hline $\begin{array}{l}\text { 67. Given the skills l've learned, I'll be just fine during } \\
\text { labor. }\end{array}$ & 1 & 2 & 3 & 4 & 5 \\
\hline
\end{tabular}




\begin{tabular}{|c|c|c|c|c|c|}
\hline & $\begin{array}{l}\text { Completely } \\
\text { disagree }\end{array}$ & Disagree & Neutral & Agree & $\begin{array}{l}\text { Completely } \\
\text { agree }\end{array}$ \\
\hline $\begin{array}{l}\text { 68. During labor, I know that I am going to use } \\
\text { breathing exercises or other skills I've learned. }\end{array}$ & 1 & 2 & 3 & 4 & 5 \\
\hline $\begin{array}{l}\text { 69. With the skills I've learned, I know I can handle } \\
\text { labor. }\end{array}$ & 1 & 2 & 3 & 4 & 5 \\
\hline $\begin{array}{l}\text { 70. I have confidence that I can control my pain during } \\
\text { labor. }\end{array}$ & 1 & 2 & 3 & 4 & 5 \\
\hline $\begin{array}{l}\text { 71. There is no way l'll go through labor without using } \\
\text { my own coping skills. }\end{array}$ & 1 & 2 & 3 & 4 & 5 \\
\hline $\begin{array}{l}\text { 72. My own coping strategies will really reduce my } \\
\text { labor pain. }\end{array}$ & 1 & 2 & 3 & 4 & 5 \\
\hline $\begin{array}{l}\text { 73. I'm perfecting my coping skills in preparation for } \\
\text { labor. }\end{array}$ & 1 & 2 & 3 & 4 & 5 \\
\hline 74. I have skills all ready for my labor. & 1 & 2 & 3 & 4 & 5 \\
\hline $\begin{array}{l}\text { 75. I know l'm ready to use my own coping skills } \\
\text { during labor. }\end{array}$ & 1 & 2 & 3 & 4 & 5 \\
\hline
\end{tabular}


Appendix K

\section{CSOCQ Relevance Ratings}

INSTRUCTIONS: The items listed below describe different ideas or beliefs expectant mothers may hold concerning childbirth pain and labor. Please look at each statement and think about relevant you believe each item to be in relation to the Stages of Change information you have just heard. Please read each statement carefully and then a circle a symbol in the space to the right of each statement that indicates how relevant you believe each item to be, with " - " = completely irrelevant and " + + " completely relevant.

\begin{tabular}{|c|c|c|c|c|c|}
\hline & $\begin{array}{l}\text { Completely } \\
\text { irrelevant }\end{array}$ & Irrelevant & Neutral & Relevant & $\begin{array}{l}\text { Completely } \\
\text { relevant }\end{array}$ \\
\hline $\begin{array}{l}\text { 1. I haven't really thought about learning self- } \\
\text { management strategies to help cope with pain } \\
\text { during childbirth. }\end{array}$ & -- & - & 0 & + & ++ \\
\hline $\begin{array}{l}\text { 2. Learning self-management skills, like breathing } \\
\text { and relaxation, to manage my labor pain, is a } \\
\text { waste of my time. }\end{array}$ & -- & - & 0 & + & ++ \\
\hline $\begin{array}{l}\text { 3. I don't need to bother learning self-management } \\
\text { strategies because there are medical ways to } \\
\text { handle labor pain. }\end{array}$ & -- & - & 0 & + & ++ \\
\hline $\begin{array}{l}\text { 4. I believe that medications or an epidural are the } \\
\text { best ways to handle labor pain. }\end{array}$ & -- & - & 0 & + & ++ \\
\hline $\begin{array}{l}\text { 5. Knowing my own pain tolerance, I think l'll need } \\
\text { an epidural or medications during labor. }\end{array}$ & -- & - & 0 & + & ++ \\
\hline $\begin{array}{l}\text { 6. I believe that medications are the only effective } \\
\text { way to cope with childbirth pain. }\end{array}$ & -- & - & 0 & + & ++ \\
\hline $\begin{array}{l}\text { 7. It would be foolish not to use medications during } \\
\text { labor to help with pain. }\end{array}$ & -- & - & 0 & + & ++ \\
\hline 8. I can only handle labor pain with medication. & -- & - & 0 & + & ++ \\
\hline $\begin{array}{l}\text { 9. I don't think I have the ability to handle labor } \\
\text { pain on my own. }\end{array}$ & - - & - & 0 & + & ++ \\
\hline $\begin{array}{l}\text { 10. I plan on receiving medicine or an epidural } \\
\text { during labor. }\end{array}$ & - - & - & 0 & + & ++ \\
\hline $\begin{array}{l}\text { 11. It's not so important to learn to cope with labor } \\
\text { pain because you'll be taken care of in the } \\
\text { hospital. }\end{array}$ & - - & - & 0 & + & ++ \\
\hline $\begin{array}{l}\text { 12. I don't think it's worth the time to learn ways to } \\
\text { cope with labor pain. }\end{array}$ & -- & - & 0 & + & ++ \\
\hline $\begin{array}{l}\text { 13. I've heard that the only way to get through } \\
\text { childbirth is with an epidural. }\end{array}$ & - - & - & 0 & + & ++ \\
\hline
\end{tabular}




\begin{tabular}{|c|c|c|c|c|c|}
\hline & $\begin{array}{c}\text { Completely } \\
\text { irrelevant }\end{array}$ & Irrelevant & Neutral & Relevant & $\begin{array}{l}\text { Completely } \\
\text { relevant }\end{array}$ \\
\hline $\begin{array}{l}\text { 14. I don't see why someone would want to go } \\
\text { through the pain of natural childbirth. }\end{array}$ & -- & - & 0 & + & ++ \\
\hline 15. l've never considered natural childbirth. & - - & - & 0 & + & ++ \\
\hline $\begin{array}{l}\text { 16. I think I might be ready to learn some self- } \\
\text { management strategies to help cope with } \\
\text { childbirth pain. }\end{array}$ & - - & - & 0 & + & ++ \\
\hline $\begin{array}{l}\text { 17. I may be able to learn some ways to cope with } \\
\text { labor pain on my own. }\end{array}$ & -- & - & 0 & + & ++ \\
\hline $\begin{array}{l}\text { 18. It is possible that self-management strategies } \\
\text { may help ease my pain during labor. }\end{array}$ & - - & - & 0 & + & ++ \\
\hline $\begin{array}{l}\text { 19. I'm still considering whether to use medications } \\
\text { or natural childbirth. }\end{array}$ & -- & - & 0 & + & ++ \\
\hline $\begin{array}{l}\text { 20. I may be interested in learning ways to manage } \\
\text { labor pain on my own. }\end{array}$ & -- & - & 0 & + & ++ \\
\hline $\begin{array}{l}\text { 21. I'm not sure that self-management skills could } \\
\text { help ease my labor pain. }\end{array}$ & -- & - & 0 & + & ++ \\
\hline $\begin{array}{l}\text { 22. I'm going to look into learning some coping skills } \\
\text { for labor, but I'm not sure they are going to help. }\end{array}$ & - - & - & 0 & + & ++ \\
\hline $\begin{array}{l}\text { 23. I still wonder if self-management strategies, like } \\
\text { breathing exercises, could help me during labor. }\end{array}$ & -- & - & 0 & + & ++ \\
\hline $\begin{array}{l}\text { 24. I wonder whether I can help myself cope during } \\
\text { childbirth. }\end{array}$ & - - & - & 0 & + & ++ \\
\hline $\begin{array}{l}\text { 25. I've heard about ways that you can cope with } \\
\text { labor on your own, but I don't know a lot about } \\
\text { them. }\end{array}$ & -- & - & 0 & + & ++ \\
\hline $\begin{array}{l}\text { 26. I'm not sure if strategies I could learn would } \\
\text { work when the labor pain gets really intense. }\end{array}$ & - - & - & 0 & + & ++ \\
\hline $\begin{array}{l}\text { 27. I'm worried that self-management techniques } \\
\text { won't help enough during labor. }\end{array}$ & - & - & 0 & + & ++ \\
\hline $\begin{array}{l}\text { 28. I'm unsure whether my own coping skills are the } \\
\text { best way to deal with labor pain. }\end{array}$ & - & - & 0 & + & ++ \\
\hline $\begin{array}{l}\text { 29. I'm not sure I want to go without medications } \\
\text { during my labor. }\end{array}$ & -- & - & 0 & + & ++ \\
\hline $\begin{array}{l}\text { 30. I've heard that some women use only natural } \\
\text { childbirth techniques, but I'm not sure I could do } \\
\text { that. }\end{array}$ & - - & - & 0 & + & ++ \\
\hline
\end{tabular}


122

\begin{tabular}{|c|c|c|c|c|c|}
\hline & $\begin{array}{l}\text { Completely } \\
\text { irrelevant }\end{array}$ & Irrelevant & Neutral & Relevant & $\begin{array}{l}\text { Completely } \\
\text { relevant }\end{array}$ \\
\hline $\begin{array}{l}\text { 31. I've decided to learn some self-management } \\
\text { skills to help cope with childbirth pain. }\end{array}$ & -- & - & 0 & + & ++ \\
\hline $\begin{array}{l}\text { 32. I think there are techniques that I could use to } \\
\text { ease labor pain. }\end{array}$ & -- & - & 0 & + & ++ \\
\hline $\begin{array}{l}\text { 33. Self-management strategies are worth looking in } \\
\text { to as a way to cope with labor pain. }\end{array}$ & -- & - & 0 & + & ++ \\
\hline $\begin{array}{l}\text { 34. I have signed up for, or already taken, a class } \\
\text { that teaches ways of coping with labor. }\end{array}$ & -- & - & 0 & + & ++ \\
\hline $\begin{array}{l}\text { 35. I plan on getting more information about } \\
\text { childbirth coping skills. }\end{array}$ & -- & - & 0 & + & ++ \\
\hline $\begin{array}{l}\text { 36. I plan on using techniques in addition to } \\
\text { medication, or instead of medication, to help } \\
\text { with pain during labor. }\end{array}$ & -- & - & 0 & + & ++ \\
\hline $\begin{array}{l}\text { 37. I plan to look for ways to cope with labor pain } \\
\text { other than medications or an epidural. }\end{array}$ & -- & - & 0 & + & ++ \\
\hline $\begin{array}{l}\text { 38. I will be exploring options for dealing with labor } \\
\text { pain other than medicine or an epidural. }\end{array}$ & -- & - & 0 & + & ++ \\
\hline $\begin{array}{l}\text { 39. I believe self-management methods will help me } \\
\text { during labor, but I haven't learned any yet. }\end{array}$ & -- & - & 0 & + & ++ \\
\hline $\begin{array}{l}\text { 40. I know there are things I can do on my own } \\
\text { during labor to help relieve pain, but I haven't } \\
\text { practiced yet. }\end{array}$ & -- & - & 0 & + & ++ \\
\hline $\begin{array}{l}\text { 41. I have information, for example, from brochures, } \\
\text { the internet, or the advice of others, that will } \\
\text { prepare me for coping during labor without } \\
\text { medications. }\end{array}$ & -- & - & 0 & + & ++ \\
\hline $\begin{array}{l}\text { 42. I know that I can learn ways to cope with labor } \\
\text { pain on my own. }\end{array}$ & -- & - & 0 & + & ++ \\
\hline $\begin{array}{l}\text { 43. I believe I can learn even more about getting } \\
\text { ready for childbirth. }\end{array}$ & -- & - & 0 & + & ++ \\
\hline $\begin{array}{l}\text { 44. I'm ready to learn ways to cope with labor on my } \\
\text { own. }\end{array}$ & -- & - & 0 & + & ++ \\
\hline $\begin{array}{l}\text { 45. I plan to find out more about ways to deal with } \\
\text { labor pain on my own. }\end{array}$ & -- & - & 0 & + & ++ \\
\hline $\begin{array}{l}\text { 46. I have begun to practice a strategy that could } \\
\text { help me deal with childbirth pain. }\end{array}$ & -- & - & 0 & + & ++ \\
\hline
\end{tabular}




\begin{tabular}{|c|c|c|c|c|c|}
\hline & $\begin{array}{l}\text { Completely } \\
\text { irrelevant }\end{array}$ & Irrelevant & Neutral & Relevant & $\begin{array}{l}\text { Completely } \\
\text { relevant }\end{array}$ \\
\hline $\begin{array}{l}\text { 47. I have learned some skills to help myself cope } \\
\text { with labor pain. }\end{array}$ & -- & - & 0 & + & ++ \\
\hline $\begin{array}{l}\text { 48. I am testing out some coping skills to use during } \\
\text { labor. }\end{array}$ & -- & - & 0 & + & ++ \\
\hline $\begin{array}{l}\text { 49. I am learning ways to control my labor pain, } \\
\text { other than with medications or an epidural. }\end{array}$ & -- & - & 0 & + & ++ \\
\hline $\begin{array}{l}\text { 50. I believe that I have some self-management } \\
\text { skills to help me cope with labor pain. }\end{array}$ & - - & - & 0 & + & ++ \\
\hline $\begin{array}{l}\text { 51. I know how to breathe properly during childbirth } \\
\text { to reduce discomfort. }\end{array}$ & -- & - & 0 & + & ++ \\
\hline $\begin{array}{l}\text { 52. I know some coping skills, like breathing, to do } \\
\text { during labor, but l'm not sure l'll remember } \\
\text { them. }\end{array}$ & -- & - & 0 & + & ++ \\
\hline $\begin{array}{l}\text { 53. I've learned some skills about coping with labor, } \\
\text { but l'm not entirely comfortable with them yet. }\end{array}$ & -- & - & 0 & + & ++ \\
\hline 54. I am going to try to have a natural childbirth. & -- & - & 0 & + & ++ \\
\hline $\begin{array}{l}\text { 55. I would really like to have a natural childbirth, if I } \\
\text { can. }\end{array}$ & -- & - & 0 & + & ++ \\
\hline $\begin{array}{l}\text { 56. I am practicing new ways to reduce discomfort } \\
\text { during labor. }\end{array}$ & -- & - & 0 & + & ++ \\
\hline $\begin{array}{l}\text { 57. I'm trying to get good at self-management skills } \\
\text { in preparation for labor. }\end{array}$ & -- & - & 0 & + & ++ \\
\hline $\begin{array}{l}\text { 58. I feel encouraged about using my own coping } \\
\text { skills during labor. }\end{array}$ & -- & - & 0 & + & ++ \\
\hline $\begin{array}{l}\text { 59. I am learning different ways to handle labor } \\
\text { pain. }\end{array}$ & -- & - & 0 & + & ++ \\
\hline $\begin{array}{l}\text { 60. I'm not quite sure that I've practiced my coping } \\
\text { skills enough yet to get through labor. }\end{array}$ & -- & - & 0 & + & ++ \\
\hline $\begin{array}{l}\text { 61. I feel comfortable handling labor pain with little } \\
\text { or no medication. }\end{array}$ & -- & - & 0 & + & ++ \\
\hline $\begin{array}{l}\text { 62. I believe that self-management skills are the } \\
\text { best way to handle labor pain. }\end{array}$ & - - & - & 0 & + & ++ \\
\hline $\begin{array}{l}\text { 63. I believe that I can cope with labor pain using } \\
\text { only self-management strategies. }\end{array}$ & $--\mathrm{t}$ & - & 0 & + & ++ \\
\hline
\end{tabular}




\begin{tabular}{|c|c|c|c|c|c|}
\hline & $\begin{array}{l}\text { Completely } \\
\text { irrelevant }\end{array}$ & Irrelevant & Neutral & Relevant & $\begin{array}{l}\text { Completely } \\
\text { relevant }\end{array}$ \\
\hline $\begin{array}{l}\text { 64. No matter what pain I experience during labor, } \\
\text { I'll be able to use my self-management skills. }\end{array}$ & -- & - & 0 & + & ++ \\
\hline $\begin{array}{l}\text { 65. I feel totally prepared to use self-management in } \\
\text { labor. }\end{array}$ & -- & - & 0 & + & ++ \\
\hline $\begin{array}{l}\text { 66. I've learned a lot about coping during labor, and } \\
\text { I know l'll remember the skills. }\end{array}$ & -- & - & 0 & + & ++ \\
\hline $\begin{array}{l}\text { 67. Given the skills l've learned, l'll be just fine } \\
\text { during labor. }\end{array}$ & -- & - & 0 & + & ++ \\
\hline $\begin{array}{l}\text { 68. During labor, I know that I am going to use } \\
\text { breathing exercises or other skills I've learned. }\end{array}$ & -- & - & 0 & + & ++ \\
\hline $\begin{array}{l}\text { 69. With the skills I've learned, I know I can handle } \\
\text { labor. }\end{array}$ & - & - & 0 & + & ++ \\
\hline $\begin{array}{l}\text { 70. I have confidence that I can control my pain } \\
\text { during labor. }\end{array}$ & -- & - & 0 & + & ++ \\
\hline $\begin{array}{l}\text { 71. There is no way l'll go through labor without } \\
\text { using my own coping skills. }\end{array}$ & -- & - & 0 & + & ++ \\
\hline $\begin{array}{l}\text { 72. My own coping strategies will really reduce my } \\
\text { labor pain. }\end{array}$ & - & - & 0 & + & ++ \\
\hline $\begin{array}{l}\text { 73. I'm perfecting my coping skills in preparation for } \\
\text { labor. }\end{array}$ & -- & - & 0 & + & ++ \\
\hline 74. I have skills all ready for my labor. & -- & - & 0 & + & ++ \\
\hline $\begin{array}{l}\text { 75. I know l'm ready to use my own coping skills } \\
\text { during labor. }\end{array}$ & -- & - & 0 & + & ++ \\
\hline
\end{tabular}


Appendix L

\section{Preliminary CSOCQ: \\ Summary of Relevance Ratings \& Interview Data from Study 2}

\begin{tabular}{|c|c|c|c|c|}
\hline PRECONTEMPLATION ITEMS & $\begin{array}{l}\text { Participant } \\
\quad \# 1\end{array}$ & $\begin{array}{l}\text { Participant } \\
\# 2\end{array}$ & $\begin{array}{l}\text { Participant } \\
\text { \# } 3\end{array}$ & $\begin{array}{l}\text { Participant } \\
\text { Comments }\end{array}$ \\
\hline $\begin{array}{l}\text { 1. I haven't really thought about learning self- } \\
\text { management strategies to help cope with pain } \\
\text { during childbirth. }\end{array}$ & ++ & + & ++ & $\begin{array}{l}\text { Participant } 1 \\
\text { liked. }\end{array}$ \\
\hline $\begin{array}{l}\text { 2. Learning self-management skills, like breathing } \\
\text { and relaxation, to manage my labor pain, is a } \\
\text { waste of my time. }\end{array}$ & ++ & + & ++ & $\begin{array}{l}\text { Participant } 1 \\
\text { liked. }\end{array}$ \\
\hline $\begin{array}{l}\text { 3. I don't need to bother learning self-management } \\
\text { strategies because there are medical ways to } \\
\text { handle labor pain. }\end{array}$ & ++ & + & ++ & $\begin{array}{l}\text { Participant } 1 \\
\text { liked. }\end{array}$ \\
\hline $\begin{array}{l}\text { 4. I believe that medications or an epidural are the } \\
\text { best ways to handle labor pain. }\end{array}$ & ++ & + & ++ & $\begin{array}{l}\text { Participant } 1 \\
\text { liked. }\end{array}$ \\
\hline $\begin{array}{l}\text { 5. Knowing my own pain tolerance, I think I'll need } \\
\text { an epidural or medications during labor. }\end{array}$ & ++ & + & ++ & \\
\hline $\begin{array}{l}\text { 6. I believe that medications are the only effective } \\
\text { way to cope with childbirth pain. }\end{array}$ & ++ & + & ++ & \\
\hline $\begin{array}{l}\text { 7. It would be foolish not to use medications during } \\
\text { labor to help with pain. }\end{array}$ & ++ & + & ++ & \\
\hline 8. I can only handle labor pain with medication. & ++ & + & ++ & \\
\hline $\begin{array}{l}\text { 9. I don't think I have the ability to handle labor } \\
\text { pain on my own. }\end{array}$ & ++ & + & ++ & \\
\hline $\begin{array}{l}\text { 10. I plan on receiving medicine or an epidural } \\
\text { during labor. }\end{array}$ & ++ & + & ++ & \\
\hline $\begin{array}{l}\text { 11. It's not so important to learn to cope with labor } \\
\text { pain because you'll be taken care of in the } \\
\text { hospital. }\end{array}$ & ++ & + & ++ & $\begin{array}{l}\text { Participant } 1 \\
\text { liked. }\end{array}$ \\
\hline $\begin{array}{l}\text { 12. I don't think it's worth the time to learn ways to } \\
\text { cope with labor pain. }\end{array}$ & ++ & + & + & $\begin{array}{l}\text { Maybe add "why" } \\
\text { such as "I know it } \\
\text { won't work." (3) }\end{array}$ \\
\hline $\begin{array}{l}\text { 13. I've heard that the only way to get through } \\
\text { childbirth is with an epidural. }\end{array}$ & ++ & + & ++ & \\
\hline $\begin{array}{l}\text { 14. I don't see why someone would want to go } \\
\text { through the pain of natural childbirth. }\end{array}$ & ++ & ++ & ++ & \\
\hline 15. I've never considered natural childbirth. & ++ & ++ & ++ & \\
\hline
\end{tabular}




\begin{tabular}{|c|c|c|c|c|}
\hline CONTEMPLATION ITEMS & $\begin{array}{l}\text { Participant } \\
\quad \# 1\end{array}$ & $\begin{array}{l}\text { Participant } \\
\quad \# 2\end{array}$ & $\begin{array}{l}\text { Participant } \\
\quad \text { \# } 3\end{array}$ & $\begin{array}{l}\text { Participant } \\
\text { Comments }\end{array}$ \\
\hline $\begin{array}{l}\text { 16. I think I might be ready to learn some self- } \\
\text { management strategies to help cope with } \\
\text { childbirth pain. }\end{array}$ & ++ & + & ++ & \\
\hline $\begin{array}{l}\text { 17. I may be able to learn some ways to cope with } \\
\text { labor pain on my own. }\end{array}$ & ++ & + & ++ & \\
\hline $\begin{array}{l}\text { 18. It is possible that self-management strategies } \\
\text { may help ease my pain during labor. }\end{array}$ & ++ & + & ++ & \\
\hline $\begin{array}{l}\text { 19. I'm still considering whether to use medications } \\
\text { or natural childbirth. }\end{array}$ & ++ & ++ & ++ & \\
\hline $\begin{array}{l}\text { 20. I may be interested in learning ways to manage } \\
\text { labor pain on my own. }\end{array}$ & ++ & + & ++ & \\
\hline $\begin{array}{l}\text { 21. I'm not sure that self-management skills could } \\
\text { help ease my labor pain. }\end{array}$ & ++ & + & + & \\
\hline $\begin{array}{l}\text { 22. I'm going to look into learning some coping } \\
\text { skills for labor, but I'm not sure they are going to } \\
\text { help. }\end{array}$ & ++ & + & ++ & Prefers 22 to 21. \\
\hline $\begin{array}{l}\text { 23. I still wonder if self-management strategies, like } \\
\text { breathing exercises, could help me during labor. }\end{array}$ & ++ & + & ++ & $\begin{array}{l}\text { Participant } 3 \\
\text { liked. }\end{array}$ \\
\hline $\begin{array}{l}\text { 24. I wonder whether I can help myself cope during } \\
\text { childbirth. }\end{array}$ & 0 & + & ++ & \\
\hline $\begin{array}{l}\text { 25. I've heard about ways that you can cope with } \\
\text { labor on your own, but I don't know a lot about } \\
\text { them. }\end{array}$ & ++ & + & ++ & \\
\hline $\begin{array}{l}\text { 26. I'm not sure if strategies I could learn would } \\
\text { work when the labor pain gets really intense. }\end{array}$ & 0 & ++ & + & $\begin{array}{l}\text { Maybe add "or if I } \\
\text { could keep } \\
\text { focused" }\end{array}$ \\
\hline $\begin{array}{l}\text { 27. I'm worried that self-management techniques } \\
\text { won't help enough during labor. }\end{array}$ & + & ++ & ++ & $\begin{array}{l}\text { Participant } 3 \\
\text { liked. }\end{array}$ \\
\hline $\begin{array}{l}\text { 28. I'm unsure whether my own coping skills are the } \\
\text { best way to deal with labor pain. }\end{array}$ & ++ & + & ++ & \\
\hline $\begin{array}{l}\text { 29. I'm not sure I want to go without medications } \\
\text { during my labor. }\end{array}$ & ++ & + & ++ & \\
\hline $\begin{array}{l}\text { 30. I've heard that some women use only natural } \\
\text { childbirth techniques, but I'm not sure I could do } \\
\text { that. }\end{array}$ & 0 & + & ++ & \\
\hline
\end{tabular}




\begin{tabular}{|c|c|c|c|c|}
\hline PREPARATION ITEMS & $\begin{array}{l}\text { Participant } \\
\quad \# 1\end{array}$ & $\begin{array}{l}\text { Participant } \\
\quad \# 2\end{array}$ & $\begin{array}{l}\text { Participant } \\
\quad \# 3\end{array}$ & $\begin{array}{l}\text { Participant } \\
\text { Comments }\end{array}$ \\
\hline $\begin{array}{l}\text { 31. I've decided to learn some self-management } \\
\text { skills to help cope with childbirth pain. }\end{array}$ & ++ & + & ++ & \\
\hline $\begin{array}{l}\text { 32. I think there are techniques that I could use to } \\
\text { ease labor pain. }\end{array}$ & ++ & + & ++ & \\
\hline $\begin{array}{l}\text { 33. Self-management strategies are worth looking } \\
\text { in to as a way to cope with labor pain. }\end{array}$ & ++ & + & ++ & $\begin{array}{l}\text { Participant } 3 \\
\text { liked. }\end{array}$ \\
\hline $\begin{array}{l}\text { 34. I have signed up for, or already taken, a class } \\
\text { that teaches ways of coping with labor. }\end{array}$ & ++ & ++ & ++ & $\begin{array}{l}\text { Participant } 1 \\
\text { liked. }\end{array}$ \\
\hline $\begin{array}{l}\text { 35. I plan on getting more information about } \\
\text { childbirth coping skills. }\end{array}$ & ++ & + & ++ & $\begin{array}{l}\text { Participant } 1 \\
\text { liked. }\end{array}$ \\
\hline $\begin{array}{l}\text { 36. I plan on using techniques in addition to } \\
\text { medication, or instead of medication, to help } \\
\text { with pain during labor. }\end{array}$ & ++ & ++ & ++ & $\begin{array}{l}\text { One participant } \\
\text { prefers over } 37 .\end{array}$ \\
\hline $\begin{array}{l}\text { 37. I plan to look for ways to cope with labor pain } \\
\text { other than medications or an epidural. }\end{array}$ & ++ & ++ & + & \\
\hline $\begin{array}{l}\text { 38. I will be exploring options for dealing with labor } \\
\text { pain other than medicine or an epidural. }\end{array}$ & ++ & ++ & ++ & \\
\hline $\begin{array}{l}\text { 39. I believe self-management methods will help me } \\
\text { during labor, but I haven't learned any yet. }\end{array}$ & 0 & + & ++ & \\
\hline $\begin{array}{l}\text { 40. I know there are things I can do on my own } \\
\text { during labor to help relieve pain, but I haven't } \\
\text { practiced yet. }\end{array}$ & 0 & + & ++ & \\
\hline $\begin{array}{l}\text { 41. I have information, for example, from brochures, } \\
\text { the internet, or the advice of others, that will } \\
\text { prepare me for coping during labor without } \\
\text { medications. }\end{array}$ & ++ & + & ++ & \\
\hline $\begin{array}{l}\text { 42. I know that I can learn ways to cope with labor } \\
\text { pain on my own. }\end{array}$ & 0 & + & ++ & \\
\hline $\begin{array}{l}\text { 43. I believe I can learn even more about getting } \\
\text { ready for childbirth. }\end{array}$ & 0 & + & ++ & \\
\hline $\begin{array}{l}\text { 44. I'm ready to learn ways to cope with labor on } \\
\text { my own. }\end{array}$ & ++ & + & ++ & \\
\hline $\begin{array}{l}\text { 45. I plan to find out more about ways to deal with } \\
\text { labor pain on my own. }\end{array}$ & ++ & + & ++ & \\
\hline
\end{tabular}


128

\begin{tabular}{|c|c|c|c|c|}
\hline ACTION ITEMS & $\begin{array}{l}\text { Participant } \\
\quad \# 1\end{array}$ & $\begin{array}{l}\text { Participant } \\
\quad \text { \#2 }\end{array}$ & $\begin{array}{l}\text { Participant } \\
\quad \text { \# } 3\end{array}$ & $\begin{array}{l}\text { Participant } \\
\text { Comments }\end{array}$ \\
\hline $\begin{array}{l}\text { 46. I have begun to practice a strategy that could } \\
\text { help me deal with childbirth pain. }\end{array}$ & ++ & ++ & ++ & \\
\hline $\begin{array}{l}\text { 47. I have learned some skills to help myself cope } \\
\text { with labor pain. }\end{array}$ & ++ & ++ & + & \\
\hline $\begin{array}{l}\text { 48. I am testing out some coping skills to use during } \\
\text { labor. }\end{array}$ & ++ & ++ & ++ & \\
\hline $\begin{array}{l}\text { 49. I am learning ways to control my labor pain, } \\
\text { other than with medications or an epidural. }\end{array}$ & ++ & ++ & ++ & \\
\hline $\begin{array}{l}\text { 50. I believe that I have some self-management } \\
\text { skills to help me cope with labor pain. }\end{array}$ & ++ & + & 0 & \\
\hline $\begin{array}{l}\text { 51. I know how to breathe properly during childbirth } \\
\text { to reduce discomfort. }\end{array}$ & ++ & + & + & \\
\hline $\begin{array}{l}\text { 52. I know some coping skills, like breathing, to do } \\
\text { during labor, but I'm not sure I'll remember } \\
\text { them. }\end{array}$ & 0 & + & ++ & \\
\hline $\begin{array}{l}\text { 53. I've learned some skills about coping with labor, } \\
\text { but I'm not entirely comfortable with them yet. }\end{array}$ & 0 & ++ & ++ & \\
\hline 54. I am going to try to have a natural childbirth. & 0 & + & ++ & \\
\hline $\begin{array}{l}\text { 55. I would really like to have a natural childbirth, if I } \\
\text { can. }\end{array}$ & ++ & + & ++ & \\
\hline $\begin{array}{l}\text { 56. I am practicing new ways to reduce discomfort } \\
\text { during labor. }\end{array}$ & ++ & ++ & + & \\
\hline $\begin{array}{l}\text { 57. I'm trying to get good at self-management skills } \\
\text { in preparation for labor. }\end{array}$ & ++ & ++ & ++ & \\
\hline $\begin{array}{l}\text { 58. I feel encouraged about using my own coping } \\
\text { skills during labor. }\end{array}$ & ++ & + & ++ & \\
\hline $\begin{array}{l}\text { 59. I am learning different ways to handle labor } \\
\text { pain. }\end{array}$ & ++ & ++ & 0 & \\
\hline $\begin{array}{l}\text { 60. I'm not quite sure that l've practiced my coping } \\
\text { skills enough yet to get through labor. }\end{array}$ & 0 & + & ++ & \\
\hline
\end{tabular}


129

\begin{tabular}{|c|c|c|c|c|}
\hline MAINTENANCE ITEMS & $\begin{array}{l}\text { Participant } \\
\quad \# 1\end{array}$ & $\begin{array}{l}\text { Participant } \\
\quad \# 2\end{array}$ & $\begin{array}{l}\text { Participant } \\
\quad \text { \# } 3\end{array}$ & $\begin{array}{l}\text { Participant } \\
\text { Comments }\end{array}$ \\
\hline $\begin{array}{l}\text { 61. I feel comfortable handling labor pain with little } \\
\text { or no medication. }\end{array}$ & ++ & ++ & ++ & \\
\hline $\begin{array}{l}\text { 62. I believe that self-management skills are the } \\
\text { best way to handle labor pain. }\end{array}$ & ++ & ++ & ++ & \\
\hline $\begin{array}{l}\text { 63. I believe that I can cope with labor pain using } \\
\text { only self-management strategies. }\end{array}$ & ++ & + & ++ & \\
\hline $\begin{array}{l}\text { 64. No matter what pain I experience during labor, } \\
\text { I'll be able to use my self-management skills. }\end{array}$ & ++ & + & ++ & $\begin{array}{l}\text { Participant } 3 \\
\text { liked. } \\
\text { "Really good" } \\
\text { (item) for } \\
\text { including "no } \\
\text { matter what." }\end{array}$ \\
\hline $\begin{array}{l}\text { 65. I feel totally prepared to use self-management } \\
\text { in labor. }\end{array}$ & ++ & ++ & ++ & \\
\hline $\begin{array}{l}\text { 66. I've learned a lot about coping during labor, and } \\
\text { I know I'll remember the skills. }\end{array}$ & ++ & + & ++ & \\
\hline $\begin{array}{l}\text { 67. Given the skills I've learned, I'll be just fine } \\
\text { during labor. }\end{array}$ & 0 & + & ++ & $\begin{array}{l}\text { Participant } 1 \\
\text { disliked. }\end{array}$ \\
\hline $\begin{array}{l}\text { 68. During labor, I know that I am going to use } \\
\text { breathing exercises or other skills I've learned. }\end{array}$ & ++ & ++ & ++ & \\
\hline $\begin{array}{l}\text { 69. With the skills I've learned, I know I can handle } \\
\text { labor. }\end{array}$ & 0 & + & ++ & $\begin{array}{l}\text { Participant } 1 \\
\text { disliked. }\end{array}$ \\
\hline $\begin{array}{l}\text { 70. I have confidence that I can control my pain } \\
\text { during labor. }\end{array}$ & 0 & ++ & ++ & $\begin{array}{l}\text { Participant } 1 \\
\text { disliked. }\end{array}$ \\
\hline $\begin{array}{l}\text { 71. There is no way l'll go through labor without } \\
\text { using my own coping skills. }\end{array}$ & ++ & + & $\begin{array}{l}\text { Didn't } \\
\text { Reply }\end{array}$ & $\begin{array}{l}\text { Participant } 3 \\
\text { disliked } \\
\text { ("confusing"). }\end{array}$ \\
\hline $\begin{array}{l}\text { 72. My own coping strategies will really reduce my } \\
\text { labor pain. }\end{array}$ & ++ & + & ++ & \\
\hline $\begin{array}{l}\text { 73. I'm perfecting my coping skills in preparation for } \\
\text { labor. }\end{array}$ & ++ & ++ & ++ & \\
\hline 74. I have skills all ready for my labor. & ++ & ++ & ++ & \\
\hline $\begin{array}{l}\text { 75. I know l'm ready to use my own coping skills } \\
\text { during labor. }\end{array}$ & ++ & ++ & ++ & \\
\hline
\end{tabular}




\section{General Comments on Preliminary CSCOQ Items \\ (Interview Data from Study 2)}

Participant \# 1: $\quad$ Favorite items: Likes \# 1, 2, 3, 4, 11, 34, and 35.

Disliked items \# 67, 69, and 70. Felt they missed the concept and assessed confidence instead (someone may have all the skills, for example, but not know for sure they can handle it because anything could happen during labor, e.g., baby in distress, that could remove their control).

Felt an over-emphasis on breathing and relaxation. She said her childbirth classes focused less on breathing and more on physical things you could do (e.g., positions, music, pictures).

Poorly worded items: Said there is not always a way to practice the skills beforehand or it is not necessary (e.g., shower, walking) and we should take that into account.

Felt was missing: seeking out resources from the hospital that you give birth at.

Participant \# 2: $\quad$ Marked particularly relevant items with a ++ . None poorly worded, nothing missing.

Feels measure may not be relevant for women having planned c-sections.

Participant \# 3: $\quad$ Liked item \# 24.

Disliked item \# 71 ("it's confusing").

Wrote "without medication? Or with? Perhaps add "and only my own coping skills."

Felt was missing: an explicit question about refusal of meds, determined to go without meds.

Noted redundancies in items and picked what she felt was the best one.

$4 \& 6$ almost same statement.

$5,8, \& 9$ almost same.

12: maybe add "why" such as "I know it won't work."

21 and 22 almost same, prefers 22.

26: maybe add "or if I could keep focused"

36 and 37 almost same, prefers 36 ("more thorough")

Prefers 49 to 47

Prefers 52 to 51 .

Items that should be in different stages: 51 \& 52 (preferred 52 over 51) 
Appendix M

Items for Study 3:

Examination of CSOCQ-pilot by Undergraduate Women

(50 items)

[Best 10 items per stage, as agreed upon in consensus meeting of 2 independent raters] PRECONTEMPLATION

1. I haven't really thought about learning self-management strategies to help cope with pain during childbirth.

2. Learning self-management skills, like breathing and relaxation, to manage my labor pain, is a waste of my time.

3. I don't need to bother learning self-management strategies because there are medical ways to handle labor pain.

4. I believe that medications or an epidural are the best ways to handle labor pain.

5. Knowing my own pain tolerance, I think l'll need an epidural or medications during labor.

6. It would be foolish not to use medications during labor to help with pain.

7. I don't think I have the ability to handle labor pain on my own.

8. It's not so important to learn to cope with labor pain because you'll be taken care of in the hospital.

9. I don't see why someone would want to go through the pain of natural childbirth.

10. I've never considered natural childbirth.

\section{CONTEMPLATION}

11. I think I might be ready to learn some self-management strategies to help cope with childbirth pain.

12. I may be able to learn some ways to cope with labor pain on my own.

13. It is possible that self-management strategies may help ease my pain during labor.

14. I'm still considering whether to use medications or natural childbirth.

15. I'm going to look into learning some coping skills for labor, but l'm not sure they are going to help. 
16. I still wonder if self-management strategies, like breathing exercises, could help me during labor.

17. I've heard about ways that you can cope with labor on your own, but I don't know a lot about them.

18. I'm worried that self-management techniques won't help enough during labor.

19. I'm unsure whether my own coping skills are the best way to deal with labor pain.

20. I'm not sure I want to go without medications during my labor.

\section{PREPARATION}

21. I've decided to learn some self-management skills to help cope with childbirth pain.

22. Self-management strategies are worth looking in to as a way to cope with labor pain.

23. I have signed up for, or already taken, a class that teaches ways of coping with labor.

24. I plan on getting more information about childbirth coping skills.

25. I plan on using techniques in addition to medication, or instead of medication, to help with pain during labor.

26. I will be exploring options for dealing with labor pain other than medicine or an epidural.

27. I know there are things I can do on my own during labor to help relieve pain, but I haven't practiced yet.

28. I know that I can learn ways to cope with labor pain on my own.

29. I'm ready to learn ways to cope with labor on my own.

30. I plan to find out more about ways to deal with labor pain on my own.

\section{ACTION}

31. I have begun to practice a strategy that could help me deal with childbirth pain.

32. I have learned some skills to help myself cope with labor pain.

33. I am testing out some coping skills to use during labor.

34. I am learning ways to control my labor pain, other than with medications or an epidural.

35. I know some coping skills, like breathing, to do during labor, but I'm not sure I'll remember them. 
36. I've learned some skills about coping with labor, but l'm not entirely comfortable with them yet.

37. I would really like to have a natural childbirth, if I can.

38. I am practicing new ways to reduce discomfort during labor.

39. I'm trying to get good at self-management skills in preparation for labor.

40. I feel encouraged about using my own coping skills during labor.

\section{MAINTENANCE}

41. I feel comfortable handling labor pain with little or no medication.

42. I believe that self-management skills are the best way to handle labor pain.

43. No matter what pain I experience during labor, l'll be able to use my self-management skills.

44. I feel totally prepared to use self-management in labor.

45. I've learned a lot about coping during labor, and I know l'll remember the skills.

46. During labor, I know that I am going to use breathing exercises or other skills I've learned.

47. My own coping strategies will really reduce my labor pain.

48. I'm perfecting my coping skills in preparation for labor.

49. I have skills all ready for my labor.

50. I know l'm ready to use my own coping skills during labor. 
Appendix N: CSOCQ - pilot

\section{Coping with Labor Pain Questionnaire}

INSTRUCTIONS: The items listed below describe different ideas or beliefs expectant mothers may hold concerning childbirth pain and labor. Please look at each statement and think about how much each item applies to you, keeping in mind the pregnancy instructions and the self-management definition you just read. Please read each statement carefully and then a circle a number in the space to the right of each statement that indicates how much you agree with each item in relation to your own imagined pregnancy, with $1=$ completely disagree and $5=$ completely agree.

\begin{tabular}{|c|c|c|c|c|c|}
\hline & $\begin{array}{c}\text { Completely } \\
\text { disagree }\end{array}$ & Disagree & Neutral & Agree & $\begin{array}{l}\text { Completely } \\
\text { agree }\end{array}$ \\
\hline $\begin{array}{l}\text { 1. I may be able to learn some ways to cope } \\
\text { with labor pain on my own. }\end{array}$ & 1 & 2 & 3 & 4 & 5 \\
\hline $\begin{array}{l}\text { 2. I plan on getting more information about } \\
\text { childbirth coping skills. }\end{array}$ & 1 & 2 & 3 & 4 & 5 \\
\hline $\begin{array}{l}\text { 3. I would really like to have a natural } \\
\text { childbirth, if I can. }\end{array}$ & 1 & 2 & 3 & 4 & 5 \\
\hline $\begin{array}{l}\text { 4. I know there are things I can do on my own } \\
\text { during labor to help relieve pain, but I } \\
\text { haven't practiced yet. }\end{array}$ & 1 & 2 & 3 & 4 & 5 \\
\hline $\begin{array}{l}\text { 5. I'm going to look into learning some coping } \\
\text { skills for labor, but I'm not sure they are } \\
\text { going to help. }\end{array}$ & 1 & 2 & 3 & 4 & 5 \\
\hline $\begin{array}{l}\text { 6. I'm trying to get good at self-management } \\
\text { skills in preparation for labor. }\end{array}$ & 1 & 2 & 3 & 4 & 5 \\
\hline $\begin{array}{l}\text { 7. I'm worried that self-management } \\
\text { techniques won't help enough during labor. }\end{array}$ & 1 & 2 & 3 & 4 & 5 \\
\hline $\begin{array}{l}\text { 8. I am practicing new ways to reduce } \\
\text { discomfort during labor. }\end{array}$ & 1 & 2 & 3 & 4 & 5 \\
\hline $\begin{array}{l}\text { 9. I've learned some skills about coping with } \\
\text { labor, but I'm not entirely comfortable with } \\
\text { them yet. }\end{array}$ & 1 & 2 & 3 & 4 & 5 \\
\hline $\begin{array}{l}\text { 10. My own coping strategies will really reduce } \\
\text { my labor pain. }\end{array}$ & 1 & 2 & 3 & 4 & 5 \\
\hline $\begin{array}{l}\text { 11. I've learned a lot about coping during labor, } \\
\text { and I know l'll remember the skills. }\end{array}$ & 1 & 2 & 3 & 4 & 5 \\
\hline $\begin{array}{l}\text { 12. I have learned some skills to help myself } \\
\text { cope with labor pain. }\end{array}$ & 1 & 2 & 3 & 4 & 5 \\
\hline $\begin{array}{l}\text { 13. I will be exploring options for dealing with } \\
\text { labor pain other than medicine or an } \\
\text { epidural. }\end{array}$ & 1 & 2 & 3 & 4 & 5 \\
\hline
\end{tabular}


135

\begin{tabular}{|c|c|c|c|c|c|}
\hline & $\begin{array}{c}\text { Completely } \\
\text { disagree }\end{array}$ & Disagree & Neutral & Agree & $\begin{array}{l}\text { Completely } \\
\text { agree }\end{array}$ \\
\hline $\begin{array}{l}\text { 14. I know that I can learn ways to cope with } \\
\text { labor pain on my own. }\end{array}$ & 1 & 2 & 3 & 4 & 5 \\
\hline $\begin{array}{l}\text { 15. It would be foolish not to use medications } \\
\text { during labor to help with pain. }\end{array}$ & 1 & 2 & 3 & 4 & 5 \\
\hline $\begin{array}{l}\text { 16. I'm not sure I want to go without } \\
\text { medications during my labor. }\end{array}$ & 1 & 2 & 3 & 4 & 5 \\
\hline $\begin{array}{l}\text { 17. I don't see why someone would want to go } \\
\text { through the pain of natural childbirth. }\end{array}$ & 1 & 2 & 3 & 4 & 5 \\
\hline $\begin{array}{l}\text { 18. I think I might be ready to learn some self- } \\
\text { management strategies to help cope with } \\
\text { childbirth pain. }\end{array}$ & 1 & 2 & 3 & 4 & 5 \\
\hline $\begin{array}{l}\text { 19. Self-management strategies are worth } \\
\text { looking in to as a way to cope with labor } \\
\text { pain. }\end{array}$ & 1 & 2 & 3 & 4 & 5 \\
\hline $\begin{array}{l}\text { 20. I know l'm ready to use my own coping } \\
\text { skills during labor. }\end{array}$ & 1 & 2 & 3 & 4 & 5 \\
\hline $\begin{array}{l}\text { 21. I plan to find out more about ways to deal } \\
\text { with labor pain on my own. }\end{array}$ & 1 & 2 & 3 & 4 & 5 \\
\hline $\begin{array}{l}\text { 22. I'm still considering whether to use } \\
\text { medications or natural childbirth. }\end{array}$ & 1 & 2 & 3 & 4 & 5 \\
\hline $\begin{array}{l}\text { 23. I've decided to learn some self- } \\
\text { management skills to help cope with } \\
\text { childbirth pain. }\end{array}$ & 1 & 2 & 3 & 4 & 5 \\
\hline $\begin{array}{l}\text { 24. I still wonder if self-management strategies, } \\
\text { like breathing exercises, could help me } \\
\text { during labor. }\end{array}$ & 1 & 2 & 3 & 4 & 5 \\
\hline $\begin{array}{l}\text { 25. I haven't really thought about learning self- } \\
\text { management strategies to help cope with } \\
\text { pain during childbirth. }\end{array}$ & 1 & 2 & 3 & 4 & 5 \\
\hline $\begin{array}{l}\text { 26. I'm ready to learn ways to cope with labor } \\
\text { on my own. }\end{array}$ & 1 & 2 & 3 & 4 & 5 \\
\hline $\begin{array}{l}\text { 27. I've heard about ways that you can cope } \\
\text { with labor on your own, but I don't know a } \\
\text { lot about them. }\end{array}$ & 1 & 2 & 3 & 4 & 5 \\
\hline 28. I've never considered natural childbirth. & 1 & 2 & 3 & 4 & 5 \\
\hline
\end{tabular}


136

\begin{tabular}{|c|c|c|c|c|c|}
\hline & $\begin{array}{c}\text { Completely } \\
\text { disagree }\end{array}$ & Disagree & Neutral & Agree & $\begin{array}{l}\text { Completely } \\
\text { agree }\end{array}$ \\
\hline $\begin{array}{l}\text { 29. It is possible that self-management } \\
\text { strategies may help ease my pain during } \\
\text { labor. }\end{array}$ & 1 & 2 & 3 & 4 & 5 \\
\hline $\begin{array}{l}\text { 30. No matter what pain I experience during } \\
\text { labor, l'll be able to use my self- } \\
\text { management skills. }\end{array}$ & 1 & 2 & 3 & 4 & 5 \\
\hline $\begin{array}{l}\text { 31. I am testing out some coping skills to use } \\
\text { during labor. }\end{array}$ & 1 & 2 & 3 & 4 & 5 \\
\hline $\begin{array}{l}\text { 32. I am learning ways to control my labor pain, } \\
\text { other than with medications or an epidural. }\end{array}$ & 1 & 2 & 3 & 4 & 5 \\
\hline $\begin{array}{l}\text { 33. I plan on using techniques in addition to } \\
\text { medication, or instead of medication, to } \\
\text { help with pain during labor. }\end{array}$ & 1 & 2 & 3 & 4 & 5 \\
\hline $\begin{array}{l}\text { 34. During labor, I know that I am going to use } \\
\text { breathing exercises or other skills I've } \\
\text { learned. }\end{array}$ & 1 & 2 & 3 & 4 & 5 \\
\hline $\begin{array}{l}\text { 35. I'm unsure whether my own coping skills } \\
\text { are the best way to deal with labor pain. }\end{array}$ & 1 & 2 & 3 & 4 & 5 \\
\hline $\begin{array}{l}\text { 36. I feel comfortable handling labor pain with } \\
\text { little or no medication. }\end{array}$ & 1 & 2 & 3 & 4 & 5 \\
\hline $\begin{array}{l}\text { 37. I have begun to practice a strategy that } \\
\text { could help me deal with childbirth pain. }\end{array}$ & 1 & 2 & 3 & 4 & 5 \\
\hline $\begin{array}{l}\text { 38. I know some coping skills, like breathing, to } \\
\text { do during labor, but l'm not sure l'll } \\
\text { remember them. }\end{array}$ & 1 & 2 & 3 & 4 & 5 \\
\hline $\begin{array}{l}\text { 39. I don't need to bother learning self- } \\
\text { management strategies because there are } \\
\text { medical ways to handle labor pain. }\end{array}$ & 1 & 2 & 3 & 4 & 5 \\
\hline $\begin{array}{l}\text { 40. I believe that self-management skills are } \\
\text { the best way to handle labor pain. }\end{array}$ & 1 & 2 & 3 & 4 & 5 \\
\hline $\begin{array}{l}\text { 41. I feel totally prepared to use self- } \\
\text { management in labor. }\end{array}$ & 1 & 2 & 3 & 4 & 5 \\
\hline $\begin{array}{l}\text { 42. It's not so important to learn to cope with } \\
\text { labor pain because you'll be taken care of } \\
\text { in the hospital. }\end{array}$ & 1 & 2 & 3 & 4 & 5 \\
\hline $\begin{array}{l}\text { 43. I have signed up for, or already taken, a } \\
\text { class that teaches ways of coping with } \\
\text { labor }\end{array}$ & 1 & 2 & 3 & 4 & 5 \\
\hline
\end{tabular}




\begin{tabular}{|c|c|c|c|c|c|}
\hline & $\begin{array}{l}\text { Completely } \\
\text { disagree }\end{array}$ & Disagree & Neutral & Agree & $\begin{array}{l}\text { Completely } \\
\text { agree }\end{array}$ \\
\hline $\begin{array}{l}\text { 44. Knowing my own pain tolerance, I think I'll } \\
\text { need an epidural or medications during } \\
\text { labor. }\end{array}$ & 1 & 2 & 3 & 4 & 5 \\
\hline $\begin{array}{l}\text { 45. I don't think I have the ability to handle } \\
\text { labor pain on my own. }\end{array}$ & 1 & 2 & 3 & 4 & 5 \\
\hline 46. I have skills all ready for my labor. & 1 & 2 & 3 & 4 & 5 \\
\hline $\begin{array}{l}\text { 47. I believe that medications or an epidural are } \\
\text { the best ways to handle labor pain. }\end{array}$ & 1 & 2 & 3 & 4 & 5 \\
\hline $\begin{array}{l}\text { 48. I feel encouraged about using my own } \\
\text { coping skills during labor. }\end{array}$ & 1 & 2 & 3 & 4 & 5 \\
\hline $\begin{array}{l}\text { 49. Learning self-management skills, like } \\
\text { breathing and relaxation, to manage my } \\
\text { labor pain, is a waste of my time. }\end{array}$ & 1 & 2 & 3 & 4 & 5 \\
\hline $\begin{array}{l}\text { 50. I'm perfecting my coping skills in } \\
\text { preparation for labor. }\end{array}$ & 1 & 2 & 3 & 4 & 5 \\
\hline
\end{tabular}


Appendix $\mathrm{O}$

Demographic Questionnaire

INSTRUCTIONS: Please answer the following items in the appropriate response spaces.

1. What is your age? years

2. What is your race or ethnic background? (please check one):

White/Caucasian, not Hispanic:

Black/African-American:

Asian-American:

Hispanic:

Native American:

Pacific Islander:

Other:

If other, please specify:

3. What is your marital status?

Single

Married

Live-in partner
Separated

Divorced

Widowed

4. How would you describe the place, or the type of place, that you most closely identify with (e.g., your hometown)? (please check one):

Rural (less than or equal to 2,500 residents):

Urban (more than 2,500 residents): 
5. Do you have any reason to believe that you are, or may be, pregnant? (please check one):

Yes:

No:

6. Have you ever been pregnant before? (please check one):

Yes:

No:

7. Have you ever given birth to a child before? (please check one):

Yes:

No:

8. Do you plan to have a child / children in your life? (please check one):

Yes: (if yes, complete \# 9-10)

No:

(if no, skip to \# 11)

9. If yes, when are you likely to have a child? (please write in answer):

Your likely age at the birth of first child:

10. If yes, how many children do you expect to have? of children 
11. What is the chance that you will have at least one child in your lifetime? (please check one):

$$
\begin{array}{r}
0-10 \%: \\
11-20 \%: \\
21-30 \%: \\
31-40 \%: \\
41-50 \%: \\
51-60 \%: \\
61-70 \%: \\
71-80 \%: \\
81-90 \%: \\
91-100 \%:
\end{array}
$$

12. Have you ever been through the pregnancy of a close friend or family member? (please check one):

Yes:

(if yes, complete \# 13)

No: (if no, skip to \# 14)

13. If yes, how many times?

14. Have you ever witnessed a child being born (in person, not on TV or film)? (please check): Yes:

No: 
15. Have you ever attended a childbirth class or a prenatal (OB/GYN or midwife) visit, either for yourself or with a family member or friend? (please check one):

Yes:

No:

16. Have you ever been fearful that you were pregnant, and you did not want to be? (please check one):

Yes:

No:

17. How much knowledge would you say you have about pregnancy? (please check one):

None:

A little:

Some:

A great deal:

18. How much knowledge would you say you have about childbirth (that is, labor and delivery)? (please check one):

None:

A little:

Some:

A great deal: 
19. How much knowledge would you say you have about the Stages of Change Model of behavior change, developed by Prochaska \& DiClemente? (please check one):

None:

A little:

Some:

A great deal: 
Appendix P

The questionnaire you are about to complete asks questions about self-management of childbirth pain.

What is self-management of childbirth pain?

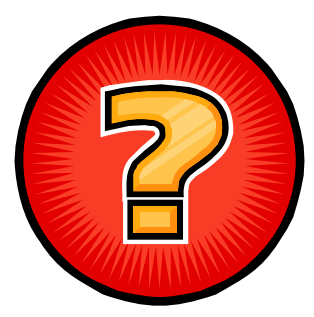

SELF-MANAGEMENT means using your own ways of coping with childbirth pain.

SELF-MANAGEMENT does not refer to medicines or epidurals. It does refer to:

- Lamaze techniques (relaxation, positioning, etc.)

- Breathing

- Walking or using birthing ball

- Distraction with music, movies, conversation, etc.

- Massage or back rub

- Bath or shower

- Imagery

- Self-hypnosis, use of a focus point, prayer

Any non-medical way of handling pain is SELF-MANAGEMENT. 
Appendix Q

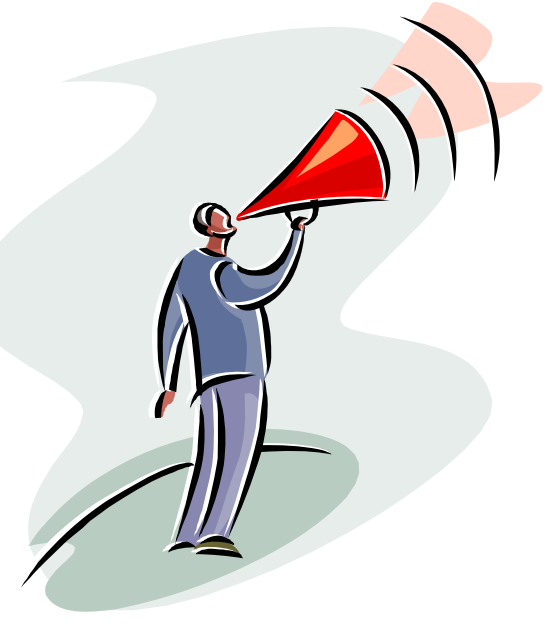

\section{IMPORTANT INSTRUCTIONS!} READ BEFORE CONTINUING !

\section{PLEASE IMAGINE THAT ...}

\section{You are pregnant right now}

2. You're in the $1^{\text {st }}$ month of a 9-month pregnancy

Thank you for your participation in this research! For the purpose of the study, it is important that you read the following instructions carefully before completing the following questionnaire.

As you complete the questionnaire, it is critical that you imagine that you are currently pregnant. Before beginning, please take a few moments to reflect on how you would think and feel if you were pregnant right now. Picture yourself in the first month of your pregnancy. This is a planned pregnancy. You discovered that you are expecting only last week. This is your first pregnancy. Throughout the questionnaire, please keep this scenario in mind and do your best to respond as if you were actually in the first month of a nine-month pregnancy.

Please read the yellow instructions before going on! 


\section{IMPORTANT INSTRUCTIONS!}

\section{READ BEFORE CONTINUING !}

PLEASE IMAGINE THAT ...

\section{You are pregnant right now}

\section{You're in the $5^{\text {th }}$ month of a 9-month pregnancy}

Thank you for your participation in this research! For the purpose of the study, it is important that you read the following instructions carefully before completing the following questionnaire.

As you complete the questionnaire, it is critical that you imagine that you are currently pregnant. Before beginning, please take a few moments to reflect on how you would think and feel if you were pregnant right now. Picture yourself in the fifth month of your pregnancy. This is a planned pregnancy. This is your first pregnancy. Throughout the questionnaire, please keep this scenario in mind and do your best to respond as if you were actually in the fifth month of a nine-month pregnancy.

Please read the yellow instructions before going on! 


\section{IMPORTANT INSTRUCTIONS!}

\section{READ BEFORE CONTINUING !}

PLEASE IMAGINE THAT ...

\section{You are pregnant right now}

\section{You're in the $9^{\text {th }}$ month of a 9-month pregnancy}

Thank you for your participation in this research! For the purpose of the study, it is important that you read the following instructions carefully before completing the following questionnaire.

As you complete the questionnaire, it is critical that you imagine that you are currently pregnant. Before beginning, please take a few moments to reflect on how you would think and feel if you were pregnant right now. Picture yourself in the ninth and final month of your pregnancy. This is a planned pregnancy. This is your first pregnancy. You are expecting your baby in just one week. Throughout the questionnaire, please keep this scenario in mind and do your best to respond as if you were actually in the ninth month of a nine-month pregnancy.

Please read the yellow instructions before going on! 
Appendix R

\section{Decisional Balance Worksheet}

\section{Instructions:}

When we think about making choices, most of us don't really consider all "sides” in a complete way. Instead, we often do what we think we "should” do, avoid doing things that we don't feel like doing, or just feel confused or overwhelmed and give up thinking about it at all. Thinking through the pros and cons of both making a choice and not making a choice is one way to help us make sure we have fully considered a possible decision. This can help us to "hang on" to our plan in times of stress or temptation. Below, write in all of the reasons that you can think of in the appropriate areas. In this instance, please consider all of the possible pros and cons of self-managing childbirth pain. Please consider the decision as it relates to you personally. Self-management means trying to use your own coping strategies to handle pain during labor (not including medications or drugs).

First, please consider the pros and cons of:

\section{CHOOSING TO SELF-MANAGE THE PAIN OF CHILDBIRTH}

\section{Benefits / Pros:}

\section{Costs / Cons:}




\section{Decisional Balance Worksheet, Continued}

Now please consider the other choice. Below, write in all of the reasons that you can think of in each of the appropriate areas. This time, please consider all of the possible pros and cons of not self-managing childbirth pain. Please consider the decision as it relates to you personally. Self-management means trying to use your own coping strategies to handle pain during labor (not including medications or drugs).

Second, please consider the pros and cons of:

CHOOSING NOT TO SELF-MANAGE THE PAIN OF CHILDBIRTH

Benefits / Pros:

Costs / Cons: 


\author{
Appendix S \\ Items for Study 4: \\ CSOCQ-Revised Administered to Expectant Mothers
}

(40 Items)

\title{
[Items produced from Study 3 Factor Analysis]
}

Note: Study \# 3 Factor Analysis:

4 factors produced, accounting for $52 \%$ of the variance in CSOCQ responding in Study 3

\section{PRECONTEMPLATION (Factor \# 2, accounted for 9\% of the variance in Study 3 responding)}

1. I believe that medications or an epidural are the best ways to handle labor pain.

2. It would be foolish not to use medications during labor to help with pain.

3. Knowing my own pain tolerance, I think l'll need an epidural or medications during labor.

4. I don't see why someone would want to go through the pain of natural childbirth.

5. I don't think I have the ability to handle labor pain on my own.

6. I've never considered natural childbirth.

7. I'm not sure I want to go without medications during my labor.

8. I don't need to bother learning self-management strategies because there are medical ways to handle labor pain.

\section{CONTEMPLATION}

(Factor \# 4, accounted for 4\% of the variance in Study 3 responding)

1. I know some coping skills, like breathing, to do during labor, but I'm not sure I'll remember them.

2. I still wonder if self-management strategies, like breathing exercises, could help me during labor.

3. I'm unsure whether my own coping skills are the best way to deal with labor pain.

4. I'm going to look into learning some coping skills for labor, but l'm not sure they are going to help.

5. I've learned some skills about coping with labor, but I'm not entirely comfortable with them yet.

6. I'm worried that self-management techniques won't help enough during labor.

\section{NEW contemplation item from the decisional balance data:}

7. I'm concerned that self-management strategies alone won't be enough to reduce my labor pain. 


\section{PREPARATION}

(Factor \# 3, accounted for 7\% of the variance in Study 3 responding)

1. I think I might be ready to learn some self-management strategies to help cope with childbirth pain.

2. I plan to find out more about ways to deal with labor pain on my own.

3. I will be exploring options for dealing with labor pain other than medicine or an epidural.

4. I know that I can learn ways to cope with labor pain on my own.

5. I may be able to learn some ways to cope with labor pain on my own.

6. I'm ready to learn ways to cope with labor on my own.

7. I've decided to learn some self-management skills to help cope with childbirth pain.

8. Self-management strategies are worth looking in to as a way to cope with labor pain.

9. It is possible that self-management strategies may help ease my pain during labor.

10. I plan on getting more information about childbirth coping skills.

ACTIONIMAINT. $\quad$ (Factor \# 1, accounted for 31\% of the variance in Study 3 responding)

1. I have begun to practice a strategy that could help me deal with childbirth pain.

2. I am practicing new ways to reduce discomfort during labor.

3. I have skills all ready for my labor. (Note: maintenance items are italicized.)

4. I am testing out some coping skills to use during labor.

5. I'm perfecting my coping skills in preparation for labor.

6. I have signed up for, or already taken, a class that teaches ways of coping with labor.

7. I know l'm ready to use my own coping skills during labor.

8. I have learned some skills to help myself cope with labor pain.

9. I've learned a lot about coping during labor, and I know l'll remember the skills.

10. I feel totally prepared to use self-management in labor.

11. I am learning ways to control my labor pain, other than with medications or an epidural.

12. I'm trying to get good at self-management skills in preparation for labor.

13. I feel encouraged about using my own coping skills during labor.

14. During labor, I know that I am going to use breathing exercises or other skills I've learned.

NEW maintenance item from the decisional balance data:

15. I'm convinced that it would be best for my baby's health if I use self-management strategies instead of medications during labor. 


\section{Coping with Labor Pain Questionnaire}

INSTRUCTIONS: The items listed below describe different ideas or beliefs expectant mothers may hold concerning childbirth pain and labor. Please look at each statement and think about how much each item applies to you, keeping in mind your own pregnancy and the self-management definition you just read. Please read each statement carefully and then a circle a number in the space to the right of each statement that indicates how much you agree with each item in relation to your own pregnancy, with $1=$ completely disagree and $5=$ completely agree.

\begin{tabular}{|c|c|c|c|c|c|}
\hline & $\begin{array}{c}\text { Completely } \\
\text { disagree }\end{array}$ & Disagree & Neutral & Agree & $\begin{array}{c}\text { Completely } \\
\text { agree }\end{array}$ \\
\hline $\begin{array}{l}\text { 1. I may be able to learn some ways to cope } \\
\text { with labor pain on my own. }\end{array}$ & 1 & 2 & 3 & 4 & 5 \\
\hline $\begin{array}{l}\text { 2. I have begun to practice a strategy that } \\
\text { could help me deal with childbirth pain. }\end{array}$ & 1 & 2 & 3 & 4 & 5 \\
\hline 3. I have skills all ready for my labor. & 1 & 2 & 3 & 4 & 5 \\
\hline 4. I've never considered natural childbirth. & 1 & 2 & 3 & 4 & 5 \\
\hline $\begin{array}{l}\text { 5. I'm concerned that self-management } \\
\text { strategies alone won't be enough to reduce } \\
\text { my labor pain. }\end{array}$ & 1 & 2 & 3 & 4 & 5 \\
\hline $\begin{array}{l}\text { 6. I don't need to bother learning self- } \\
\text { management strategies because there are } \\
\text { medical ways to handle labor pain. }\end{array}$ & 1 & 2 & 3 & 4 & 5 \\
\hline $\begin{array}{l}\text { 7. It is possible that self-management } \\
\text { strategies may help ease my pain during } \\
\text { labor. }\end{array}$ & 1 & 2 & 3 & 4 & 5 \\
\hline $\begin{array}{l}\text { 8. I'm convinced that it would be best for my } \\
\text { baby's health if I use self-management } \\
\text { strategies instead of medications during } \\
\text { labor. }\end{array}$ & 1 & 2 & 3 & 4 & 5 \\
\hline $\begin{array}{l}\text { 9. I think I might be ready to learn some self- } \\
\text { management strategies to help cope with } \\
\text { childbirth pain. }\end{array}$ & 1 & 2 & 3 & 4 & 5 \\
\hline $\begin{array}{l}\text { 10. I'm not sure I want to go without } \\
\text { medications during my labor. }\end{array}$ & 1 & 2 & 3 & 4 & 5 \\
\hline $\begin{array}{l}\text { 11. I still wonder if self-management strategies, } \\
\text { like breathing exercises, could help me } \\
\text { during labor. }\end{array}$ & 1 & 2 & 3 & 4 & 5 \\
\hline $\begin{array}{l}\text { 12. I believe that medications or an epidural are } \\
\text { the best ways to handle labor pain. }\end{array}$ & 1 & 2 & 3 & 4 & 5 \\
\hline
\end{tabular}


152

\begin{tabular}{|c|c|c|c|c|c|}
\hline & $\begin{array}{l}\text { Completely } \\
\text { disagree }\end{array}$ & Disagree & Neutral & Agree & $\begin{array}{l}\text { Completely } \\
\text { agree }\end{array}$ \\
\hline $\begin{array}{l}\text { 13. I have learned some skills to help myself } \\
\text { cope with labor pain. }\end{array}$ & 1 & 2 & 3 & 4 & 5 \\
\hline $\begin{array}{l}\text { 14. I plan on getting more information about } \\
\text { childbirth coping skills. }\end{array}$ & 1 & 2 & 3 & 4 & 5 \\
\hline $\begin{array}{l}\text { 15. I am testing out some coping skills to use } \\
\text { during labor. }\end{array}$ & 1 & 2 & 3 & 4 & 5 \\
\hline $\begin{array}{l}\text { 16. I plan to find out more about ways to deal } \\
\text { with labor pain on my own. }\end{array}$ & 1 & 2 & 3 & 4 & 5 \\
\hline $\begin{array}{l}\text { 17. It would be foolish not to use medications } \\
\text { during labor to help with pain. }\end{array}$ & 1 & 2 & 3 & 4 & 5 \\
\hline $\begin{array}{l}\text { 18. I'm worried that self-management } \\
\text { techniques won't help enough during labor. }\end{array}$ & 1 & 2 & 3 & 4 & 5 \\
\hline $\begin{array}{l}\text { 19. I've decided to learn some self- } \\
\text { management skills to help cope with } \\
\text { childbirth pain. }\end{array}$ & 1 & 2 & 3 & 4 & 5 \\
\hline $\begin{array}{l}\text { 20. I'm unsure whether my own coping skills } \\
\text { are the best way to deal with labor pain. }\end{array}$ & 1 & 2 & 3 & 4 & 5 \\
\hline $\begin{array}{l}\text { 21. I'm ready to learn ways to cope with labor } \\
\text { on my own. }\end{array}$ & 1 & 2 & 3 & 4 & 5 \\
\hline $\begin{array}{l}\text { 22. I feel totally prepared to use self- } \\
\text { management in labor. }\end{array}$ & 1 & 2 & 3 & 4 & 5 \\
\hline $\begin{array}{l}\text { 23. I am practicing new ways to reduce } \\
\text { discomfort during labor. }\end{array}$ & 1 & 2 & 3 & 4 & 5 \\
\hline $\begin{array}{l}\text { 24. I don't see why someone would want to go } \\
\text { through the pain of natural childbirth. }\end{array}$ & 1 & 2 & 3 & 4 & 5 \\
\hline $\begin{array}{l}\text { 25. I've learned some skills about coping with } \\
\text { labor, but l'm not entirely comfortable with } \\
\text { them yet. }\end{array}$ & 1 & 2 & 3 & 4 & 5 \\
\hline $\begin{array}{l}\text { 26. I am learning ways to control my labor pain, } \\
\text { other than with medications or an epidural. }\end{array}$ & 1 & 2 & 3 & 4 & 5 \\
\hline $\begin{array}{l}\text { 27. During labor, I know that I am going to use } \\
\text { breathing exercises or other skills l've } \\
\text { learned. }\end{array}$ & 1 & 2 & 3 & 4 & 5 \\
\hline $\begin{array}{l}\text { 28. Knowing my own pain tolerance, I think l'Il } \\
\text { need an epidural or medications during } \\
\text { labor. }\end{array}$ & 1 & 2 & 3 & 4 & 5 \\
\hline
\end{tabular}


153

\begin{tabular}{|c|c|c|c|c|c|}
\hline & $\begin{array}{c}\text { Completely } \\
\text { disagree }\end{array}$ & Disagree & Neutral & Agree & $\begin{array}{l}\text { Completely } \\
\text { agree }\end{array}$ \\
\hline $\begin{array}{l}\text { 29. I'm trying to get good at self-management } \\
\text { skills in preparation for labor. }\end{array}$ & 1 & 2 & 3 & 4 & 5 \\
\hline $\begin{array}{l}\text { 30. Self-management strategies are worth } \\
\text { looking in to as a way to cope with labor } \\
\text { pain. }\end{array}$ & 1 & 2 & 3 & 4 & 5 \\
\hline $\begin{array}{l}\text { 31. I have signed up for, or already taken, a } \\
\text { class that teaches ways of coping with } \\
\text { labor. }\end{array}$ & 1 & 2 & 3 & 4 & 5 \\
\hline $\begin{array}{l}\text { 32. I'm going to look into learning some coping } \\
\text { skills for labor, but l'm not sure they are } \\
\text { going to help. }\end{array}$ & 1 & 2 & 3 & 4 & 5 \\
\hline $\begin{array}{l}\text { 33. I'm perfecting my coping skills in } \\
\text { preparation for labor. }\end{array}$ & 1 & 2 & 3 & 4 & 5 \\
\hline $\begin{array}{l}\text { 34. I don't think I have the ability to handle } \\
\text { labor pain on my own. }\end{array}$ & 1 & 2 & 3 & 4 & 5 \\
\hline $\begin{array}{l}\text { 35. I know that I can learn ways to cope with } \\
\text { labor pain on my own. }\end{array}$ & 1 & 2 & 3 & 4 & 5 \\
\hline $\begin{array}{l}\text { 36. I've learned a lot about coping during labor, } \\
\text { and I know l'll remember the skills. }\end{array}$ & 1 & 2 & 3 & 4 & 5 \\
\hline $\begin{array}{l}\text { 37. I feel encouraged about using my own } \\
\text { coping skills during labor. }\end{array}$ & 1 & 2 & 3 & 4 & 5 \\
\hline $\begin{array}{l}\text { 38. I will be exploring options for dealing with } \\
\text { labor pain other than medicine or an } \\
\text { epidural. }\end{array}$ & 1 & 2 & 3 & 4 & 5 \\
\hline $\begin{array}{l}\text { 39. I know some coping skills, like breathing, to } \\
\text { do during labor, but l'm not sure l'll } \\
\text { remember them. }\end{array}$ & 1 & 2 & 3 & 4 & 5 \\
\hline $\begin{array}{l}\text { 40. I know l'm ready to use my own coping } \\
\text { skills during labor. }\end{array}$ & 1 & 2 & 3 & 4 & 5 \\
\hline
\end{tabular}


Appendix U

\section{Demographic Questionnaire - Study 4}

INSTRUCTIONS: Please answer the following items in the appropriate response spaces.

Code Number:

Date:

\section{Background}

1. What is your age? years

2. What is your race or ethnic background? (please check one):

White/Caucasian, not Hispanic:

Black/African-American:

Asian-American:

Hispanic:

Native American:

Pacific Islander:

Other:

If other, please specify:

3. What is your marital status?

$\begin{array}{ll}\text { Single } & \text { Separated } \\ \text { Married } & \text { Divorced } \\ \text { Live-in partner } & \text { Widowed }\end{array}$

4. In what city and state do you live?

\section{City} State

5. How would you describe the place, or the type of place, that you most closely identify with (e.g., your hometown)? (please check one):

Rural (less than or equal to 2,500 residents):

Urban (more than 2,500 residents): 
6. Number of years of education? GED High School Some College College Degree Other:

7. What is your current job or occupation status? Working full time

Working part time

Homemaker

Looking for work, unemployed

Retired

Disabled - unable to work

8. What kind of work do you do or did you do in the past? (For example, electrical engineer, stock clerk, typist, farmer). Please list all types of jobs you have now or have ever had.

9. What is the total yearly income (in US dollars) for everyone in your household put together? (please check one):

Less than 10,000 :

$10,000-14,999$ :

$15,000-24,999$ :

$25,000-34,999$ :

$35,000-49,999$ :

$50,000-74,999$ :

$75,000-99,999$ :

$100,000-149,999$ :

$150,000-199,999$ :

200,000 or more :

Don't know :

No response :

\section{Health}

10. What month of pregnancy are you in? 
11. Have you ever been pregnant before? (please check one):

Yes:

No:

12. Have you ever given birth to a child before? (please check one):

Yes:

No:

\section{If "Yes":}

A. How many children have you given birth to?

1) Of those, how many were born vaginally?

2) Of those, how many were born cesarean (c-section)?

\section{If "Yes":}

B. What strategies have you used to help manage childbirth pain in the past?

(please check all that apply):

1) Oral medication (e.g., Tylenol, oral painkillers):

2) IV (intravenous drip) medication:

3) Epidural:

4) My own (self-management) strategies:

If so, please list all the strategies you've used: 
13. Have you ever attended childbirth education classes? (please check one):

Yes:

No:

\section{If "Yes":}

A. How many classes have you attended?

B. Did a partner / friend attend classes with you? (please check one):

Yes:

No:

C. Have you attended class(es) during your current pregnancy? (please check one):

Yes:

No:

D. Have you attended class(es) during a past pregnancy? (please check one):

Yes:

No:

14. Was this pregnancy planned? (Please circle a number on the scale below)

Completely Unexpected

1

23

Completely Planned

345

15. Have you experienced any health problems during this pregnancy? YES

NO If yes, please list all of them. 